\title{
BLACK WOMEN'S NARRATIVES OF RESILIENCE THROUGH VICARIOUS INCARCERATION AND REINTEGRATION
}

A Dissertation
presented to
the Faculty of the Graduate School
at the University of Missouri-Columbia
In Partial Fulfillment
of the Requirements for the Degree
Doctor of Philosophy
TEAH MONIQUE HAIRSTON
Dr. Wayne Brekhus, Dissertation Supervisor
December 2020


The undersigned, appointed by the dean of the Office of Graduate Studies, have examined the dissertation titled

\section{BLACK WOMEN'S NARRATIVES OF RESILIENCE THROUGH VICARIOUS INCARCERATION AND REINTEGRATION}

presented by Teah Monique Hairston, a candidate for the degree of doctor of philosophy, and hereby certify that, in their opinion, it is worthy of acceptance.

Professor Wayne Brekhus

Professor S. David Mitchell

Professor Jay Gubrium

Professor Ty-Ron Douglas

Professor Scott Brooks 


\section{ACKNOWLEDGEMENTS}

I give thanks to the Divine Creator, The Source of all love, light, and life.

I offer my sincerest gratitude the sistas who allowed me into their lives, their inner thoughts, and deepest emotions. Thank you for taking time out of your busy lives to share such profound, powerful, inspiring stories with me. I learned so much from you, received so much love and guidance from you, and I sincerely appreciate your support in this huge endeavor.

I give the highest honor to my mother, Lisa Ann Rice, who has been a continued source of encouragement and inspiration throughout my life. You taught me very early on about unconditional love, compassion, kindness, and goodness, by modeling all of those things. My care and concern for human beings, including our incarcerated brothas and sistas, begin with you before I even understood how important it is in a world plagued by hate, racism, oppression, and social inequality.

Dr. Wayne Brekhus, thank you for your instruction, guidance, and patience throughout this process. I value your knowledge and your work ethic, which kept me motivated over the last few years. You gave me plenty room to carry out a project that was meaningful and special to me, trusting my knowledge and experience to produce quality work.

Dr. S. David Mitchell, meeting you, taking class with you, and chatting during office hours are some of my most memorable moments as a graduate student at Mizzou. I am in awe of your level of expertise about law, policy, and criminal justice. You always ask the most thought-provoking questions, and challenged me in ways I have never been, and for that, I am grateful. 
Dr. Jay Gubrium, your humor and candidness made taking your courses so enjoyable, interesting, and easily digestible. More importantly though, I learned a great deal from you about the value and significance of story-telling and narrative analysis. You provided me with the tools to be able to conduct this vital research. Thank you for a lasting learning experience.

Dr. Ty-Ron Douglas, taking your class and subsequently working with you on other projects like Bridge to Mizzou, the Back-to-School Explosion, the community forum after the murder of Walter Scott, and the AESA Conference, was so powerful and inspiring. It was you who introduced me to the idea of establishing institutions of healing, and it is the way you walk in your faith that made me believe that healing our communities is not only possible, but absolutely necessary. Thank you for praying for me and my (at the time) unborn child and reminding me that I am doing God's work. I will carry that with me always.

Dr. Scott Brooks, I deeply appreciate you for giving me a sense of familiarity and comfort at a time when, and in a space where, I felt so out of place. You encouraged me never to sell myself short, and assured me that my authenticity is one of my strongest assets to the academy, specifically, and the world, in general. I keep that gem in my pocket every time I speak to an audience, or am in a room full of esteemed individuals, to remind me that I have something to offer and that I belong.

Thank you to the James S. Rollins Slavery Atonement Endowment with the University of Missouri Black Studies Program and the Graduate Research and Training Award with the Department of Sociology at the University of Missouri for recognizing the importance of this work and providing financial support to carry it out. I would also 
like to express my appreciation and gratitude to the Office of Graduate Studies at the University of Missouri for seeing the value in my research and my efforts as a community engaged scholar by choosing me as a recipient for the Mary Elizabeth Gutermuth Community Engagement Award.

Dr. JT Thomas and Afton Thomas, without your encouragement, I would have never considered pursuing a PhD. I express my deepest gratitude for welcoming me in your home, your and your children's lives, and introducing me to some really amazing people in Columbia. This journey would not have been conquered without your friendship and support.

Dr. Barbara Combs, your mentorship and guidance through my master's program was vital to my growth and development as a scholar of social science. The tough and sobering conversations we had revealed so much to me about what it takes to persevere as a Black woman in America and in academia. You showed me that it is possible to build a family and a home without giving up on my own dreams and ambitions. You are Black Girl Magic!

Dr. Ruth Wilson, you saved me! You humbled me, you strengthened me, you gently pushed me to be great during some of the hardest times in my life. I had completely lost my faith in God and all things good; but you showed me that there is still life after tragedy and hardship and that life is what we make of it. I hold our walks and talks near and dear to my heart, with your words frequently replaying in my head to this day.

Dr. Steven Millner, you're undoubtedly the dopest professor I have ever had the pleasure of studying under! Every class I took with you left a mark on my heart and my 
soul and left me hungry to learn more about Black life and Black resilience. Your love for our people, for your family, and your students is so admirable. Your continued encouragement throughout my entire academic career-especially during some of my darkest days - has certainly been a key factor in my arrival at this moment of completion.

My dearest Laura-Boo, your sisterhood has been everything to me! Who would have known we would grow so close and establish one of the most beautiful friendships I will ever know? Thank you for being present and available during my pregnancy, and for holding my hand during Daelan's birth. You and your family have been so incredibly supportive and caring and truly model what it means to do God's work. I love yall.

My father, Sam Hairston, and step-mother, Terri Hairston, you have always been supportive of my academic and professional endeavors and were adamant about providing any and everything I needed to ensure my success. Thank you for teaching me about accountability and responsibility, Dad. Thinking about how hard you worked to provide for our family was constant motivation during my academic career to get my behind up and go! I hope you know your stern talks were not lost on me.

Tywon Hairston, You, your drive and ambition, your fearlessness, and your tender heart, inspired this work. Despite the age difference, it is because of our closeness as siblings that I understand and empathize with men and women with your shared experience and see them in a much different light than the rest of society. It is the beauty of your person that compelled me to learn more about our incarcerated/formerly incarcerated brothas and sistas and hopefully find ways to show and highlight their beauty and depth to people who fail to see or acknowledge it. You are a living, breathing, 
walking demonstration of grace and redemption. I am so proud of you and I am so lucky you are my big brother.

Friends, family, and fellow Mizzou "socies" who supported me throughout this journey—whether by meeting up for study dates, babysitting my children, giving pep talks, sending inspirational gifts, or getting me out of the house to remind me that life exists outside of school-you are appreciated.

My soul brotha, my soulmate, my soul twin, my twin flame, my biggest supporter, my homie, my healer, my lover, my light, my protector, my friend, my confidant, my intellectual partner, my fellow freedom fighter, Keon Johnson-thank you for being all of these things. Thank you for never allowing me to feel alone. Thank you for being present in every way possible during crunch time - talking ideas out with me, encouraging me to rest and making sure I could do exactly that by managing our home and our children.

Thank you for believing in me and celebrating every win. I feel so extremely blessed that you were here for this, and are here for whatever is to come. Us for us.

To my beautiful sons, Daelan and JahRuah, everyday with you is pure happiness and joy. You inspire me to be a better human being. You remind me to practice patience and compassion. You affirm for me that my purpose on this Earth and beyond is nothing less than divine. I am forever grateful to The Creator for granting me stewardship over you both in this lifetime. 


\section{TABLE OF CONTENTS}

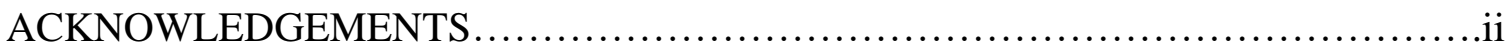

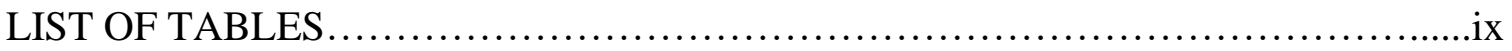

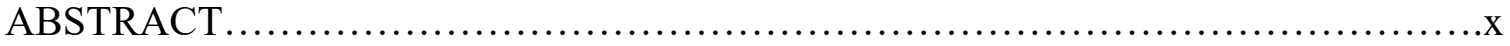

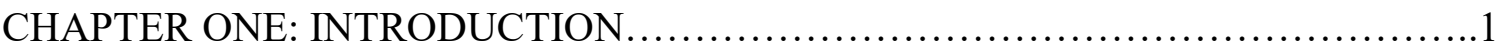

Background and Impetus........................................................

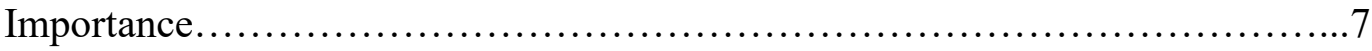

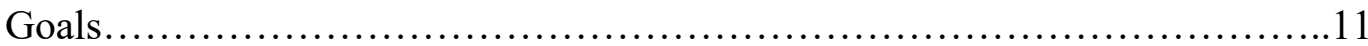

Preview of Chapters............................................................

CHAPTER TWO: LITERATURE REVIEW \& CONCEPTUAL FRAMEWORK

Black Womanhood in the U.S.............................................14

Black Women's Connectedness to Incarceration.............................15

Effects of Vicarious Incarceration/Reentry on Women........................16

Black Women's Resilience............................................. 18

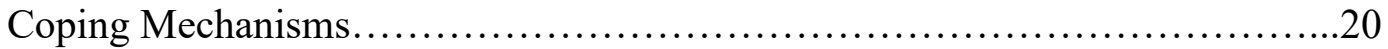

Loved One's Incarceration Effects on Health.................................21

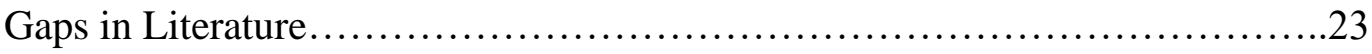

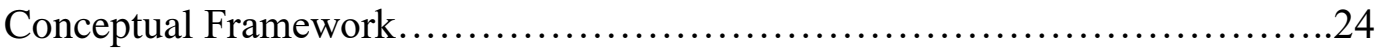

Feminist Standpoint Theory \& Intersectionality ............................25

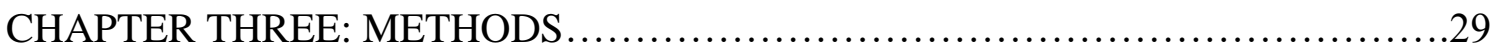

Research Design....................................................... 31

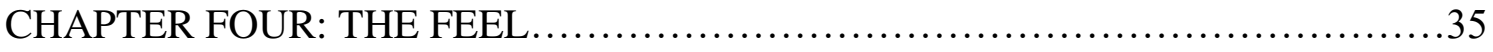

Why We Support, How We support, and What Support Looks Like..............36

Impact of Loved One's Incarceration: Psychological, Emotional, Financial......53

Other Daily Issues and Concerns.........................................62

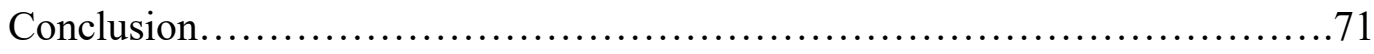

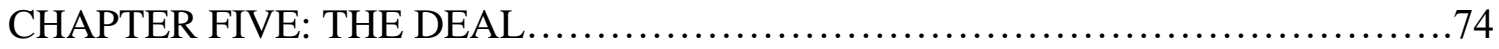

Holistic Health: Navigating and Interacting with Daily Life....................75 
Who Supports Black Women........................................... 99

Resources for Black Woman Impacted by Incarceration.......................105

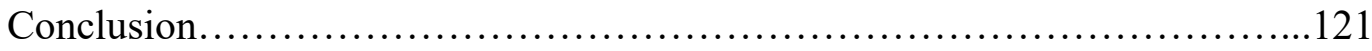

CHAPTER SIX: THE HEAL

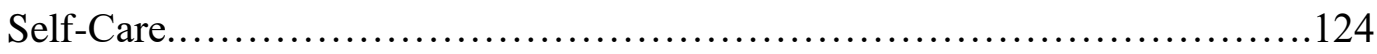

Self-Care, Caregiving and Caretaking ....................................130

Lessons Learned........................................................

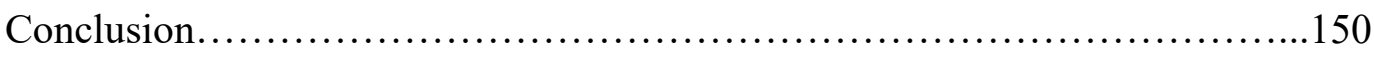

CHAPTER SEVEN: THE IDEAL

Healing from the CJ System: Black Women Impacted by Incarceration Envision the Future..............................................................

CHAPTER EIGHT: DISCUSSION AND CONCLUSIONS .........................171

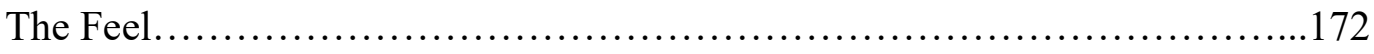

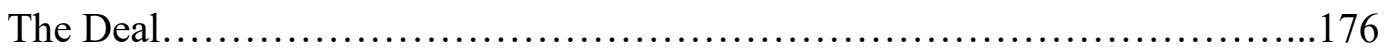

The Heal....................................................................... 180

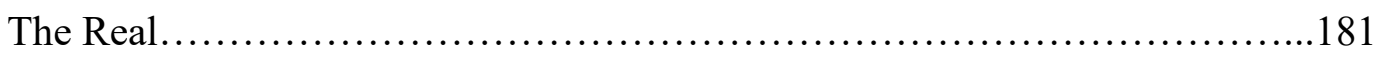

Implications: The Ideal................................................. 181

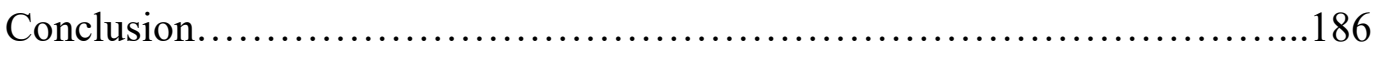

Limitations............................................................ 190

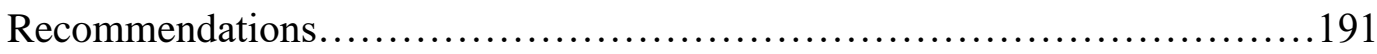

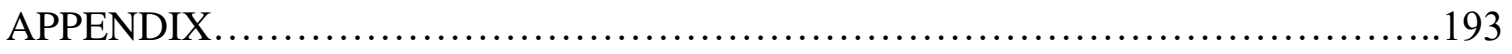

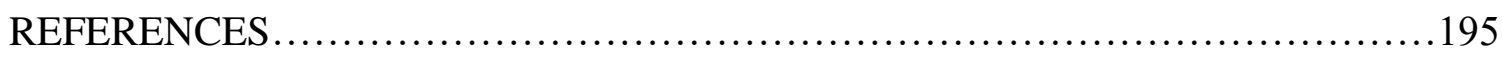

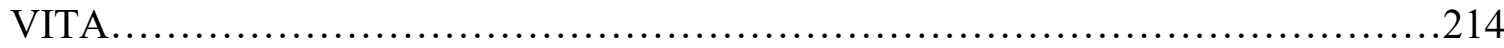




\section{LIST OF TABLES}

Table 1. Participant Background Information.................................. 193

Table 2. Personal Strengths: What Resilience Looks Like........................... 194 


\begin{abstract}
Systemic racism has resulted in the disproportionate imprisonment of Black people. With Black men constituting a large percentage of incarcerated bodies, many Black women (44\%) — mothers, wives, sisters, etc.-will experience vicarious incarceration. This research examines the ways this population, as caretakers and supporters of their incarcerated loved, ones manage resilience in their daily lives as they navigate a racist, sexist society. Ten women were interviewed about their experiences with vicarious incarceration and reentry. I conclude that the women manage resiliency largely through the support of other Black women and community-family, who—in many instances_-are also experiencing vicarious incarceration and/or other racial stress and trauma. Findings provide implications for the need for effective resources, more specifically, culturallyinformed, culturally-relevant resources - to assist Black communities with healing from the effects of incarceration, and to prevent and intervene in the intergenerational cycles of criminal justice entanglement.
\end{abstract}

Key words:

Black women, family, vicarious incarceration, collateral consequences, resilience, community 


\section{CHAPTER ONE: INTRODUCTION}

The mass incarceration of men and women of color has been a hot topic over the last 40 years. Regardless of the findings over time — demonstrating the negative effects of the criminal justice system on Black people in America, and countless pleas, demands, for radical reform - the consequences of imprisonment continue to disproportionately impact African American communities blatantly and insidiously. There are various studies that examine the effects of incarceration on individuals and the families from which they are removed (Green 1982; Carlson and Cervera 1992; Travis et al. 2005; Green et al. 2006; Martinez and Christian 2009; Christian and Kennedy 2011; Bailey 2011; Cox 2011; Turney et al. 2012; Lee et al. 2014; Fishman 2018; Sirois 2020), however, very little work has been done in the way of understanding how Black families/communities respond to the removal of a beloved member(s). More specifically, there is a dearth of research focused on Black women, — the population most disproportionately affected by the incarceration of a loved one, - - how they function without beloved family/community members, and how they push forward in their absence, and/or upon their return to society.

The purpose of this research is to enrich our thoughts and thinking about the collateral consequences - the spillover effects, or, the adverse impacts on families and communities - of the mass incarceration of Black men and women. It is important to note that I use the term collateral consequences unlike criminal justice literature which underscores the legal disabilities imposed by law as a result of a criminal convictionsuch as voter disenfranchisement, barriers to employment and housing, etc.- - but in a way that emphasizes the indirect impacts and ripple effects incarceration has on the 
families and communities of the imprisoned. Although we have an idea about the financial, emotional, and even social impact of imprisonment on incarcerated/transitioning individuals and their families, we have very little understanding of the ways in which Black women/communities deal with, persist through, and heal from the loss of a loved one to imprisonment, and what dealing, and healing looks like upon one's return to society. The strategies Black women and Black communities use to persist as they experience vicarious incarceration and reintegration has been largely ignored. Because of the disproportionate number of Black men, and rising number of Black women, under some form of correctional supervision, Black women (mothers, wives/partners, daughters, sisters, etc.) are disproportionately impacted by vicarious imprisonment and often bear the brunt of the collateral consequences from the incarceration of a loved one. Not only do Black women and Black communities have to endure the direct and residual effects of losing a loved one to incarceration, but they are essentially tasked with facilitating the successful reentry of their loved one(s) postrelease.

A great deal of criminological, social deviance, and social control literature asserts that the family is one of the greatest determinants of one's ability to survive imprisonment and "successfully" reintegrate, i.e. not-recidivate (Christian et al. 2006; Green et al. 2006; Comfort 2008; Hiller 2013). Incarcerated humans rely on loved ones to support them emotionally, financially, among other things, to maintain and sustain themselves over the course of their incarceration (Christian et al. 2006; Comfort 2008). In fact, studies show that the social capital fostered by contact with family manifests itself in...fewer disciplinary infractions within the institution and more successful outcomes 
upon release from prison (Christian et al. 2006). Over two-thirds of incarcerated individuals expect to live with family members upon their release (Hiller 2013:6). Stable families are considered a valued and valuable resource for incarcerated and formerly incarcerated individuals (Holt and Miller 1972; Green,1982; Taylor 2016). This indicates that the family — whomever that may consist of — must be stable enough (financially, psychologically, etc.) to offer the assistance (room and board, emotional support, etc.) one needs to successfully transition from a penal institution back into society.

The responsibility of the family becomes amplified when the incarcerated human is Black and male. It has become clear that incarceration is a "(gendered) family ordeal as opposed to an individual experience" (Halsey and Deegan 2014:131). With two in every five Black women related to someone who is incarcerated (Ella Baker Center 2015), and due to the nature of our history and socialization as the caregivers and caretakers of our households and communities (Harris 2015), Black women, in particular, have an especially important role in the support and fortification of our incarcerated/transitioning loves ones. However, it may be particularly difficult for Black women and communities to support incarcerated/transitioning loved ones if the women/communities, themselves, are trying to deal with, and navigate, critical issues (e.g. social inequalities) permeating their own daily lives (un-/underemployment, work-related stress, racial stress). Lee et al. (2015:270) assert "it is likely that mass imprisonment has fundamentally reshaped inequality not only for the adult men for whom imprisonment has become common, but also for their friends and families." Thus, it is especially important to lend our attention to the ways in which communities - many of them carried by Black women — are able to 
maintain and sustain, in spite of various intersecting social inequities, in the absence of vital members of their homes and communities.

Harris and Miller (2003) consider the emotional, social, and financial ramifications of incarceration on Black families in efforts to maintain relationships with our incarcerated loved ones in their text, Impacts of Incarceration on the African American Family, a collection of essays by various social scientists. Among the authors' findings, we see a distinct connection between the incarceration of a loved one and the troubling disruptions in the daily lives of the families they leave behind. Comfort (2008) considers the direct and vicarious experiences and painful consequences of men's incarceration on their wives, fiancés, and girlfriends in her study, Doing Time Together: Love and Family in the Shadow of the Prison. Comfort found that while not imprisoned themselves, the criminal justice system and the prison as an institution exerts a level of social control over the women's lives complicating the relationships with their men and with their loved ones on the outside. Travis and Waul (2004) also compiled various works from a number of scholars chronicling the many ways the criminal justice system impacts not only the lives of prisoners, but also their families and the communities from which they come. Shining light on the struggles of families and communities from which the incarcerated come, the authors of this volume both demonstrate the issues and offer useful information for the development of promising solutions for strengthening fragile families, rebuilding communities, restoring justice and bringing about change. Braman's (2007) ethnography offers a close look at the effects of imprisonment on the families and communities of the incarcerated. Braman shows how criminal justice/incarceration policies further the problem of social disorder, visible through the social consequences of 
incarceration endured by the incarcerated themselves and their loved ones-primarily, African Americans.

While absolutely relevant and imperative for understanding the complexities of mass incarceration and the criminal justice system, and the, often, debilitating effects on Black families and communities, the aforementioned studies focus more on the issues and less on potential solutions. The insight provided leaves us better equipped to begin discussions about how to address inequities caused and exacerbated by the incarceration of Black men and women. However, as the largest, most vulnerable population affected by this phenomenon, we must place a pointed focus on both the issues that Black women vicariously impacted by mass incarceration face and how they overcome/push through such issues. Discovering ways to reduce the burden placed on Black women supporting incarcerated/formerly incarcerated loved ones will not only benefit our incarcerated/transitioning loved ones, but our families and communities in general. Thus, this study aims to inform extant research by not only exploring the ways Black women, specifically, are (w)holistically impacted by the incarceration of a loved one (e.g. mentally, emotionally, financially, spiritually, socially, socioeconomically, etc.), but also by offering community-defined, culturally-grounded strategies for addressing the intersections of struggle for Black women of this population. Background and Impetus for Study

I first visited a detention center in 1989 (I was 4) when my brother got into some trouble and was sent to juvenile hall (he was 14). The next time I remember visiting a loved one in jail, I was 6. One of my brother's best friends—-whom my mother had taken in because he was experiencing trouble in his own home-was awaiting trial in a county 
jail about an hour south of where we lived. The ride to the facility seemed so long; the land desolate, daunting even. (I remember having to pee on the side of the road because there was nothing but land for miles.) I did not yet understand that these long, arduous travels would be something I would grow accustomed to throughout my adolescence and into my adulthood.

My first experiences with incarceration occurred during a time at which gang wars were intense and the War on Drugs was being viciously fought by both the government and community members within the neighborhoods afflicted by drugs. The War on Drugs fueled gang wars across the nation. The government's crackdown on nonviolent offenders and tougher sentencing (such as three-strike laws and mandatory minimums), in addition to the internal conflict among disadvantaged community members fueled by the drug war (systemic racism), claimed the lives of many young brothers from my neighborhood. By the time I was 18, I had already been corresponding with, going to visit, or otherwise supporting seven different brothers (family members, family friends, schoolmates, and community members) that had been removed from my life/community; and I knew several others who lost their lives to gang/community violence - whether by imprisonment or murder (death). To this day, I have loved oneschildhood friends, family members, former co-workers, etc.- - in prison, some of which were charged with the death (literal murder) and destruction (through drugs and gangs) of our communities.

My experience with the incarceration of Black males and the loss felt from their removal from my life and my community is hyper-recurring. Yet, hearing that one of my brothers - one of our brothers, fathers, uncles, etc. - has been taken and caught up in the 
criminal justice system never gets easier. The pain is the same; the devastation is the same; the concern is the same. The extent to which these feelings and emotions are experienced may vary, but the loss is never easy to bear. But life must go on- for us on the outside, and hopefully for our loved ones on the inside.

This research is about women like me-who spend much of their time and energy adjusting to the loss of, yet, still supporting, an incarcerated and/or transitioning loved one while also trying to balance the challenges of everyday life as Black women in America. My goal is to highlight strategies this population uses to manage everyday life with the criminal justice system ever lurking in the shadows. Once these strategies have been identified, I intend to explore which are hurting, which are helping, and which are healing Black women and the communities we lead. In other words, because I understand that all coping strategies are not necessarily healthy in the long term, I am interested in identifying the best strategies for helping and healing Black women, specifically, and Black communities, in general, from the wounds of incarceration-one of the most racially oppressive phenomena of our nation's history.

\section{Importance of the Study}

Before we discuss the ways in which incarceration affects how Black women navigate the everyday, let us acknowledge the many ways, and the various intersections at which Black women are always and already oppressed in this country.

We can begin with the fact that Black women make 61 cents for every dollar made by white/non-Hispanic men (National Partnership for Women and Families 2020). A recent fact sheet published by NPWF found that the median income for Black women in the United States is $\$ 38,036$ per year, compared to a median salary of $\$ 61,576$ for 
white men (National Partnership for Women and Families 2020). That means the average black woman makes $\$ 23,540$ less than her white male counterparts every year. US Census Bureau (2018) data shows that more than half (54.5\%) of Black mothers co-reside with their children with no partner present, compared to 16 percent of white/nonHispanic mothers. At the very least, this data shows that Black women are being paid less and raising children alone with less income and support than our non-Black counterparts.

The Status of Black Women in the United States, which the Institute for Women's Policy Research recently published in collaboration with the National Domestic Workers Alliance, reports health disparities for Black women such as higher rates of heart disease mortality, breast cancer mortality, AIDS, diabetes, and other often-preventable conditions (DuMonthier et al. 2017). These statistics suggest that in spite of Black women having the highest percentages of earned degrees (National Center for Education Statistics 2019), we are still underemployed, underpaid, overly-ill, and lack access to quality, culturally competent health care.

Add to the constraints and strains on our daily being/existence our disproportionate connectedness to incarcerated humans. Extant research suggests that "Black women are far more likely to have an acquaintance (35\% vs. 15\%), family member ( $44 \%$ vs. $12 \%)$, neighbor (22\% vs. $4 \%$ ), or someone they trust (17\% vs. $5 \%)$ in prison than are White women. Because of this, a larger percentage of Black women's social networks are composed of prisoners, suggesting that these women may carry an especially heavy burden" (Lee et al. 2015:271). Thoroughly identifying what this burden looks like, and how it plays out in one's life would be a daunting task; that is precisely why I am not going to try. Nevertheless, I intend to offer several perspectives and lenses 
through which one may see the various ways heavy, complex burdens plant themselves on the shoulders of Black women as a consequence of vicarious incarceration.

The daily inequalities Black women face in the workplace (e.g. hair discrimination; see Crown Act), educational institutions (microaggressions), and society in general, exacerbated by the responsibility (whether self- or socially-assigned) of supporting an incarcerated/transitioning loved one, or a beloved family member transitioning back into society deserves pointed attention. Carrying all of this can be stressful; unchecked stress can influence physiological reactions that may in turn influence one's physical health (Nuru-Jeter 2018). All of this affects the way Black women are able to move through this world; how we receive and understand information, our level of access, availability, and opportunity. More specifically, it affects the way we navigate and operate in, and manage our households and communities.

This manuscript aims to lift the voices and experiences of Black women impacted by the imprisonment of a loved one, with the intent to understand the effects of incarceration on our mental, physical, emotional, and spiritual health. It is important to note that being supportive of an incarcerated and/or transitioning loved one means enduring hard times; facing complex situations and addressing complex thoughts, feelings, and emotions. Years of confinement can change the thoughts, beliefs, behaviors, personality, etc. of an incarcerated individual as much as it has the potential to change the thoughts and behaviors of their loved ones on the outside (Dallao 1997; Harris and Miller 2003). Understanding how Black women not only cope with and adapt to the loss of a loved one to imprisonment, but how we remain resilient — maintaining and sustaining households, roles in the community, careers, etc.- - will allow us to identify ways to better 
support and uplift Black women experiencing vicarious incarceration and/or reintegration, and Black women in general.

Supporting Black women is imperative for the survival and resilience of Black people. Both our ancestral customs and our western socialization has groomed our proclivity, capacity, and our expectation as Black women to love hard and take care of those we love. With more than half of Black women heading single-parent households, we are a driving force of our families and communities. Black women are Black children's first teachers; we are decision and miracle makers; we are advocates, activists, hell raisers, peace makers, bridge builders; the list goes on. Considering the various roles we play, and the critical positions we occupy, our health and wellness is vital.

However, because of the way we love and are expected to take care (whether we actually want to or not), we will endure the separation of a loved one by incarceration; for love, we will endure financial strain to provide a feeling of security for someone else; we will endure the emotional distress, the physical toll, the mental overload and psychological dismay, the struggle of solo parenting, and other social struggles. For love, Black women will maintain, and often times, manage to make heavy burdens look easy to carry. Appearing as if, or even pretending, our load is not straining, inhibiting, and draining; masking and carrying on in unaddressed pain and stress can become harmful to one's health and wellbeing. In fact, recent studies have "focused on health implications of strong Black womanhood in light of alarming disparities in Black women's health (Walker-Barnes 2014) with a focus on issues of health implications of the mandate including the tensions inherent in strength" (Scott 2017:9). Findings from these studies suggest that the "superwoman role had benefits contributing to self, family and 
community preservation, but also liabilities including relationship strain and stress embodiment" (Wood-Giscombe 2010; Scott 2017:9). Therefore, not only must we strive to understand how Black women persist through adversities, but also make it a point to identify and adopt strategies that are conducive to one's health and wellness and the wellbeing of our communities.

\section{Goals of the Study}

This project will examine the resilience strategies Black women use to sustain themselves and their families/communities as they navigate daily life while also supporting an incarcerated loved one. I will share the narratives of the lived experiences of Black women impacted by the incarceration/transition of a loved one with the goal of adding perspective to our current understanding of the collateral consequences of mass incarceration, particularly, how Black women's lives are affected. This inquiry is especially important for a more comprehensive understanding about how this experience impacts the function of Black families/communities.

The ultimate aim of this project is to identify and highlight the needs of a very large and vulnerable population of Black women and discover ways to adequately and sufficiently address our specific needs. Addressing these issues may, in turn, have a positive effect on the relationships and the support this population of women are able to offer our incarcerated/transitioning loved ones. Black women are primarily responsible for the care and support of incarcerated Black men and women, thus, strengthening us by providing adequate resources for healthcare, financial assistance, employment, education, affordable housing, childcare, etc. for the vicariously impacted will inevitably strengthen families/communities. 
The main objectives of this project are:

- Inform our understanding about the lived experiences of Black

women who have previously, or are currently, vicariously experiencing the criminal justice system

- $\quad$ Add perspective and insight into what we know about the ways entanglement in the criminal justice system effects the lives and social position of Black families/communities

- $\quad$ Provide implications for social work and social services, mental and physical health professionals; incarceration, reentry, rehabilitation and corrections studies, etc.

- $\quad$ Provide some form of reference for other Black women who are experiencing, or will eventually endure the incarceration/reentry of a loved one

- $\quad$ Offer a starting point for beginning to increase the chances of successful reentry/reduce chances of recidivating

Preview of Chapters

The following chapters will explore the narratives of Black women reflecting on their experiences supporting an incarcerated and/or transitioning loved one. I use my experience as a woman belonging to the community of women who have previously supported and/or are currently supporting an incarcerated/transitioning loved one to highlight many of the nuanced and unknown issues Black women experience daily as we navigate life and society. In Chapter Two, I will introduce the theoretical lens with which I analyze and conceptualize interview content and review literature on mass incarceration and its affects/collateral consequences on Black women, families, and communities; 
Black women and their connectedness to incarcerated humans, Black womanhood, and Black women's health and wellness. Chapter Three will introduce the methods by which this study was conducted. Chapter Four will explore the ways in which each of participant conceptualized the idea of support, including why they offer/-ed support (e.g. type of relationship), how, or in what ways support is/was offered (e.g. emotional, financial), what support looks/looked like (e.g. letters, visits, etc.), and the impact vicarious incarceration has on our lives. Chapter Five will discuss strategies Black women use to deal with our experiences of vicarious incarceration as we navigate everyday life, including the ways we manage our thoughts and emotions surrounding the absence and/or return of our loved one(s). Chapter Six will explore how Black women use love (e.g. caregiving, community service) as a method of healing ourselves and the ways in which such expression may be to our own detriment considering the physical, emotional, and psychological impacts. Chapter Seven examines what the women of this study are working toward and what they envision for the future of our families and communities. Chapter Eight will conclude the manuscript, highlighting sociological implications, offering recommendations for future research in community trauma and healing, and briefly discussing limitations. 


\section{CHAPTER TWO: LITERATURE REVIEW \& CONCEPTUAL FRAMEWORK \\ Black Womanhood in the U.S.: Socialization, Expectation, Manifestation}

It is useful and important to position this research within an understanding of Black women's lived experiences as Black women in the U.S. It is vital to make the distinction between Black women in/from the U.S. and Black women raised outside of the U.S., or in households with immigrant parents/family members to avoid cultural confusion; in other words, U.S. born/raised Black women's understandings, perspectives, and experiences may greatly differ from Black women from other countries with different cultural backgrounds. Thus, as we move forward, our discussion of Black women refers specifically to those born and/or raised under western cultural influence.

In her text, Too Heavy a Yoke: Black Women and the Burden of Strength, WalkerBarnes (2014:4) argues that from childhood, Black women are taught that a "good woman, especially a good Black woman, is independent, a giver (and not a receiver) of help, including emotional, financial, or instrumental support.” Within Black culture, African American women are considered and expected to be strong (Hart-Johnson 2014:63); expected to be able to handle anything (Scott 2017:xi). Scott (2017:xvi) asserts that “post-slavery, Black women's strength continued to provide a vital function in the survival of self, family, and community." Having been historically regarded as the major provider, Black women's expectations to assume major responsibility for providing their family's basic needs has not ceased (Green 1982:10). In their study on the multidimensionality of Black womanhood, Abrams, Maxwell, Pope and Belgrave (2014:511) highlight how "dedication to care for others is so strong that it often takes priority over care for self, potentially causing harm to physical and mental wellbeing. 
One of their interviewees asserts: "By definition [to be] a Strong Black Woman is to deny your own needs" (Abrams et al. 2014:511). King and Ferguson (2006:113) describe ways in which "Black woman's faithfulness in both providing for her family and in executing the nurturing functioning both outside and inside the home serves a vital function in Black communities and intersecting the nurturing role designated to her by patriarchal society."

\section{Black Women's Connectedness to Incarceration}

Black women are disproportionately impacted by the incarceration of a loved one (Apel, Blokland, Nieubeerta, and Schellen, 2010; Massoglia, Remster, and King 2011; Lee et al. 2015). In their study about racial inequality and connectedness to incarceration, Lee, McCormick, Hicken, and Wildeman (2015) report that Black women are far more likely to have an acquaintance ( $35 \%$ vs. $15 \%$ ), family member ( $44 \%$ vs. $12 \%$ ), neighbor (22\% vs. $4 \%$ ), or someone they trust (17\% vs. $5 \%$ ) in prison than are White women (p. 269). Because of this, a larger percentage of Black women's social networks are composed of prisoners, suggesting that these women may carry an especially heavy burden (Lee et al. 2015:271).

According to the Equal Justice Initiative (2018), "Black people are 50 percent more likely than white people to have a family member who is formerly or currently incarcerated, and three times more likely to have a family member who has spent at least 10 years in prison. The survey found that six of 10 African Americans and Native Americans have an immediate family member who has been in jail or prison." Mike Maciag wrote in Governing (2019) that Black men are incarcerated at 25 times the rate of Black women, and suggests that the single biggest driver behind the absence of many 
black men in predominantly Black communities is mass incarceration. Based on 2018 data from the U.S. Bureau of Justice Statistics, 2,272 per 100,000 Black men are incarcerated compared to 88 per 100,000 Black women. These data support the fact that Black women (mothers, wives, daughters, etc.) are impacted by the absence of Black men (husbands, sons, fathers etc.) more often than the reverse.

In their report, Who Pays? The True Cost of Incarceration on Families, researchers from the Ella Baker Center (2015:9) emphasize that collateral impacts of incarceration "hit women of color and their families more substantially than others, deepening inequities and social divides that have pushed many into the criminal justice system in the first place. Almost one in every four women and two of five Black women are related to someone who is incarcerated." Hiller (2013:118-119) argues that the high rate of incarceration of African-American males means that more Black mothers than any other group are affected. Hiller's (2013:15) study on Black mother/Black son relationships found that "it is usually the mother who faces the immediate repercussions of supporting this person in prison. Furthermore, because 85 percent of African Americans marry within their own ethic group (Passel, Wang, and Taylor 2010), African American women who are in significant relationships with African American men are disproportionately affected by high incarceration rates (Modecki and Wilson 2009). Chaney (2011) reminds that Black women may have multiple family members who are incarcerated — not just [a] spouse or partner.

Effects of Vicarious Incarceration/Reentry on Women

Women bear the brunt of the costs— both financial and emotional—of their loved one's incarceration (Ella Baker Center 2015). One study reports that in $63 \%$ of cases, 
family members on the outside were primarily responsible for court-related costs associated with conviction. Of the family members primarily responsible for these costs, 83\% were women (Ella Baker Center 2015:9). Grinstead, Faigeles, Bancroft, and Zack (2001:59) assert that "for every man who is incarcerated and has a female partner the woman will suffer financial social and psychological consequences." These consequences are usually in the form of loss of income, stigmatization, and stress of maintaining contact when a loved one is incarcerated (Hart-Jonson 2014; Myers 2016).

Women with incarcerated partners have disproportionately low incomes, with few economic resources and little social capital (Sugie 2012), and they face high rates of stress even before their partner's incarceration (Wildeman et al. 2012; Geller and Franklin 2014). Once Black fathers/spouses are incarcerated, their families and female spouses/partners are placed at increased risks of stress, crisis, economic, social, and personal harm, and dependency (Green 1982). Mothers with recently incarcerated partners, on average, faced approximately $50 \%$ greater odds of housing insecurity than other mothers (Geller and Franklin 2014:423). Women shoulder the burden of childcare and household management and maintain connections to their imprisoned male family members or romantic partners (Lee et al. 2014: 421). While often bearing the responsibilities of keeping the family together, the imprisoned man's wife or girlfriend is left to negotiate her life alone. She has to juggle the care and support of the children, while maintaining contact through visits, letters, and phone calls, and at the same time deal with the loss of her partner's support and companionship (Miller et al. 2003:88). Explorations of the 'gendered nature of imprisonment' (Codd 2000:63) reveal 'almost universally, [that] it is women who must cope with men's problems' (Fishman 1990:262, 
emphases in original) - a situation far less likely to be reciprocated when women are imprisoned (Pollock 1998; Codd 2000:133).

\section{Black Women's Resilience}

Enduring the experience of vicarious incarceration/reintegration requires much patience, commitment, and resilience. Black women - as the primary support systems for incarcerated Black men and women — must maintain and sustain themselves to be able to support an incarcerated/transitioning loved one. Lorde (2007:150) offers the perspective that "survival is the greatest gift of love. Sometimes, for Black mothers, it is the only gift possible..." Scott (2017) reminds that being strong enough to survive emotional and psychological assaults on our dignity (among other daily abuses) means living another day to provide for our family and others in a larger network of relatives/community. Thus, the concept of resilience is important to explore if we are to better understand the lived experiences of Black women impacted by vicarious incarceration/reintegration.

According to Bernard (2004:10), "resilience is a normative process of human adaptation, encoded in the human species and applicable to development in both favorable and unfavorable environments." Arditti (2005:257) defines resilience as an individual or family system's capacity to survive, regenerate, and grow out of crisis and challenge. Resilience suggests a hardiness, a viability, and an ability to cope creatively even in the midst of complex stressors, obstacles, and difficulties associated with incarceration. Luthar et al. (2000) define resilience as "a dynamic process encompassing positive adaptation within the context of significant adversity" (also see Chaney 2011:96). Black women, in particular, have described resilience as “overcoming various 
challenges and being able to regain composure in the midst of adversity" (Abrams et al. 2014:509).

Various Afrocentric writers have identified major resiliency factors indigenous to African American family functioning, including extended family networks and kinship bonds, role flexibility in the family, strong spiritual orientation, cultural strengths, and flexible coping skills (Billingsley 1992; Kane, 2000; Jackson, 2011). In a study focusing on the intricacies of Black womanhood, Black women participants describe how they reflect and draw from ancestral resilience for empowerment and motivation to "reconstruct and embody the resilient identities of their enslaved ancestors (Abrams et al. 2014:509). Christian, Martinez, and Martinez (2015) assert that for some family members of incarcerated loved ones, resilience is centered on managing the relationship, while for others, it requires managing the hardships related to the incarceration.

Practicing and maintaining resilience for Black women, however, may come in the way of adopting maladaptive coping strategies. For example, Walker-Barnes (2014:148) argues "individual and collective experience has taught StrongBlackWomen that physical and emotional survival depends, at least in part, upon adopting a stance of cynicism, in which one expects the worst to happen. In order to protect themselves, African American women have effectively 'walled themselves off' behind a façade of emotional distance and imperturbability." Thus, as Black women garner strength, practice resilience, and ultimately manage to survive to offer continued support to their incarcerated/transitioning loved one(s), the mechanisms and strategies used to do so could be detrimental to their overall health and wellness in the long term. Put simply, if 
we are not careful, in efforts to ensure the safety and wellbeing of others, Black women run the risk of harming ourselves (Scott 2017).

\section{Coping Mechanisms}

Coping mechanisms are the strategies people use in the face of stress or trauma (e.g. loss of a loved one to incarceration) to help manage painful or difficult emotions (e.g. fear, anxiety, etc.). Chaney, Lawrence, and Skogrand (2012) indicated that African American women use spirituality and familial support to help them cope with many difficulties (Hart-Johnson 2014:7-8). Abrams et al. (2014:515) suggests that maybe it is "unity in pride and self-confidence that have allowed Black women and families to survive, thrive, and to be strong in the face of oppression, marginalization, and personal adversities." In fact, other researchers argue that "under the conditions of racism, ethnic and racial pride support favorable coping strategies and wellbeing (Ghavami, Fingerhut, Peplau, Grant, and Wittig 2011; Rowles and Duan 2012). However, too often, people adopt poor habits as a means of coping that are counterproductive to their stress management.

With regard to Black women and our responses to loss, Woods-Giscombe (2010:505) argues that "some women employ coping strategies that enable them to develop alternative ways to respond to their loss. Comprising resilience and independence, the SBW (StrongBlackWoman) schema exists as a psychological coping mechanism that facilitates familial and community preservation." In their study about the coping strategies of women romantically involved with incarcerated men, Myers (2016) found that women are less likely to seek out social and emotional support when coping with the stress of having a loved one incarcerated. Many women believe independent 
strength to be a necessity for an SBW due to lack of supportive networks, especially in the absence of male partners (Abrams et al. 2014:508). In their study, Grieb et al.

(2014:1193) found that women impacted by incarceration were more likely to hold stress in, fight or 'explode' and/or cry" than they were to discuss their problems with others. Watson-Singleton (2017) looked at the relationship between emotional support, the SBW schema, and psychological distress among African American women. They and found that 1) perceived emotional support partially mediated the link between the SBW schema and psychological distress, and 2) the SBW schema was directly associated with decreased perceived emotional support and increased psychological distress, buttressing extant research that suggests SBW contributes to chronic stress (Abrams et al. 2014).

Though coping strategies of Black women, specifically, have been meagerly explored, most studies on coping focus on the mechanisms, but not necessarily the effects of such mechanisms, especially in the long-term. With growing interest in health disparities for Black women (e.g. heart disease, hypertension, high blood pressure, etc.), there has been increased focus on the potential consequences of strong Black womanhood, and how "the physical and emotional impact of this historical practice of neglect is compounded in everyday lived experiences" (Scott 2017:xviii).

\section{Loved One's Incarceration Effects on Health}

The stigma, isolation, and trauma associated with incarceration have direct impacts across families and communities. In fact, mass incarceration's impacts on health have compelled some health professionals and social scientists to advocate for broad acknowledgement of mass incarceration as a public health crisis (Acker, Braveman, Arkin, Leviton, Parsons, and Hobor 2018; Wildeman and Wang 2017; Dyer, Hardeman, 
Vilda, and Young 2006), arguing that breaking up families results in poor health outcomes. One study showed that one in every two formerly incarcerated persons, and one in every two family members, experienced negative health impacts related to their own or a loved one's incarceration (Ella Baker Center 2015). Families, including their incarcerated loved ones, frequently reported PTSD, chronic stress, nightmares, hopelessness, depression, and anxiety (Ella Baker Center 2015). Another study showed "that even when controlling for a range of demographic and health related factors, incarceration of a friend or relative was associated with the physical and mental health of individuals in the community; the degree of closeness with someone incarcerated was positively correlated with worse physical and mental health" (Grieb 2014:1184). Data from the National Survey of American Life found that women with incarcerated significant others had a 95\% greater chance of high-risk, health-related conditions than those who did not (Hart-Johnson 2014). In general, "communities of color, women, and low-income communities in the United States suffer from poorer health outcomes than the rest of society"; thus, "incarceration and its consequences exacerbate health risks for people who are already vulnerable to poorer health outcomes" (Ella Baker Center 2015).

Lee et al. (2015:421) argue that "because the experience of incarceration is concentrated among men, incarceration's indirect consequences on women's healthtransmitted through the incarceration of a family member - are likely more relevant for health among women than are their own experiences of incarceration on the aggregate level." Women who experience separation and loss because of a loved one's incarceration experience a plethora of responses: depression, anger, fear, numbness, separation anxiety, sleep disorders, and other problems (Chui 2010; Turney et al. 2012; 
Fahmy and Berman 2012; Hart-Johnson 2014; Lee et al. 2014, 2015;). BeauboeufLafontant (2003) found the assumption of multiple roles (e.g. caregiver, breadwinner, single parent, etc.) coupled with limited resources, to be related to self-neglect and the mismanagement of one's physical health and weight (also see Abrams et al. 2014). Lee, Wildeman, Wang, Matusko, and Jackson (2014) found that family member incarceration was associated with higher odds of obesity, heart attack or stroke, and fair or poor selfreported health for women but not men. Lee at al. (2014) also argue that family member incarceration has profound implications for women's cardiovascular health across race and should be considered a unique risk factor that contributed to racial disparities in women's health because of the disproportionate burden of this experience among Black women.

Considering acute and chronic stress, and how continued incarceration of family members from incarceration "hot spots" may develop into chronic stress, are important to understanding individuals' experiences with a loved one's reentry and how these may affect health in a community (Grieb et al. 2014:1195). Psychologically, disenfranchised grief—or, grief that is not widely acknowledged by society—exacerbates problems and emotional reactions for the bereaved, an area yet to be explored carefully by researchers examining the effects of incarceration on survivor family members and children (Arditti 2005:254).

\section{Gaps in Literature}

There is little research which focuses on the various ways Black women are impacted by vicarious incarceration/reintegration. More specifically, there is a dearth of research on how Black women manage resilience as they navigate their daily lives under 
such circumstances. Although the impact of general stress on women has been welldocumented, studies primarily focusing on women's coping with incarceration of a loved one, and the long-term effects of chosen coping mechanisms, has not. Furthermore, research examining the impact of vicarious incarceration on the overall health and wellness of Black women is lacking.

One thing is certain: "Black women experience a double whammy: they suffer from high rates of stress, depression, and anxiety, and they are less likely to seek help for their problems" (Walker-Barnes 2014:53). The belief that even in stressful and/or traumatic situations, Black women must maintain our strength and ability to endure can be stressful in and of itself, "and may also undermine physical health" (Abrams 2014:513). Abrams et al. (2014) argue that characteristics associated with being a SBW and attempts to live up to the ideals of strong black womanhood contribute to the stress Black women experience in our daily lives. In fact, the StrongBlackWoman schema has also been implicated in the development of chronic stress (Abrams et al. 2014:506). Nevertheless, very little work has been done in the way of examining how experiencing vicarious incarceration and supporting incarcerated/reintegrating loved ones impacts the overall health and wellness of Black women - the population most gravely impacted by mass incarceration.

\section{Conceptual Framework}

In this manuscript, I use my experience and understanding as a Black woman vicariously impacted by incarceration/reentry to uncover, demonstrate, and underscore how countless Black women manage resiliency and even thrive under oppressive, stressful circumstances. I employ a womanist perspective and the concept of 
intersectionality to guide this work with the intention to facilitate a clearer understanding of the complexity of Black women's existence and everyday lives, as well as the transformational nature of our survival tactics (i.e. resilience strategies). I use standpoint theory to guide the research questions and inform participants' responses throughout the manuscript.

\section{Feminist Standpoint Theory \& Intersectionality}

Collins (1986) reminds us that Black women possess a unique standpoint on, or perspective of, their experiences. Since standpoints refer to group knowledge, recurring patterns of differential treatment...suggest that certain themes will characterize U.S. Black women's group knowledge or standpoint (Collins 2008:29). The collective wisdom on how to survive as U.S. Black women constitutes a distinctive Black women's standpoint on gender-specific patterns of racial segregation and its accompanying economic penalties (Collins 2008:28). Black feminist thought "demonstrates the epistemological and political significance of theorizing from individual experience in the context of a community with shared experiences, identities, and standpoints (Collins 2019:185). Because we recognize the disproportionate connectedness Black women have with incarcerated humans, we may comfortably assert that the experience of vicarious incarceration/reintegration is a common occurrence that contributes to our shared knowledge as a group. Furthermore, "the substance of experience matters in relation to diagnosing social problems and in figuring out ways to address them. Relying on experience as a way of knowing can bring wisdom to critical inquiry, but only if that wisdom itself remains under construction" (Collins 2019:186). 
Collins (2019:137) also points out that "experience as a way of knowing is routinely dismissed as mere opinion rather than informed testimony that illuminates the truths of being silenced and subordinated." My position as both a member of the impacted community of focus in this manuscript, as well as a trained academic researcher, permits me a level of privilege, access (to knowledge and information), and validity to operate and be a voice in both spaces. Using informed social action in response to my experiences with incarceration and reentry, my actions in turn shape my intersectional analysis of Black women and our strategies of managing resilience.

Kimberle Crenshaw introduced the term intersectionality to describe how Black women's experiences, with the combination of racism and sexism, were cloaked and/or complicated by treating race and sex discrimination as separate matters in U.S. law and in feminist antiracist activism (Moradi and Grzanka 2017). Crenshaw initially defined intersectionality as a "constellation of empirical phenomena grouped into three categories: structural, political, and representational intersectionality, reflecting how Black women's life chances were unfairly and systemically limited in the economy, law and throughout society; in antiracist, feminist, and other forms of single-axis politics; and in the cultural construction of women of color, respectively" (Crenshaw 1989; Moradi and Grzanka 2017:503). Crenshaw's articulation of intersectionality functioned as a critique of single identity politics and challenged structures/systems of oppression (Moradi and Grzanka 2017: 502-503).

Intersectional paradigms remind us that oppression cannot be reduced to one fundamental type, and that oppressions work together in producing injustice (Collins 2009:21). In this case, being Black, being woman, and having an incarcerated or 
previously incarcerated loved one are but three of the various types of oppressions the women of this study were/are combatting. Treating this population and topic from a feminist intersectional lens allows for analyses that "emphasize how social structures interlock to shape particular social outcomes (Collins 2019:162).

Moradi and Grzanka (2017) contend that intersectionality is interventionist to the extent that it is a social justice movement. Centering voices, they argue, should also mean studying strategies of resistance.... and doing coalitional and ally work to enact resistance and activism as a central rather than ancillary part of research (Moradi and Grzanka 2017:509). My positions as an academic and community servant, or community engaged scholar, qualify me as a conduit of information between both institutions. I am committed to using my academic platform to bring marginalized voices into scholarly discourse, and taking academic knowledge into marginalized communities, thus maintaining a mutually beneficial exchange of thought and information.

Returning to my hometown, working alongside community members/advocates on matters of equity and fairness helped me understand my own lived and vicarious experiences with poverty, the criminal justice system, mental illness, addiction, domestic abuse, etc., simultaneously lending me the capacity to sympathize/empathize, connect, build rapport, and communicate effectively with other humans experiencing similar struggles and circumstances. My personal experience, community partnerships, and academic erudition equip me with tools necessary for researching, analyzing, and reporting culturally-specific issues, and lands me in a more fitting position to identify culturally-informed solutions. 
Collins (2019:139) assert that "claiming situated standpoints, especially groupbased standpoints, and theorizing from those social locations can be a form of empowerment for subordinated groups." Serving as a healing circle facilitator, interviewing Black women impacted by incarceration, and being impacted by the same social issue, has not only provided Black women safe spaces and opportunity to share their stories, but also informed my research on Black women's resilience strategies, and enhanced my own understanding of my experiences as a member of the impacted community.

Thus, it is my goal to use my intersectional standpoint, as a Black woman community-engaged scholar impacted by vicarious incarceration, as a tool to demonstrate the oppressive nature of the criminal justice system on the families-namely, Black women — of incarcerated/transitioning humans, as well as the strategies these women use to resist, persist, and manage resiliency throughout their experiences.

As a scholar, activist, and a Black woman vicariously impacted by incarceration like the women of this study, I employ very specific strategies in researching, analyzing, and reporting the findings of this work. Collins (2000:27) argues that "being Black and female in the United States continues to expose African-American women to certain common experiences." Thus, throughout this manuscript, I often use "we," “our," and, "us" to describe and reference my connection and shared experience with the women of this study, and to emphasize my shared experience and understanding as a Black woman in general. I made the linguistic and political choice to use we/our/us with the intent to identify with, rather than objectify, the participants of this study. 


\section{CHAPTER THREE: METHODS}

Drawing on in-depth interviews with ten Black women who, at the time of our interview, were supporting, or had previously supported, an incarcerated/transitioning loved one, I explore narratives regarding their navigation of everyday life with the criminal justice system playing a constant, antagonistic role. The central research question of this study is: what strategies do Black women use to manage resiliency as they navigate daily life while also supporting a loved one who is incarcerated or formerly incarcerated?

This study also addresses the following research sub-questions:

1. How does the experience of supporting an incarcerated/transitioning loved one affect Black women's mental, spiritual, emotional, and physical wellbeing and overall ability to care for self?

2. How does the experience of supporting an incarcerated/transitioning loved one affect the way Black women show up, i.e. operate, function, in the world (e.g. their homes, their communities, their workplaces, etc.)?

3. What types of resources do Black women experiencing vicarious incarceration/reintegration have, utilize, and/or need to sustain ourselves, our families, and our communities?

The narratives of these women are used to examine individual and shared experiences of those enduring vicarious incarceration/reintegration, specifically noting strategies of resilience utilized in everyday life. Holstein and Gubrium (1995:1-2) refer to interviewing as "the universal mode of systematic inquiry," with the interview itself “'prospecting' for true facts and feelings residing within.” Riessman (1993:2) asserts that "the purpose [of narratives] is to see how respondents make sense of events and actions 
in their lives.” Thus, analyzing narratives of Black women experiencing vicarious incarceration and reentry is an ideal method to garner this information; and informing the work with my own personal knowledge and experience with these phenomena will allow for a more comprehensive description and understanding of participants' constructed realities and interpretations of their experiences, as a means of answering the research questions.

As with other studies which aim to lift the voices of individuals and groups often silenced or muted, this research employs a phenomenological approach for examining the resilience of Black women in our daily lives while also supporting an incarcerated/formerly incarcerated loved one. The goal of the phenomenological approach is to gather lived experiences that can provide a meaningful reflective look at particular experiences resulting in scholarship that emphasizes the experiential rather than the experimental (Houston 1989; van Manen 1990; Scott 2017).

The art of storytelling and sharing intimate information is influenced by various social processes, therefore it is important to acknowledge that the participants' narratives may have unfolded differently with a different interviewer (Scott and Lyman 1968; Holstein and Gubrium 1995; Riessman 2008; Presser and Sandberg 2015). As a Black woman, servant of the community involved in social justice and racial healing work throughout Sacramento, and a known $\mathrm{PhD}$ candidate, the participants of this study viewed me as a "sista" trying to draw attention to the struggles of our people and move our people forward. This made the establishment of rapport particularly easy, which is a strength of this study. Due to my role and intimate connections in the community, the participants were glad to share their stories with me. They were very open and raw in 
their sharing, and encouraged me to ask as many questions as I needed, which was likely in response to my own candidness and shared experiences as a Black woman. Upon conclusion of the interviews, the majority of respondents mentioned that they enjoyed sharing their stories and appreciated my inquiry because it provided an opportunity to release and reflect on their own ways of dealing with, and healing from their experiences. This further supports the contention that storytelling provides a powerful platform to make sense of life experiences (Holstein and Gubrium 1995; Riessman 2008).

Research Design

\section{Recruitment}

I recruited participants across my social and professional networks. I used men and women I met through volunteer work throughout the community (e.g. communitybased organizations, churches, non-profits, etc.) to conduct purposeful, snowball sampling (Weiss 1994).

I distributed a recruitment flyer across my networks via social media and used word-of-mouth to recruit volunteers. Upon viewing recruitment flyers or hearing about the research study, potential participants contacted me via phone, email, social media, or in person. Once an individual who fit the research criteria agreed to participate, I requested their assistance in identifying additional potential participants.

I provided a waiver of documentation of consent to each participant for review. Upon determining eligibility and explaining their role in the study, verbal/oral consent was all that was required to participate.

All participants identified as Black females and were at least 18 years of age. Each confirmed experience with vicarious incarceration and/or reintegration. 


\section{Sample}

The women of the study came from various backgrounds (see Appendix). However, eight of the ten were involved in some form of social justice work. Having an understanding of their demographics is important because it helps to contextualize their responses. Participants' ages at the time of the study ranged from 24 to 68 years old. The participants were generally well-employed with most maintaining professions in education, social services, and self-employment. Four of the ten women had retired, but were still actively involved in social justice work (e.g. youth advocacy; homeless veterans; prison reform, etc.). Though education level was not asked as an interview question, conversations revealed that each of the ten participants had graduated high school, five had graduated with a four-year degree, four had graduate degrees, and three had some college experience.

In terms of the incarcerated and/or transitioning loved one(s) these women were supporting or had previously supported: Two of the participants supported their child, three supported a sibling; four supported a parent; two supported a significant other; four of the women supported multiple loved ones. Four of the ten participants were married at the time of the interviews. Eight of the ten participants had children or other dependents.

\section{Data Collection}

Semi-structured interviews were used to collect the data. Interviews were conducted in various public places, such as restaurants, coffee shops, churches, and parks. The interviews were preceded with an explanation of the purpose and procedures of the study, as well as a brief description of participants' research rights, as part of the consent process. This consent process ensured that participants were not coerced into the 
study, and allowed them the opportunity to consider whether they wanted to participate. The participants' names, the names of their incarcerated and/or transitioning loved ones, as well as other identifiable information have been changed to protect their identities. The interviews lasted between 30 to 140 minutes. I recorded the interviews and transcribed the recordings; in addition, I took notes during the interviews and after the interviews.

I used twelve pre-constructed questions specifically designed with the research questions in mind to guide the interviews. The interviews were open-ended to allow participants autonomy throughout the process. I encouraged participants to speak freely, making the option available to answer beyond the original questions. This also allowed me to seek clarification as needed.

Participants were compensated with \$20 cash for their participation and were treated to a meal (or snack) not exceeding the amount of $\$ 20$; one participant requested that her cash compensation be anonymously donated to a Go Fund Me account to support the efforts of a local nonprofit organization.

\section{Data Analysis}

After interviews were transcribed, the text was examined, and a set of codes were generated. Then, axial coding was used to aggregate the codes into common themes (Charmaz 2014). This process occurred for all ten interviews and ultimately generated six predominant themes. The themes that emerged became the titles to the chapters throughout the manuscript. Codes and themes were determined based on the combination of my personal experience with, knowledge about, and understanding of the impacts of vicarious incarceration, my academic research, and my familiarity with community experiences with incarceration as an activist. 


\section{CHAPTER FOUR: THE FEEL}

Incarceration impacts much more than just the individual being punished.

Families are left behind-wives disproportionately lose husbands, children disproportionately lose fathers, mothers disproportionately lose sons. The effects of incarceration ripple from families to communities to institutions and beyond Harris and Miller 2003; (Braman 2007; Comfort, 2008; Alexander, 2012; Goffman, 2015). The support of family, friends, and community is widely recognized as a predictor of successful release, reentry and reintegration (Hairston 1991; Crutchfield 1997; Travis 2005; Martinez and Christian 2009; Shanahan and Agudelo 2012). While the financial and social impacts of a loved one's incarceration have been reasonably, albeit, incompletely documented, the more nuanced details of how families/communities conceptualize support and what certain types of support look like and require (e.g. emotionally, psychologically, legally, etc.) have been largely ignored, or at best understudied.

Although people who experience vicarious incarceration share common struggles and/or run into similar obstacles, the overall experience is unique for every individual. This section will explore what support for an incarcerated loved one looks/-ed like and how an incarcerated loved one's absence impacts/-ed the participants' daily lives. I argue that the incarceration and/or reintegration of a loved one compounded with the everyday stresses and concerns that present themselves in the lives of Black women, affects how we are able to support our loved ones, and how we are able to manage psychologically, emotionally, financially, and whatever more. 
Why We Support, How We support, and What Support Looks Like

Several of the interview questions were designed to probe responses regarding the ways in which each participant conceptualized the idea of support. Participants discussed why they offered support (e.g. type of relationship), how, or in what ways support was offered (e.g. emotional, financial), and what support looked like (e.g. letters, visits, etc.). Extant research has revealed that social support from family/community during and postimprisonment is viewed as a treatment strategy (Hairston 1991; Comfort 2007; Martinez and Christian 2009; Shanahan 2012; Holligan 2016; Travis, McBride, and Solomon 2016). However, support looks and feels different depending on who is giving and getting the support, what the person being supported needs and what the supporter is able to provide, taking into consideration things like social position and financial standing, among other factors. For example, Sister Tyra explained why and how she supported her father and others, and not only what that looked like for her, but also what it meant to the people she was supporting:

With my dad, it was more of an emotional thing. But when it comes to moving forward, it was more financial support. It was little things that matter to people who are incarcerated like a 3-way call with a girlfriend or sending a package through whoever...ok, you send me the money, I'mma do this or do that...little things that make a difference to people who don't have nothing to essentially look forward to living. That's just all a perspective thing too. It's like, if I'm eating, if I'm able to wait for that next phone call if I'm able to get that 3-way phone call... Tyra described being supportive both emotionally and financially, indicating that she did the "little things that matter to people who are incarcerated," further demonstrating that 
some forms of support, like a 3-way call, may be more important to one individual than it is to another individual, who may need money for commissary at the time. In Tyra's words, its "all a perspective thing."

What "matters" to the imprisoned, i.e. what they want and need, may not always be aligned with what supporting family/community is able to provide. Tyra briefly described elements of a hypothetical (but realistic) transaction between her and an imprisoned loved one (“ok, you send me the money, I'mma do this or that") in which she did not have the financial means to offer support, but she was capable of being the broker, coordinator, or performing the leg work for a particular request. Her incarcerated family may be aware the Tyra cannot afford to send a monthly package, but she almost always answers her phone when they need a 3-way call. In both situations, Tyra is unable to be financially supportive, yet she serves as a reliable, valuable resource for communication between the inside and outside world.

Sister Amanifu's experience with support was unique in its own right having never known her father prior to meeting him in her 40s while he had already been incarcerated for more than 40 years. Amanifu explained what inspired her to be supportive of the father she had never met prior to his incarceration:

I think the main thing that influenced my decision was the void of that father daughter relationship and my willingness to always meet people right where they are...

Amanifu's response indicates that support for her father manifested out of a self-serving desire to fill the void she felt in her father's absence. As time went on, however, Amanifu 
and her father grew extremely close and she became both compelled to, and intentional about providing support:

I offered my dad love support, the support of a family. We wrote each other every day and I visited him every weekend for 22 months. Every weekend. I didn't miss a weekend in those 22 months. I saw him every Sunday and every other Saturday and on the off Saturday, my grandmother saw him (his mom). And for him, that was a lot. We don't think about what a letter or a visit or a phone call will do. And once I realized how important writing him was, and how powerful an impact you can make by writing, I wanted to keep that up. And I remember when I got to see him for the first time, that's when I made up my mind that I was going to write him every day. And his response was, "Well, honey, I don't know if I'll be able to keep up but I'll try."

Her responses suggested that Amanifu was initially seeking a closeness she was never afforded due to her father's confinement. However, the more she was able to see him, the more aware she became of how important her support for him (i.e. letters, visits, etc.) was. Researchers highlight that "staying connected to a prisoner at the most basic level, of going on a prison visit requires resources in the form of time, money, and energy (Comfort 2003; Braman 2004; Christian 2005). When I asked how she was able to maintain the energy and wherewithal to visit every weekend and write letters consistently, Sister Amanifu explained:

I just made it a priority. I made it a priority. Especially when I knew how it affected him and it really made a difference. 
Amanifu's choice to not only support her father, but also to prioritize supporting him, points to both her desire and ability (e.g. time and resources) to do so. Abrams, Maxwell, Pope and Belgrave (2014) remind us that Black women often prioritize care for others, with our needs taking a backseat, thus increasing the potential of harm to our physical and mental wellbeing. While efforts to provide moral support for an incarcerated loved one(s) are thought to counter some of the psychological damage resulting from the incarceration of the individual(s) themselves, the psychological toll it takes on the supporting party is not necessarily considered (Christian 2005). Taking into consideration the psychological effect on Black women supporting their incarcerated loved ones is especially important being that such a large population of Black women are impacted by this phenomenon. However, in line with writers from the Combahee River Collective of 1977 who assert that "there is a very low value placed upon Black women's psyches in this society, which is both racist and sexist," Black women's wellbeing often takes a backseat while our families/communities' wellbeing is prioritized instead.

Other women described their decisions to become supportive as being part of their responsibility as mothers, daughters, or sisters of their incarcerated loved one(s). From their stories, it appears that the women prescribed to the faithful role of providers to their incarcerated loved ones on the inside as well as their families on the outside. For example, when asked how she became a member of her daughter RiRi's support system, Suzie Cain explained her perceived responsibility:

I was going to face it...The fact is, you are still mine, whatever mistakes I made, you are still mine, and no one is going to be with you through —'cause you're 
getting ready to go through the worst of the worst, and I just felt like that's something I'm supposed to go through with you.

Sister Suzie went on to explain her husband's influence on her decision to support RiRi, despite their opposition to her crime:

Because one of the things—my husband is a phenomenal man - one of the things he and I agreed to do is that we were not going to allow her to do this by herself. Even though we are totally opposed to someone taking somebody else's life, even though we are law-abiding citizens, we are not going to let her have to suffer by herself. And now that we've been walking with her these past 18 years, that is far more than most would do. And so once we committed ourselves to that, we just do it.

Suzie's response demonstrates both her and her husband's sense of responsibility to maintain a secure relationship with RiRi, despite her offense, an important value in African culture that has been transmitted to Black families in America (Degruy 2005). Popular adages like, "riding it til the wheels fall off"; "stick together through thick and thin"; "ride or die"; "I got yo back" are some of the key mottos Black folks live and die by. So, although Suzie and her husband disagreed with RiRi's behavior, they were committed to supporting her through her term of imprisonment because they believed it was their responsibility as parents and as a family to do so.

Most of the women shared the belief of family support for one another. Hence, they often gave me puzzled looks when I posed the question, "How did you become a part of your loved one's support system?" To the mothers of incarcerated children, in particular, the answer was a given; 'He's my son,' or 'She's my daughter' were thought to 
be explanation enough, thus, at times, I had to rephrase the question to obtain more detailed responses. Tia Cason responded to the question about how she became a member of her son Jason's support system by expressing a sense of responsibility and genuine concern about his need for support, especially as an individual with mental health needs:

First, being his mom and knowing I needed to be his voice. Because I knew something was going on; this isn't my child. There's some trauma, there's something going on, I need to be his voice, I need to get power of attorney, and I need to do these things right now just in case he isn't able to speak for himself. And I did that. I let my presence be known. 'Cause a lot of times, people put their faith in the judicial system and think they'll handle it to help them and they don't. They get put in jail....

Tia speaks to the common issue of mental illness in jails and prisons. Jason is one among an estimated 30-60 percent of incarcerated people reported as having some type of mental health condition (Bureau of Justice Statistics 2017). Supporting an incarcerated loved one with a mental health problem can easily exacerbate stress and strain, and one's overall mental health. Not only does Tia worry about Jason's confinement, but also if he receives the attention and care he needs as it pertains to his mental health needs, and if he is experiencing difficulty with his condition, among other concerns.

In addition to being a voice for Jason and letting her presence be known in the courtroom and beyond, Sister Tia explained what support for Jason looked like typically: ... any time I got the opportunity to speak, or email a judge that was on my son's case... and just coming out the pocket and answering that phone as quickly as I 
can and getting him what he needs - shoes, he needs another pair of shoes now cause he's flat footed, having his t-shirts, and pictures, envelopes, stamps.

Tia shared about what it takes to offer this and other types of support and why it is important when she explained:

I can say since my son has been in and out of prison since 2012, I've spent thousands on TV, cd players, DVDs and some people would say they [incarcerated humans] don't need these things. But when you're somebody whoI don't have no degree in mental illness or nothing—but I know when there's voices going on between your two ears that have altered your state of mind, you need some support and Mama's the one that's gon be the one to do it.

From her descriptions of support, Sister Tia demonstrates that her role as a mother did not stop because her son was removed from the home. If anything, Tia's responsibilities as a mother expanded having to learn how to manage care from the outside via the institution. Nonetheless, Tia tried her best to make Jason's stay as comfortable as possible by providing everyday necessities (e.g. shoes for his flatfeet) and tending to his unique needs (e.g. TVs, CD players, and DVDs to help him cope with his mental illness).

Suzie Cain described what support for RiRi looked like and how RiRi benefited from her parents' support:

...we send her whatever she needs, and she probably lives large compared to others - but those items and things that we send her are kind of the bargaining chips too, you know. Not only bargaining chips to get something back, but it helps her to build community. Like she said that for whatever the last holiday 
was, she was able to--we had bought her a grocery list of things she had sent for, and she made something for her and her roommate. So she kind of "entertains", you know what I mean? So it's not like she sits high and lifted up in any way but it helps her to develop relationships. So in order to fund that for her, we have to do without some things here.

Sister Suzie's testimony speaks to the sacrifices she and her family had to make to support RiRi (e.g. "do[ing] without"), and further elaborates on how that support intended for RiRi extends/extended to other women who are/were incarcerated with her, and women who were released as RiRi remains in confinement:

There have been, over the course of these 18 years, so many young women whom I have met through my daughter—because my daughter's faith was renewed. And so now she is known in that institution as someone who believes and follows after prayer. Not saying she's perfect cause she's had some girlfriends in there and they've fought and they've done this and, she's still herself. But they know her to be a woman of God. So what's surrounding her, then, are people who are faithful and a lot of those women have no support system. So as I'm supporting her, as I'm send her video tapes and sermons and things like that to help undergird her faith, it is undergirding their faith also. I sent these girls, I sent her a video about 8-9 years ago and it's a video that has gospel singing intermixed with a lot of testimonies of people who have not just been in church all their lives; people who have been drug addicts (actually I'm using it with the Del Paso Heights women) and from that video I got about 50 or 60 notes from all of these different inmates who had said, "you don't know how this helped me think better about myself, 
about coming out from..." and I was just trying to reach out and help my own. I mean, I want to help other people too, but that particular gesture was to give my daughter something that says, these are people who have been where you are, and they have lived to see the end result and now they are coming back and telling folks. And we reached like 50 or 60 women in that institution. Those are the kind of things that makes our journey—-the difficult of the journey (it's really difficult, it really is!) — but hearing from those 50 women, or one of two of them who have gotten out and have come back to Sacramento, and the thing that they did was they went to one church or another and asked them do you know Suzie Cain. To pastors in the city. Cause my daughter tells them you know, "My mom's doing all this stuff and she connected to these pastors in Sacramento, and if you go back to Sac just ask somebody."

Suzie's testimony demonstrates how her work as a mother to RiRi reached other women as well. And with the activism and spiritual work Suzie performed in the community in her daily life — which many of those released women sought out upon their release—it is likely that they benefited in some way (psychologically, emotionally, spiritually) because of Suzie's care and concern for the wellbeing of her own child.

Sister Cheree described what support for her son, Jamal, looks like:

On [some] days I will stop everything that I have to do if the phone rings, or if it's for a visit. I think I've given up every Saturday for almost three years. I don't think I've missed a visit. It used to be every Saturday and Sunday, and now that he's farther away it's every Saturday. I think I made him miss one Saturday. Last week was the first I had ever missed 'cause I took a cruise and went to Mexico. 
It was extremely important for Cheree to remain a constant presence in Jamal's life, so much so that she sacrificed every weekend to visit him. Cheree's commitment to visiting Jamal spoke to "Black family situational dynamics that prompt extreme self-sacrificial responses and behaviors" (King and Ferguson 2006:110). In response to Jamal's incarceration, Cheree learned how to make "trade-offs with other areas of [her life]" to be able to provide the level of support she thinks he needs (see Christian, Mellow, and Thomas 2006:447-448).

Sister Asali explained that much of her decision to support her incarcerated loved ones was influenced by empathy and guilt:

Sometimes I reach out to them [her cousins] just because, you know, that empathetic part. The other [incarcerated loved] one was someone I was dating, and it was a question that came up, 'cause we hadn't been dating that long. And someone was like, “oh you not gon' support your man?”

Having experienced a bout with the criminal justice system herself, Asali empathized with her incarcerated cousins and was thus moved to support them by writing letters occasionally. However, she would have felt a level of guilt had she not supported the man she was dating at the time when he was sent to prison. Asali went further to explain how and why she continued to support her former romantic partner:

I drove to Modesto and went to the jail to see him. And he was like, the look on his face, and how surprised he was that I was there, and how happy he seemed that I was there, it was like, I felt the need to continue to support him. But it was a very different type of support because it wasn't a monetary support at all. Which I 
will definitely say I did not support him monetarily one bit when he was in jail. It was more of an emotional support. It was different.

Sister Asali also explained how her support for her former romantic partner differed from the support she offered her incarcerated family members:

With the [romantic] relationship, I did the whole thing: Took the time, took the weekends and went up to go visit, the whole nine. But with [my] cousins, I had already been through a bad situation the second time around so I wasn't going to visit nobody. You need a letter? I'll write a letter. You need a couple dollars? I'll give you a couple dollars here and there. When my cousin went the first time ('cause he has gone multiple times) I went out of my way. And I was in high school, and I made sure I'd give him some money, letters, so it wasn't that bad. Already having had several different experiences with vicarious incarceration, Sister Asali had to create certain boundaries with certain people and relationships. For example, Asali shared with me that the legal trouble she has experienced was related to a visit with her former partner. After that bad experience, she no longer wanted to make visits to any prison. Thus, she supported her loved ones in other ways that she felt did not jeopardize her freedom.

When asked why she provided different types and levels of support to each of the incarcerated loved ones she shared about, Asali responded that the "level of empathy...despite the fact of everything we went through personally" was different for her romantic partner than what she possessed for her cousins. With regard to the support she offered her previous romantic partner, she went on to say: 
I'm not gon' say we do therapy 'cause I can't do therapy with him cause I know him, but we talk but it's not on a relationship tip and it's not anything sexual, it's just more of a...just somebody being there as a friend.

Asali's responses implied her support for her loved ones was less about relational obligation or responsibility, and more about compassion and sympathy.

Kali responded to the question about how she became a member of her incarcerated father's support system describing what sounded like more of a "by default" circumstance:

I was his only, first and only child...so I kept him going during his time of incarceration. So I guess I was more of support system to him in that sense. Although Kali was just a child, in hindsight, she felt as though she needed to be supportive of her father; that being locked away, there was not much he could do in the way of effectively supporting her.

Kali further explained how her mother's support of incarcerated humans throughout her life influenced Kali's decisions to support not only her father, but other humans who are or have been imprisoned:

My mom has supported a lot of people in jail. When I was growing up, my mom used to get a lot of jail letters. And I knew them. I recognized them. A lot of our cousins, a lot of people she grew up with in the neighborhood, going in and out constantly, constantly. She was very supportive of a lot of people who have been incarcerated. So it's good I can talk about it, we can talk about it, I can relate, we can both relate vs having a mom that, "ooooh I made that one wrong mistake with 
that one person" and then wanna shut the door on it, never wanna talk about it, it's old news.

As my father was incarcerated and then watching my mom support so many incarcerated individuals, it allowed me to not only accept people who are incarcerated, but also, find myself, maybe in a relationship now where I'm supporting somebody, maybe I'm writing somebody now. Or maybe I'm trying to keep in touch with somebody I went to high school with who is incarcerated. I don't think it's a bad thing, but I think that finding that balance and not losing yourself in the relationship, in that type of support is important. Because they need our support; they need our support.

Kali's testimony suggests that her mother's support for incarcerated loved one's/community members opened Kali's mind and heart to be accepting of, and compassionate toward incarcerated humans. Her decision to do so was less about expectation than it was compassion and benevolence.

Like many of the women, Sister Oprah described her decision to support her brother Randi out of familial obligation and loyalty:

We family, so there's no question about who's supporting what in our family. Our family is family and what that means is we have ties that bind and there is nothing that separates us from that. So there's a certain level of connection and respect and connecting that we do that reiterates the importance around connection and family.

Oprah's sentiment is echoed by participants in a study on incarceration and reentry, in which one explained: "You gotta be there for them...you don't give up on family. At 
least that's what I was taught. I still believe that today and I am always going to believe you don't give up on family." Another expressed his belief regarding why family supports family saying, "Nobody really cares about all the people who are incarcerated [and in reentry] but the family" (Grieb et al. 2014:1189).

Oprah went on to offer insightful detail about what support for Randi during his incarceration looks like:

I support him in ways that work for me. So what does that look like? That looks like, I send money when I can, I write letters. And although my letters are not as frequent as the letters he sends me, I do make sure that I respond. I know that it's important for him and it's also important to me to communicate that level of care to him.

Also, we provide financial resources for him. We don't swim in a whole lot of money. I have money. But I have enough money to do what we gotta do to maintain our lives. I'm not, you know, have above and beyond, or have exuberant ways. That's not the life I'm living. So while, yes, I do give money, I also recognize that that money is being directed toward him and not being directed toward other things in our home. And thank God it's not anything substantial, but I notice. I notice. It's not like, oh this is nothing. It's not that. So yeah I definitely support him in that way but I think the other thing is that I get a certain benefit from being able to be supportive for him. Being supportive to him is not only a way in which I honor him, and honor our relationship as brother and sister, but also a way that I honor my mother. 
Oprah's testimony speaks to both her feelings of relational obligation and Black women's roles as caregivers. Although Oprah feels a sense of obligation to support her brother because of her role as an older sibling, she made it a point to mention supporting him as a way to honor their mother. Oprah wanted to care for and protect Randi as she believed her mother would have and would have expected Oprah and her sisters to in her absence - a role Black women are socialized to undertake early on.

Sister Raychelle had two brothers and two younger male cousins (with whom she had grown up with closely) incarcerated at the time of our interview, and a brother who had just recently been released. Raychelle's relationships and proximity to each of them is merely a demonstration of the assertion made by Lee et al. (2015:271) that, often, a large "percentage of Black women's social networks are composed of prisoners, suggesting that these women may carry an especially heavy burden." Raychelle's accounts often oscillated between family members dependent upon the subject at hand. Raychelle's older brother, a year and a half her senior, had been the first to get caught in the criminal justice system, making his first trip to juvenile detention at the age of 13 . She described how she became a member of his support system and what that looked like for her at the tender age of 12 :

That early, and having a momma who was an addict, at the time- - who was physically present but mentally absent—caused me to write to [address of detention center]. To write him letters to let him know that I was thinking about him; that he was missed. I was supporting him in that manner, that young, and then I followed him to going to the youth authority after 13. 
Raychelle went on to describe how she easily transitioned into offering support to her younger brother when he was arrested and detained at age 12:

When my younger brother, Damon, went to jail for the first time, I knew I needed to be there. Court - that was the first thing. If he could see my face, he knows I'm here, we gon' be alright. So from already having that experience with that emotional support with my oldest brother, I already knew what to do with [my younger] brother. I was 16 years old, was at court, right there to get my baby. By the time Raychelle was 16, she had already grown familiar with the juvenile justice system. Thus, by the time her youngest sibling had his first run-in with the law, Raychelle already knew what to do and how important her presence alone would be in supporting Damon.

Raychelle went on to describe the different ways in which she was able to offer support for her brothers at different times in her life. Detailing her ability and level of support for Damon when he was charged with murder at age sixteen:

At that time, I was there for him; it was slightly different though, at that age. I was a mother of my first child. Nyla [her daughter] was one year old when Damon first went to jail, but I was still there, again for the emotional support, the mental support, the moral support. He still needed somebody. And again, my mom, she was there but she wasn't there. So he didn't have regular visits but he had somewhere to call home. 'Sister, I need this.' Or, 'are you guys coming?' (when he would get home passes), 'are you gonna be there to pick me up?' I had to be there. Somebody had to be there cause my mom wasn't there. His dad is in prison serving a life sentence since he was one year old so it was really....Me. 
Sister Raychelle also offered insight into the complexities of supporting her brother, Marshawn, who had recently been released after five years of imprisonment, often speaking as if directly to him:

I'm like, well, you can come here. We have a four-bedroom house. This nigga snores like a damn bear! You better make it work down there with that door shut. I just don't want to hear you. But you can come here. You don't have to pay rent, utilities; I know you're trying to get on your feet, I know you're trying to figure that part out. But there are things that cannot come here with you. Under any circumstance. Period, point blank. Cause we'll fight nigga. And he gives me that respect, he's not gon' be disrespectful, but I'm raising your son and my three children. Certain conversations can't come up in here, certain behaviors can't come up in here. And because of that, he hasn't chosen to come and stay here. And that's ok. But I just need you to know, when you're ready, if you ever get to that point, we got you. You'll be ok here.

Research suggests that the most secure family relationship for a male prisoner is his mother (Brodsky 1975; Green 1982). However, we see in Raychelle's case, her mother was mentally and emotionally unavailable for her brothers; therefore, despite their closeness in age, Raychelle assumed a motherly role early on, before she became a mother to her own children. This behavior is not uncommon, as the idea that "well before mid-life Black girls, demonstrating receptivity to Black women's gender socialization, begin their induction to the role of self-sacrifice" (King and Ferguson 2006:112). Raychelle's role assumption further supports King and Ferguson's aforementioned assertion that "the Black woman's faithfulness in both providing for her family, and in 
executing the nurturing function both outside and inside the home serves a vital function in Black communities and intersecting the nurturing role designated to her by patriarchal society" (King and Ferguson 2006:113).

Furthermore, Raychelle's testimony supports Christian et al.'s (2006) assertion about boundary setting. Christian et al. (2006:450) argue that "in order to sustain a relationship with an incarcerated person, many families employ a strategy of setting clear boundaries with the prisoner." Raychelle explained that it was important for her to let Marshawn know he was loved, supported, and welcomed in her home upon his release. However, she had to set very strict boundaries with him considering his lifestyle prior to imprisonment as well as the behavior manifestations of his institutionalization. Impact of Loved One's Incarceration: Psychological, Emotional, Financial

This section captures the various ways the women's loved one's incarceration, and/or their return home, impacted their holistic wellbeing — meaning the women's psychological, emotional, physical, financial, social and spiritual wellbeing, among other things.

Unlike some women who find solace and/or relief in the incarceration of a loved one due to previous abuse or other negative behaviors of the incarcerated (McCarthy and Adams 2018), each of the women in this study described having adverse reactions to their loved one's imprisonment. Each of the women expressed some sense of loss from their loved one's absence: loss of time together, loss of security, loss of access, and more. For example, Sister Tyra shared her thoughts on the abstruse impacts of incarceration: There's no resolution ever! (laughter) like honestly! Especially with the climate we're in these days. Like I said earlier, it's not even the individual's fault that 
they're in that position. It could be something wrongfully accused all the way to the highest extent, you know? Like, do you really...even though that person gets out—oh they out now, so it's good? Like no, that time is never given back. If they got a child, especially. That baby lived without that individual for them two and half years or whatever the case. So why would we just let that go? But then that does damage in itself. Whatever. You know?

Tyra's testimony speaks to the systematic racism many people experience getting caught in the web of the criminal justice system, especially considering the ways implicit bias plays out, harsh sentencing, and the high rates of wrongful convictions in this country. She briefly alludes to the time incarcerated loved ones spend away from their children and other unknown, but lasting, impacts of their absence.

Sister Tyra also described the unexplainable feeling of having a loved one forcefully removed from her life:

It's like, some people—especially people who haven't dealt with incarcerated family members can't imagine having somebody that you deal with on a daily basis, that you're tight with, that you confide in, all that...you know, that you work with or whatever the case—is stripped from you, but still alive, still living and breathing, but just absent from your life. Just like that! And forcefully—not because they made that choice.

Hart-Johnson's (2017:41-42) work buttresses Tyra's statements concluding that "forced separation between family members because of incarceration may cause disruption, crisis, and trauma to the non-incarcerated family members... all forms of breakup in the 
family system could cause varying degrees of trauma. Tyra also powerfully described how inaccessibility to a loved one was one of her first human experiences:

It was the first experience I've had as a human being to know that my father is not in my reach.

Having grown up with many people around her caught in the criminal justice systembeginning with her father-Tyra described coming to accept persistent grief:

My dad was a typical career criminal. You know the type that go in, get out for a couple days, go back for a couple years, get out, go back in for a couple weeks...even since before I was even thought of. In the bay area, he was a significant name with that lifestyle...In a sense, I grew up in mourning. I grew up and my cousins started going down and other people started going down and it was like, that's just what happens to us. That was definitely the main sprout of that.

Overall, Tyra's accounts demonstrate the gamut of emotional and psychological turmoil people experience from separation and loss as a result of their loved one's incarceration. Research shows Black women disproportionately experience a plethora of stressful conditions; for example, relational stressors (such as the incarceration of a spouse), vicarious or network stress (stressors experienced by people in one's social network), and increased exposure to such stressors - such as that Tyra experienced. Emotional and psychological responses to these stressors, such as depression, anger, fear, numbness, separation anxiety, sleep disorders, and other problems, are linked to the development of, and have the potential to create, mental-health problems (Fahmy and Berman 2012; HartJohnson 2015; Walker-Barnes 2014). The normalization of loss and grief due to the 
constant removal of beloved family and community members by the criminal justice system could have lasting impact on one's mentality about self, kith and kin.

Sister Amanifu experienced two types of loss—one through her father's incarceration and the other through her father's death during his incarceration. Amanifu described the lingering pain of incarceration even after her father's death. Amanifu explained that her father was murdered by members of the Aryan Brotherhood as an initiation process:

And I'm still dealing with the fact that we haven't even gone to trial. No court date has been set. And he's been gone four years.

Amanifu's experience may be better understood in the context of disenfranchised grief, a type of grief that is not socially accepted or sanctioned, and in which the griever may feel their experience is unimportant or even wrong. In Amanifu's case, the fact that her father was 1) a prisoner, 2) a Black prisoner, 3) a Black prisoner charged with sexual assault, 4) a Black "rapist" murdered by a white supremacist, Amanifu was led to feel as though her father's life, and justice for his murder, was not important to virtually anyone but her. The lack of attention to her father's case and the lack of closure from her father's murder, has the potential to "exacerbate problems and emotional reactions for the bereaved, an area yet to be explored carefully by researchers examining the effects of incarceration on survivor family members and children" (Arditti 2005:254).

Suzie described the emotional impact her daughter's incarceration had on both her and RiRi early on:

She would write scathing letters of, “you guys didn't raise me right...all the reasons I'm a bottle of nerves..." you know, it had to be somebody else's fault. 
So those first two years of her incarceration, about a year and of half of it was here, in the county jail. That was not a good time, we were not united at all. I was just trying to stay alive.

Suzie's account of her experience with RiRi supports extant research suggesting "both children and parents might have to deal with issues of abandonment and loss, [and] weakened attachment caused by separation" (Travis et al. 2005:1-2). Not only did RiRi's incarceration cause a strain on their relationship early on, but it also caused both RiRi and Suzie to look at and consider past experiences that influenced RiRi to commit the crime for which she was imprisoned. Because RiRi felt as though she had not been "raised right," and Suzie questioned her own role in RiRi's choices and behavior, their attachment was momentarily weakened as Suzie struggled with the agony and guilt she felt surrounding RiRi's imprisonment.

Sister Tia described the psychological and physical impacts of her son's incarceration, and the lack of empathy from others - especially, yet surprisingly, her own family:

...I talk about how I've been impacted: the sleepless nights, the worrying, the family members not wanting to talk about it because it's too painful and [people say] "well, you had him, deal with it."

In addition to separation from an incarcerated loved one(s), individuals are often distant from family members and friends on the outside due to judgement, stigma, and/or lack of support, all of which could lead to social isolation. Furthermore, Arditti (2015:253) argues that "hostile, disapproving, or indifferent social attitudes"-like those displayed 
by Tia's family members - "most likely compound the pain of losing a family member to imprisonment."

Discussing the emotional and mental struggle she experienced receiving and reading letters from her father, Sister Erin explained:

I think it's the reality that he's gone; I see that he's aging. I see that his love for me is still very much intact. It reminds me that I am now 30 years old and there's no way he can know anything about my reality, the things I've experienced, it's odd. It's almost like an alternate reality. Like there is a love that's so strong, that this individual that's been in prison for so many years—because he's caged up. It's almost like he's frozen in time. But for me, I've been out here living every single day, and I've been growin up, and I've been lost, and I've been confused, and I've been hurt, and happy, and so, things have changed for me. So again, when I read the letter, I see, wow, this is real life. And it just all comes out at that time.

Erin's responses are important to note, as psychological and emotional responses to loss including anger, depression, isolation, sadness, frustration, guilt, worry, among others, are similar to characteristics of grief (Morse and Furst 1979; Chui 2009; Myers 2016), and learning how Black women cope with the grief associated with the loss of a loved one to incarceration is important for understanding their resilience.

Recalling the experience of her father's incarceration and reintegration, Sister Kali described feeling less support from her father once he was released from prison than when he was incarcerated: 
And to keep that conversation, relationship going, um, but then we he got home I think it was a little bit harder. I guess it was harder to be a parent out here in these streets vs. when you're locked up, you know? You got different responsibilities now, it's not just about communication. You know? Where's the financial support? Where's the physical presence? Are you going to get back with my mom? Are you going to be present in the house now? You know? How are you going to be a dad long distance, but not bounded by that cell? Because that was I guess, something you could fall back on. If there was anything that was limiting in the relationship, that was something you could always fall back on. "Well, I'm in prison. What can I do from all the way back here?" But then when you get out, and you don't have that barrier anymore, you don't have nothing to fall back on. My dad was released summer going into my 8th grade year. He went in when I was 4 years old and came out when I was 11 . So my age had a lot to do with it too. As far as parenting goes, absolutely. But that amount of love that I felt, I guess it got harder for him to keep giving it.

Kali's concerns about her father's involvement pre- and post-release are shared by many. Researchers have documented that "children retain bonds and love for parents regardless of the label attached to these parents by society; however, once a parent is incarcerated, research has found that children experience feelings of shame, stigma, isolation, blame, guilt, and anger" (Harris and Miller 2003:91). Fritsch and Burkhead (1981) found that children of incarcerated fathers were more likely to display acting-out, and were at increased risk for behavioral and developmental problems among children (Geller et al. 
2012; Wakefield and Wildeman 2013). Kali acknowledges her feelings of isolation and anger throughout the interview, and admits to acting out upon her father's release:

When he came home and he tried to be a father, physically present, it was rough... it was rough, it was rough because... I rebelled. I rebelled..."You ain't even been around! You just coming home, now you tryna tell me what to do." Even though Kali and her father maintained a decent relationship during his imprisonment, Kali still resented the fact that he had been absent. Hence, upon his return, Kali did not respect his attempt to reestablish his parental authority and it showed in her poor behavior.

Coates (2015) reminds us that having a loved one incarcerated "takes a lot out" of the family. Sister Oprah discussed the matter of finances and working together with family to make sure her brother had sufficient support:

The financial piece, it's a thing! You know, it's a thing. I remember when the whole thing first happened, we're talking about lawyers, and different fees, and who's going up there to make sure somebody is there for him when he's in court and we're talking about all this different stuff and that impacts everybody. Oprah's experiences corroborate research findings which suggests family memberspredominantly women — primarily bear the financial costs of maintaining contact and providing support (Ella Baker Center 2015:30). Money for pre-paid and collect phone calls from detention centers; travel costs for visits; legal fees; funds lost from missing work to attend court dates, etc.- - these expenses add up. And if families are not careful, they can wind up neck-deep in debt trying to offer sufficient support to their incarcerated/transitioning loved one(s). 
Raychelle described the emotional toll her loved ones' absence took one her emotional wellbeing:

Nobody wants their people to miss a birthday or a holiday; nobody. Just being in the room with somebody you love can be enough, especially when it's hard times. So nobody wants to be away from them. And for a long time at that! Can't call, can't talk to them, can't see, can't touch, can't hug, can't wipe a tear. You know, you're crying together but it's over the phone? So it's like me and my years of experiencing my brothers being incarcerated, my mom being incarcerated, I would say it's more of an emotional damper on me than it is anything because nobody wants their people to be incarcerated.

Raychelle also provided insight on the difficulty of having (or the inability) to maintain an illusion of emotional contentment for the sake of her loved ones' mental and emotional contentment:

I have to talk to my brothers on the phone. They've never been to...Damon has never been to a birthday party, he's never been there for Christmas, he's never been there for a thanksgiving. And my kids have seen me get emotional when we get off the phone cause I gotta keep my face straight while I'm talking to him cause if he hears I'm sad or if I'm weak, that brings his spirit down. I can tell over the phone. So my kids have seen me breakdown, they have seen me cry because I miss them so so much.

Raychelle admits to trying to suppress her feelings, which can have dangerous impacts on one's physical and mental health (Chapman et al. 2013). Though it is not uncommon for Black women to avoid being outwardly vulnerable and maintain a strong, resilient 
posture, hence tropes like StrongBlackWoman (SBW), the Superwoman schema, and the like. Nonetheless, Raychelle tries her best not to display her pain and sadness as to not break her loved ones' spirits.

At one point, for two and a half years, all three of Raychelle's brothers were incarcerated at the same time. She also had two close cousins imprisoned during that time. Fourteen years, eleven years, seven years, five years, and three years were the amounts of time they had been gone. Raychelle explains her emotional turmoil during the time of their collective absence:

For Christmas of 2016, I was all in every emotion. I wasn't around any of them for Thanksgiving that year; Christmas or New Year's Eve; it was like a whole year of skipped holidays 'cuz none of our men were out. It was tough.

The testimonies of these women are in line with explorations of the "gendered nature of imprisonment" (Codd 2000:63) and reveal "almost universally, it is women who must cope with men's problems" (Fishman 1990:262) — a situation far less likely to be reciprocated when females are imprisoned (Pollock 1998; Codd 2000). Since Black men and women are disproportionately incarcerated, and our networks often constitute more incarcerated/formerly incarcerated individuals, the emotional, psychological, spiritual, physical, and financial impacts on Black women are greater.

Other Daily Issues and Concerns

Aside from dealing with the reality of having a loved one absent due to incarceration, Black women endure a variety of other problems by virtue of being Black, woman, and a Black Woman. In other words, some of the issues women described having were those often disproportionately felt by Black people in America; other issues were 
more specific to women in America; while others disproportionately affected Black women, in particular. Of course, many of the daily concerns were common to regularly functioning human beings/adults such as work, family, etc. However, Walker-Barnes (2014:54) reminds that Black women "disproportionately experience a number of stressful conditions and events that are linked to the development of mental-health problems, including low-wage employment, caregiver and multiple-role strain, medical problems and disability, social isolation, bereavement, exposure to traumatic events, and poor access to health care"- each of which have the potential to exacerbate common concerns.

For example, though they are her brothers and each are relatively close in age, Raychelle has played just as much of a mother-like role in their lives as she has the role of sister due to "...having a momma who was an addict, at the time—who was physically present but mentally absent." Raychelle emphasized "my mom, she was there but she wasn't there." After having supported her brothers for so long during her adolescence, and now, as an adult, having children of her own, Raychelle must find balance between her role as mother to her three children and othermother (see Tafari 2015) to her brothers. Kali expressed the difficulty of being raised by her single mother in a low-income neighborhood in the absence of her father due to his imprisonment:

You know growing up in a single parent household when most of the kids you're going to school with is a dual parent household, definitely above the median salary; they're not on food stamps, they're not on any type of welfare, public assistance. 
Kali's reality was that of many black children in the U.S. Black children are two times as likely to have an incarcerated parent as white children (Murphey and Cooper 2015), with the incarcerated parent likely being the father (Reckdahl 2014). Though parental incarceration is not uncommon for Black children, Sister Kali recognized early on that her homelife and circumstances were different than many of her non-Black peers. Kali went on to discuss how it felt being one of few Black children in school:

But not having someone to really understand what that's like- to be in a space at that age where you're heavily judged and everyone is different. I didn't go to school with all black kids - I went to school the majority of my life where I was one of the only Black girls.

For Kali, being Black was different; living in a single-parent household with an incarcerated father was different; being on public assistance was different. Not to mention the harsh criticisms children face from their peers just by way of being children. Kali recalls feeling isolated and misunderstood and believes that not having someone to talk to about what she was feeling led to some of the mental and emotional issues she suffers from as an adult (discussed further in Chapter Five).

Erin was also among the population of children with an incarcerated parent/father. As a social worker who predominantly served disadvantaged Black communities, Erin sometimes shared minor details of her experience having an incarcerated father and sibling to build rapport and/or advise clients. Erin discussed the consequences of doing so in her workplace:

My colleagues though, they almost did not perceive me to be intelligent or,these are MY perceptions — not intelligent enough. I often went up to be 
promoted, was never promoted, never would get a pay raise. There were just like other things that were not happening for me that were happening for other professionals at my job that made me wonder if it was because of some type of implicit bias that you know my leaders or predecessors had against me because of the things that I disclosed in my profession. I don't know. It could be not that, it could be my lack of merit, it certainly could be. But I cannot help but to wonder. Erin shares experiences of microaggressions and systemic oppression in her professional atmosphere. For her to say "these are MY perceptions" and "I don't know... it could be my lack of merit...But I cannot help but wonder" is an example of the way American society has caused Black women to question ourselves, our capabilities, our belongingness and, and often disqualify ourselves from places and positions we actually belong and could be useful in our occupation. In spite of our level of education, or the extent of our professional and/or personal experience, Black women often feel imposter syndrome and that we have to work ten times harder to deserve/earn certain recognitions (Cokley et al. 2013; Hill 2019). Even when we are certain in our hearts and minds that we are being discriminated against, or unfairly treated because of our Blackness and/or our womanness, we tend to question the truth of our reality.

Asali also provided insight into how her connection to incarcerated loved ones impacted her quests for employment:

But there was also a lot of guilt that I had to explain my involvement. Cause they want to know who you know. But also, when I went to apply for probation, I hadn't had any involvement with the criminal justice system personally. When they ask for your background check, they were going to ask what family members 
and friends you knew with involvement in the criminal system, I was like, I'm not applying for this cause I'm not 'bout to tell you 'bout my cousins, you not 'bout to be in my business. I mean, it caused me to not want to do it. I just chose not to be involved.

Sister Asali's recount of her job search process demonstrates the insidious ways vicarious incarceration, or just family/community connectedness to incarceration, can influence and impact one's navigation of the everyday. Though she had no criminal involvement at the time, simply being connected to individuals in prison prevented Asali from seeking out certain career opportunities since extensive background checks would reveal those connections and potentially, negatively influence hiring outcomes. Furthermore, Asali attempted to keep a level of separation between herself and the names, identities, and crimes of her loved ones by not applying for positions within certain entities that would pry into her personal background.

Tia discussed her daily concerns regarding her son's return. Although she has no tangible idea when he will be released, she worries about what it will be like once Jason is back home:

Sometimes, my anxiety gets up 'cuz I think he's getting ready to get out within a year, he has 'good time' so he's getting ready to get out and it's like what are we going to do? When he's here, I don't know what he's gonna do; how is his mind? He'll be like, "Mom, why you keep looking at me?" And then I'll know when he's withdrawn because he'll stop eating. And I let him know, food nourishes you, you need to drink a lot of water. We need water to clear our minds, we need it to function. 
Tia not only anticipates having to tend to Jason's basic needs (e.g. food and shelter), but she is also concerned about how to adequately address Jason's mental health needs ("how is his mind?”; "when he's withdrawn...he'll stop eating"). She mentions earlier on that she is not a mental health expert, thus has little informed capacity—outside of her role as his mother,- and is ill-equipped to address issues related to Jason's mental health. Her lack of information, understanding, or training in matters of mental health leave her uneasy about her ability to effectively support Jason upon his return.

In addition to worrying about her adult son, his imprisonment, and eventual release, Tia expressed her concern for her daughters and other family members: I gotta be here for my grandchildren, my children. And I kinda feel like I am what they call the midlife crisis; I don't feel like I'm havin' no type of crisis though, but I am feeling pulled. I'm feeling like I wanna be in New Mexico with my mom, but I wanna be here with my grandchildren, I gotta daughter, she's gay and we bump heads. Not because of her being gay or anything. but she's got some stuff so we bump heads a lot. And then having Kenny in prison and I wanna go to New Mexico, like do my mama need me? And I got my daughter there. She getting ready to have surgery and she might not be able to have no kids. So I'm just like, BE wherever you gon' be.

Tia's feeling of being pulled in multiple directions, or feeling stretched, is not uncommon for Black women. For Black women experiencing vicarious incarceration/reintegration, that feeling can intensify. Christian and Kennedy (2011:387) discuss how disruption due to incarceration often "necessitates reorganization of the family's life and relationships with those who are not incarcerated." Jason's incarceration not only caused disruption in 
Tia' life, but it forced her to consider how to reorganize her life in a way that she could be present and supportive of him without neglecting her relationships with her other children, grandchildren, and her own mother.

In addition to feeling overextended, Tia also voiced her concerns about aging while her son is away:

I'm pushing 60 but I feel like I'm pushin' 80 sometimes with my body but then I get up and I'm like, you lookin' alright there!

Sister Tia had several health conditions, some worse than others. Throughout our interview, she discussed how they sometimes slow her down, debilitate her, or prevent her from doing things altogether. Although Tia was only 60 at the time of our interview, the physical breakdown of her body was making her feel older. But Tia's beauty, style, and grace veils the mental, emotional, and physical stress and strain she endures as she tries to maintain a supportive presence for her loved ones.

Suzie similarly expressed concerns about aging while her daughter is serving a life sentence:

I am beginning to try to be very intentional about taking care of myself more than I have been because I am—and I haven't shared this with her yet, and I don't know that I will—but I am, I really want to live to her come out. I really do. And I know if I don't really begin to lean in and attend to myself, and take care of myself and rest and you know, just invest in me, that could be in jeopardy. I think the worst thing in the world that could happen to my daughter is if something happens to me before she is released. Is that deep? 
The women's worry about aging left room for two potential outcomes: positive lifestyle changes in hopes of longevity, or additional stress as they anxiously awaited the fate of their children. In essence, the anticipation of reuniting with their children gave Suzie and Tia something to live for, and encouraged them to take action where they could (e.g. Tia looking up healthy recipes; Suzie taking walks) to maintain decent health. However, at the same time, their dedication to supporting their children required much time and effort - especially as older women - to keep up with their loved ones' needs on the inside (i.e. the imprisoned) and those on the outside (i.e. family and community), which can take a physical (e.g. missing medical appointments), psychological (e.g. worrying), and emotional (e.g. feelings of guilt and/or sadness) toll.

Suzie was also concerned about RiRi's survival, and expressed the daily fear for her daughter's safety and wellbeing:

I feel like I'm in life and death situations day-by-day. 'Cause there is some dangers for her in there and I always think about that.

Suzie's faith in God allows her to not be consumed by worry for RiRi. But she is also intentional about doing what she can to support $\mathrm{RiRi}$ and take care of herself in anticipation of their reunification.

Reflecting on the time period when RiRi initially went to prison, Suzie recalls how the difficulty of adjusting to the circumstances:

I was actually trying to live again. I had two other children and the youngest one was quite small. He would've been 3 or 4 . And I was just trying to figure out how to keep doing the mother thing and the wife thing at the time. So that was a bad time. I don't even remember a lot of the specifics of it. 
Suzie also described how RiRi's early incarceration impacted her work at the time:

I had already been mentoring other younger people-younger women in particular--I concluded in my head that if I can't do any better than what I did with her, I don't need to be doing this. So I really did quit all of the things that you know me to do now and all that I had been aspiring to do, training to do. I quit all of that because it didn't feel like I was qualified.

Suzie was extremely critical of herself-her role as a mother and her role in the community — due to her feelings of parental failure. She reported feeling lost, questioning her roles and her life purpose. Lack of confidence in her capability to be an effective mentor pushed Suzie to resign from her positions in the community and focus on "just surviv[ing]" RiRi's imprisonment. Suzie's grappling with motherhood, skepticism regarding her mentoring work, and constant concern for RiRi's safety, is demonstrative of the gamut of emotions Black women experience as a response to a loved one's incarceration, on top of other everyday life concerns and issues.

As exhibited in this study, extant research has also shown that incarceration impacts family dynamics along multiple dimensions (Nurse, 2002; Comfort 2007; Hagan and Dinovitzer 1999). Sister Amanifu's discussed family conflicts that caused "drama" and stress while her father was alive and after his death:

Because there was his murder, then there was these family dynamics going on about sue or not to sue and I had some decisions to make. There were some judgements against my dad. There were times that things were being said and I never would say anything. One time, I just decided I didn’t wanna hear anybody say anything about my dad...Not today! Today is not the day you gon' talk about 
him. If you say anything negative about my dad today, you're going to make me angry and I'm going to tell you." And the family member I was talking to said, "You already look angry.” I said, “Oh I'm not angry. You ain't seen angry...until you start talking negative about my dad.

Even in his death, Amanifu had to endure negative talk and feelings about him from their own family. Having such a close relationship with him by the time of his death, Amanifu did not appreciate her family's judgment of him, which caused strife between her and them. The people who she thought would be more supportive, instead, added to the stress and turmoil she experienced surround his incarceration and death.

In addition to coping with family issues, Amanifu revealed she had serious trouble sleeping: "I probably average about 3-4 hours of sleep per day. With my fibromyalgia, I have insomnia." Lilian Comas-Diaz, a Washington, D.C. based clinical psychologist who specializes in trauma and multicultural issues, says, "Sleep is a psychological issue and also a physiological issue. It becomes a constant source of even more stress when you don't sleep well, you worry more—and that enforces this cycle" (Wilson 2020). Fibromyalgia is also regularly associated with stress and trauma, and thus both conditions ought to be thoughtfully considered when discussing the health consequences of vicarious incarceration and supporting imprisoned loved ones.

\section{Conclusion}

It is clear that each of the women displayed a level of strength required to deal with the stress and strain associated with their vicarious imprisonment in addition to that which occurred in their everyday dealings. A sentiment Suzie shared describing how 
RiRi's incarceration affected her, seemed to be reflective of the other women's experiences, as well:

...emotionally I'd say it's hardened me and that can be good or bad.

Emotional hardening is just one of the many consequences or results of enduring a loved one's imprisonment. Acknowledging the emotional and psychological consequences and the impact of vicarious incarceration on one's being is necessary to understanding the ways supporting an incarcerated loved one influences our daily dealings and the way we navigate the world as Black women. All of the women expressed some level of worry and concern for the wellbeing and safety of their incarcerated loved one(s); many of them expressed some level of guilt or shame; most of them expressed feelings of isolation. Most of them only felt comfortable sharing with or seeking support from individuals in their inner circles—overwhelmingly comprised of other Black women. Thus, navigating daily life in the home, at work, school, and elsewhere while worried, stressed, and anxious, may prove more difficult like it did for many of the women.

From their testimonies, we get a glimpse of the psychological, emotional, spiritual, and even physical impacts that their loved one's imprisonment has on their overall wellbeing. The women's responses are characterized by persistent anticipation and feelings of powerlessness. For example, constantly in a state of waiting for and worrying about phone calls, court dates, letters, communication from lawyers, transfers, and release dates, among other things, sometimes led to feelings of stress and anxiety. The inability to change the circumstances for themselves (vicarious incarceration) and their loved one(s) on the inside; not being able to protect their loved one(s) on the inside 
and being concerned for their safety and wellbeing, engendered feelings of helplessness and powerlessness.

The physiological responses from troublesome thoughts and emotions like the one's the women described, have the potential to both compromise health (e.g. high blood pressure) and usher in maladaptive coping behaviors which will be discussed in the next chapter. All of these things influence the way these women navigate their daily lives at home, work, school, and other social settings. Thus, left unattended, troubling thoughts, feelings, and behaviors as a result of vicarious incarceration may negatively impact the way these women wish to navigate social spaces, and the capacity they have to do so. While the women's persistence and endurance may ultimately make them feel emotionally and mentally stronger (e.g. "emotionally hardened"), their emotional, psychological, and physical health is simultaneously at risk. Their connectedness to their incarcerated loved one(s), alone, puts them at greater risk for health issues (mental and physical), financial struggles, and other tribulations that take a toll on overall wellbeing. 


\section{CHAPTER FIVE: THE DEAL}

Just as individuals experience and endure different struggles and obstacles while supporting an incarcerated loved one, there are different methods used to navigate these experiences. In other words, each individual has their own "stocks of knowledge" (Berger and Luckman 1966) and "tool kits" (Swidler 1986) from which they pull information and strategies to guide them through life. The knowledge and tools with which one is equipped are very largely socially determined by variables such as race, class/socioeconomic status, gender, age, cultural background, etc. Thus, the ways in which the women of this study discussed how they dealt with their circumstancesincluding managing their emotions and feelings surrounding the absence and/or return of their loved one-were both similar and gravely different across the group.

After having sat down with the women, there were two central themes that stood out: caregiving and caretaking as a method of "dealing," and the lack of care/support provided for them from outside of their own families/communities-individuals and groups who were often also trying to adjust to and deal with the loss of a loved one. Most of the women actually laughed when I asked the question "What types of resources are available to you?" and usually listed family, friends, and community members as their only, or primary, support systems who help them deal with the stresses that accompany the loss of a loved one to the criminal justice system and everyday life in general. This chapter sheds light on the various ways Black women carry the load, cope and manage, and from where/who they receive support to do so. 


\section{Holistic Health: Navigating and Interacting with Daily Life}

The women of this study came from a multitude of backgrounds in terms of socioeconomic status, religious affiliation, and sexual identity, among other things. Thus, their daily dealings greatly differed. However, their most salient identity and position as Black women, and their shared experience as supporters of incarcerated loved ones, relegated them to a great deal of common issues. For example, when asked "How did/does the incarceration/transition of your loved one influence your mental state? Emotional state? Physical state? Spiritual state?,” Tyra described how worry often consumed her:

I guess, you know, if your family member is doing so bad that they haven't eaten in months and you put your last towards a bill on their well-being while they're locked up. I guess that can affect you but, deeper than financial maybe just the stress that's involved with that. You know? Thinking about that person, worrying about what that person is going through even if their choices is what put them in that situation. It could be something more than that, involved with that. If you were involved in a dynamic that landed that person in jail...that holds a weight that's involved in dealing with that. It's an unexplainable, heavy, suppressing feeling that is involved. You know?

Tyra went on to explain in more detail the effects on her mental state:

Mentally — cause that's where a lot of it starts—mentally, it puts you in a sense of depression almost... You know what I'm saying? So it kind of shifts your mindset to where it's like you have to cope with that person...it's like developing a habit and having that habit instantaneously stripped from you without you being able to 
ween yourself off of it. You know what I mean? So it's like, you're just sitting there, like damn! Now what do I do? You know? And putting yourself in that headspace it starts to affect the spiritual, it starts to affect the physical. You know what I'm saying, because some people, when they miss their loved ones, they can't eat for a time on time; they constantly thinking about it at work so it effects their work ethic...it's just a domino effect and a ripple of hurt and it starts from that person being extracted from your life. It's not like something that you manifested it, it's just something that is out of your control. So that gets deeper than anybody can have words for.

Tyra's responses to her loved ones' incarceration (e.g. feelings of depression) are reflective of the experiences many families with incarcerated loved ones associate with the worry and guilt that comes with supporting the imprisoned, as well as their own personal struggles (Ella Baker Center 2015:37). While acute stress is common for most people in everyday life (e.g. rushing to meet work deadlines; trouble with children in school, etc.), chronic stress (such as having and/or supporting an incarcerated loved one) can lead to depression and other mental health issues, in addition to physiological problems that are detrimental to our overall wellbeing. Having a relatively large network of incarcerated Black men (father, cousins, community-family) over the course of Tyra's life has not only compromised the quality and the growth of her familial/communal connections, but it also increases the likelihood that she, and others with similar experiences, will experience feelings of depression, helplessness, or have negative physiological responses such as high blood pressure. 
When I asked Amanifu about the ways her father's incarceration impacted her health and wellbeing, Amanifu described how his incarceration and then his passing affected her:

I probably average about 3-4 hours of sleep per day. With my fibromyalgia, I have insomnia. I am declaring 2020 my year, a year for me. Cause looking at the last 4 years since my dad died, I see that the lack of self-care to me shows. My black is cracking. I'm gaining weight. I'm still smoking these damn cigarettes. I've gotten a little passive aggressive about the anger or the upset about the anger and the injustices.

Similar to other chronic stressors, such as poverty and discrimination, family member incarceration can lead directly to negative physical health outcomes or affect physical health via maladaptive coping behaviors (Lee et al. 2015:425). Amanifu mentioned lack of sleep and weight gain; smoking cigarettes; feeling like she was losing her youthful appearance ("My black is cracking"); and becoming "passive aggressive." Amanifu recognized changes to her sleep patterns, her weight, her mood/attitude as having been influenced by her father's incarceration and his death. Amanifu's cigarette habit (maladaptive coping behavior) alone has the potential of aggravating her fibromyalgia symptoms and could negatively affect her ability to maintain healthy weight (Center for Disease Control and Prevention 2019). The combination of stress, maladaptive coping behaviors, and her existing health concerns, leaves Amanifu at greater risk of experiencing negative health outcomes. 
Suzie Cain answered the question about how her daughter's incarceration impacted her mental, physical, emotional, and spiritual state by first describing the initial response to RiRi's imprisonment:

When all of that happened, I did what I think most people would do, and that is, I was in shock, I was disappointed, terribly, terribly disappointed. And I just pulled back, I shut down, and it just took probably a year and a half to two years of me being in the worst, darkest valley that I could be in... And so I stayed in that dark valley for at least two years. I wasn't able to do anything. And I think now, I look back and I know that I was in deep, deep depression, but I was numb, I was numb. And so I couldn't be of any help at all.

Ella Baker Center (2015:37) researchers emphasize that "incarceration has devastating physical, mental, and emotional health impacts on individuals"-isolation and depression being long recognized as common psychological and emotional responses. In their study, Wildeman, Snitticker, and Turney (2012:6) found high levels of depression in a sample of African American women with an incarcerated spouse, while Hiller (2013) and Green et al. (2006) had similar findings for mothers of incarcerated sons. Although Suzie is caring for an incarcerated daughter, the expectation of analogous emotional responses is reasonable.

Later in our interview, Suzie described the positive impact RiRi's incarceration eventually had on her after she got over the initial feelings of shock and helplessness: It has made me more conscientious about my physical state. Taking care of myself, staying on whatever medications the doctors put me on, staying on my exercise regimen, eating more fruit rather than junk. Mental and emotional: I 
think emotionally it has probably toughened me up and in some ways it's good and in some ways it's not so good, in a way that it's a little hard for me to feel sorry or pity for little mamsey-pamsey stuff, okey-doke stuff, you know, little I don't want to ever make anybody's issues small, but sometimes — especially as a minister-when I'm listening to the whining of something that is so shallow, I can't get there emotionally. I mean, I can always give an ear, I can ALWAYS give an ear; I just can't get there because you really haven't seen anything. And I have to be that way, I have to have a tougher emotional framework in order just to do the doing...

Along with being intentional about taking better care of herself physically, Sister Suzie explains how her "emotional framework" has been altered since her daughter's incarceration. The deep turmoil Suzie feels and has felt as a result of RiRi's imprisonment has given her a different emotional perspective when encountering new problems in her life and when hearing about the problems of others. Emotional hardening, as she called it, has made her less sensitive to certain issues. In one way, this could be a positive trait that can help Suzie get through life's trials and tribulations with less emotional, psychological, spiritual, and physical strain. On the other hand, however, it has the potential to leave Suzie less compassionate or less in tune with the suffering of others and less sensitive with herself in particular situations.

Tia Cason described how she has avoided addressing major issues with her physical health as a consequence of trying to maintain a certain level of availability and support for Jason: 
I've postponed a lot of surgeries behind my son and his mental illness. I need to have two knee replacements; I need to have surgery on my feet; I had a lifesaving surgery where my intestines were incarcerating my hernia, so it was cutting off the oxygen. I was tryna go see Jesus but it wasn't time! (laughter) We not gon see Jesus right now, we got things to do! I have so many scars from so many different surgeries; I'm tired of getting cut. Can they just find a plant and I just eat it and it'll be alright?!

Tia's admission to delaying seeking and receiving medical care speaks to Lee et al.'s (2015:425) assertion that "higher demands on time might also compromise a woman's ability to engage in preventative and self-care behavior to reduce health risks. In Tia's case, delaying care to tend to Jason's needs (e.g. attend court dates) exacerbated her physical conditions and her suffering from the stress of his incarceration, and has the potential to worsen her holistic health.

Tia described the physical manifestation of the stress precipitated by merely thinking about the reality of her son's imprisonment, and the worsening of her existing health issues:

I get a lil shaky. I start feeling not well. When one part of your body is not well, then another part will start shutting down. I've gotten out of bed not knowing whether my feet were going to hit the ground, and I was going to stand up and not fall. I was so sick going through it after his attempt [suicide by cop] that whenever I did show up for any type of protest or anything, people don't know that it took me all day just to get ready. Just to go from my room to the kitchen...I would literally have to sit in the chair and roll to get ready, wash dishes, etc. I also have 
an electric scooter; I've got canes all over the house; I got walkers all over the house; I have a walker in the room, a walker in the truck, you know? Everywhere so it effects my physical—it triggers some stuff. It affects me spiritually when I go somewhere to get fed. Sometimes when I go to church, and I'm not being fed, and all of a sudden, when they see me, then they're like, how's Jason doing, or we gon pray for Jason or whatever, but they don't do the work; they don't follow up. They don't know that I sit here sad and that affects my psyche.

Sister Tia mentions that even when people acknowledge Jason and his incarceration, they offer to pray for him, but there are never any offers to "do the work," or, help with action instead of, or in addition to, prayer. The physical, emotional, and spiritual suffering that Tia experiences surrounding Jason's absence often times go unnoticed. Even when she goes "somewhere to get fed," i.e. to be mentally, emotionally, and spiritually nourished, Tia feels her sorrow as well as her physical debilitations are not recognized or acknowledged, which in turn, negatively impacts her mentally and emotionally.

Tia explains further how her physical ailments sometimes tend to prohibit her from fighting on:

The arthritis will shut me down, then I know I need to calm down; I can't fix what I need to fix at that moment.

Thus, even in the moments she wishes to be strong and a supportive member within the community, her physical ailments prevent her from doing so, which negatively impacts her mental and emotional wellbeing even further.

Describing how her son's imprisonment influenced her holistic health, Cheree said: 
It weakened me to the point where I had no choice but to be stronger. Because it's almost like an um...it's almost like a pimp. The system breaks you down, and then you gotta figure out a way to get out and build yourself back up. So I seen it...it literally is designed to tear you apart. The family, the community, the person...It leaves nothing untouched. It tries to destroy everything about you. And it rebuilds you. Almost like slavery. Pimping was modern day slavery to me. I used to watch how these men would take these young minds, who people whothey're open — and tear them down and make them who they wanted them to be. It's almost like what the system does. They have just created so much distrust and fear that you just don't know how to...you either survive or you perish. That's kind of what I've learned: in order to survive, you have to be strong mentally physically, and hopefully financially (laughter) cause it's gon' tax you. It taxes every part of your life.

Cheree's testimony echoes sentiments of Abrams (2014:509) in her text, "Carrying the World with the Grace of a Lady and the Grit of a Warrior," in which she reminds that "in addition to being described as a mechanism for survival and growth, resilience [is] depicted as a persistent requisite for a SBW [Strong Black Woman]. Women [feel] they need to be resiliently strong even when they [feel] 'weak'." Cheree feels the need to be strong for her own survival and wellbeing, and so that she can fight for vulnerable young people who become entangled in the criminal justice system.

Asali experienced physical manifestations of stress as a consequence of dealing with her loved one's incarceration: 
Physically, I gained weight, gained a lot of weight. Very depressed. Because I was so manic-y, I had one doctor try to tell me I was bipolar. I had another doctor tell me I was ADHD. I know the difference! I'm not bipolar. It was definitely a very depressing time.

Asali's responses to her loved one's incarceration were in line with findings of extant research showing that "similar to other chronic stressors...family member incarceration can lead directly to negative health outcomes or affect physical health via maladaptive coping behaviors, such as overeating" (Lee et al. 2015:425). As a master of social work who frequently worked with mental health professionals and has been trained to recognize symptoms of trauma and stress, Asali recognized her own depressive symptoms and sought mental health services, only to be misdiagnosed. Misdiagnosis and her inability to access effective culturally competent mental health care caused Asali added frustration and stress.

Erin discussed how her father's and brother's imprisonment impacted her psychological and physical health, describing how it showed up in her work as a social worker and beyond:

I think that it has negatively affected me because I think that I can't get too close to it 'cause I won't be sound. I think that I moved out of direct service social work because I could not stop having psychosomatic complaints like my head hurting when I left work or feeling sick or you know, my health just unraveling, catching many colds, because I was working so closely in this fields with other people who were experiencing the same thing I was experiencing, or other traumas that we experience in our community. And I would literally be ill. And so I learned that 
about myself maybe 3 or 4 years ago, and I gradually transitioned out of it. So that is something that has been a negative. There are certainly limits to what I can do because the trauma is very real, and I will have a trauma response if I'm too closely linked to it, even helping.

Erin's physical manifestations of stress from having incarcerated loved ones, which were often triggered by the nature of her profession, speak to insidiousness of the collateral consequences of incarceration. Although Erin explained how her relationship with incarceration often helped her build rapport with many of her clients who were also impacted by incarceration, she also acknowledges that emotional and psychological triggers limit her in other areas of her life and work.

Since her father was no longer incarcerated at the time of our interview, Kali reflected on how his incarceration impacted her mental and emotional wellness growing up:

I would struggle as a teenager growing up. I would be upset; I was angry. Even more rebellious now toward my mom, him. Then, kind of distancing himself and not wanting to continue trying to be physically present, then it was resentment, and sadness and more anger.

Kali describes first being upset and angry about her father's imprisonment, and taking out her frustrations on her mother (e.g. becoming rebellious). Once her father was released, Kali expected him to be present and involved like he said he would in letters he wrote her as a child. However, Kali's father was not as present—distant, in fact—which not only disappointed Kali, but made her more angry and resentful. Now, Kali associates her 
mental and emotional turmoil growing up with an incarcerated father to the mental health issues she struggles with as an adult:

The sadness, the anger the frustration, um... and then carrying that into my adult life. I think that has a lot—my family trauma plays a role into depression and anxiety that I struggle with now as an adult.

Kali's personal accounts underpin other research that has found "parental separation due to imprisonment can have profound consequences for children" including, but not limited to, feelings of shame, social stigma, weakened ties to the parent, and increased delinquency (Travis et al. 2005:2). Long-term effects can include questioning of parental authority, negative perceptions of police and the legal system, and increased dependency or maturational regression to impaired ability to cope with future stress or trauma (Travis et al. 2005:2). It is not outlandish, then, for Kali to correlate her depression and anxiety as an adult with the consequences of her father's imprisonment.

Oprah openly acknowledged the emotional and mental impact her brother Randi's imprisonment had on her, including the sympathy she had for Randi's wife and children in his absence:

But even in my high level of angst and nervousness around his imprisonment, I can't imagine what his wife and his kids feel. And while I'm not in contact with them as much as I should, there's a level of contact and I recognize they hold a lot, as well, in terms of the turmoil, the stress, the anxiety, the trauma around the incident, his absence, and the impact of his absence. So there's this continuum of stuff. 
Oprah felt a level of guilt for not being in contact with Randi's wife and children "as much as [she] should"-especially when she considered how traumatic the entire experience (i.e. the incident that led to Randi's arrest, his imprisonment, and his absence) must be for them. However, Oprah went further to explain the impact Randi's incarceration had on her ability to expend energy in other places and spaces:

I find that the situation with my brother does usurp a significant part of psychological and emotional energy to the point where I don't want to give that anywhere else.

Taking into account the various roles Black women play and titles we hold, Oprah's admission to preserving her mental and emotional energy specifically for the purposes of holding space for the support she feels compelled to offer Randi speaks to the grave sacrifices Black women make for our loved ones behind bars. For often times, Black women temporarily and/or permanently withdraw from certain roles, responsibilities, social and professional interactions for self-preservation (e.g. psychological and emotional wellbeing; avoid stigma) in addition to other reasons (e.g. financial strain). Furthermore, the high level of angst and anxiety Oprah refers to makes basic daily functioning more challenging. In their interview with HuffPost, Jernigan-Noesi (2020) insists that "heightened sense of awareness that may be registering in the body...disrupts your ability to go about your day." Therefore, Oprah's efforts to preserve energy is especially vital to her capacity to function in and navigate the social world.

Responding to the question about how Randi's incarceration influences her mental, emotional, spiritual and physical health, Oprah said: 
I think it elevates a certain level of angst, you know, that's pervasive. And that's the thing: it's not like it's just because of this situation, it's this situation, it's: when he gets out, it's is he gonna get in trouble again?; it's: what happens with his record?; it's: is he gonna be able to make money?; it's on and on and on. There is this pervasive angst that's produced by these circumstances. It's hard; I can't think of anything positive that has come from this circumstance. Not one thing. Nothing positive at all besides the fact that I know he has shelter and food but at the expense of his spirit and his safety. So is that even worth it? What Oprah describes is persistent and extensive worry, or "angst" as she declaredwhich is less about herself and more about Randi-about things which she has no control over (e.g. "is he gonna get in trouble again?; is he gonna be able to make money?"). A great deal of research has shown us too much worry (angst, anxiety) can cause imbalances in one's body, trigger stress hormones and create physical and mental health issues (Richman and Jonassaint 2008; Nuru-Jeter 2018). Thus, Oprah's preservation and reservation of energy for Randi, and the boundaries she set for herself in dealing with Randi's imprisonment, are especially important to the maintenance of her psychological, emotional, physical, and spiritual wellbeing.

Raychelle described the emotional and psychological back-and-forth she experiences surrounding the painful reality of her brothers' absence, but the privilege felt from them being alive and able to communicate with her:

When I start to think about all those things, it's tough. It makes me sad. I would say the sadness but the joy...mentally, physically, emotionally, it can be sad, it can be exhausting because it's a sad that doesn't go away. So that can lead to 
being exhausting, like, damn I don't want to think about that right now, I don't want to think about it anymore. On the flip side of that, the fact that my brothers aren't dead, that's the uplift right there. Like [she claps] girl if you don't get your shit together and bring it all the way up! Girl, he gon' call you tomorrow! He's supposed to call you at 7 o'clock tonight! So it'll change that for me, right? But I do have those moments, and I do have those days, even those weeks, where I'm like, “Damn, I wish this wasn't reality. I wish this wasn't none of our lives.” But over here it's like, It's reality. This is our life. But we still talk. I'm not visiting a gravesite. I'm not putting flowers [on a grave]. I don't have a picture hanging up cause that's' ALL I've got. I can pick up the phone and be like, "what's up ugly?" That right there by itself, the fact that I still have something... a lot was taken from all of us, a lot was taken from me, a lot of memory-making, a lot of doing stuff, a lot of life was taken from me. But I'm hopeful because there's still life to gain, there's still days to come...Emotionally and mentally: For me in this situation, those two go hand in hand because the thought is what causes the emotion right? So wherever I'm at mentally is what I'm feeling. I do have the harder days, where it's like, damn. But I have more upper days where I'm appreciative; appreciative that my brothers are alive, and they can call, and we can chit chat.

Raychelle is adamant about finding the positive in a negative situation. Her outlook and conduct are merely demonstrations of the words of Abrams (2014:59): "weariness is not an option for a SBW. She must continuously regroup after difficulties without allowing herself the convenience of a break or a breakdown." 


\section{Dealing: Coping Mechanisms and Stress Management}

Though scarce, some research has been conducted focusing on the ways Black women cope with the incarceration of a loved one. For example, Stringer (2009) examined the use of religion and spirituality by African American mothers to cope with the imprisonment of their children. Jackson (2011) explored the "life experiences, values, beliefs, coping mechanisms, and strengths of single, mostly low-income, African American grandmothers who are raising their grandchildren" (abstract), several of whom were caring for a child with an incarcerated parent. However, there has been very little interest in understanding how Black women - the population most gravely impacted by incarceration - manage stress and cope with the burden that comes with supporting an incarcerated loved one. This section sheds light on the mechanisms (or lack thereof) used by women in this study to navigate the emotional and psychological stress of dealing with the incarceration of a loved one.

When asked "What do you do to manage/relieve stress?", Tyra responded:

Besides medication? Me, myself, personally—I'm in California and it's legal. I'm a more herbal therapeutic type. I might smoke a blunt here and there; conversation helps a lot; maybe doing an activity I enjoy versus sitting there dwelling on the situation. I like art, I like to hang out and do different stuff like bowling or laser tag - something active that keeps me on the focused side of life. I like to do sports; I'm a sports girl. I like to get out and might play a lil basketball game, or play a video game, just something to keep your mind focused on what you're doing in that moment. 
Tyra describes an array of coping techniques - from smoking weed to playing sports and just talking. Importantly, she emphasizes her efforts to "keep [her] mind focused" on things other than her incarcerated loved ones. Tyra's coping strategies include "bracketing" which Brekhus (forthcoming) describes as a strategy by which individuals compartmentalize different parts of their lives or identities in order to maintain some semblances of everyday life. By turning her attention to things outside of, or aside from, her vicarious incarceration and supporting her incarcerated loved ones, Tyra is able to bracket and maintain a sense of a temporary daily reality that is not consumed by the worrisome thoughts about her imprisoned loved ones. Maintaining a sense of the mundane with just talking or with playing sports helps her to stay anchored in a routine everyday world even as she confronts the lived reality of relationships with incarcerated loved ones. Smoking marijuana as a relaxing escape can also serve these bracketing functions.

Amanifu explained that before her father died, she was much more intentional about taking care of herself. However, after he was murdered, she turned to poor habits to manage her stress:

After my dad died, I forgot all about self-care. I went and got my cigarettes. I still got my cigarettes; he's probably turning over in his grave. I went and got my cigarettes and then I got busy to preoccupy my mind not to fall into the deep depression.

Reflecting on the incarceration of her former lover, Asali described her stress management practices: 
Back then I used to drink, have sex, a lot (laughter)! I didn’t really smoke weed. Travel, I did used to travel a lot before I was married. Now, it's not that big of an issue. Oh, I take that back-I would smoke a Black. Or I would sleep. In Psychology Today (2012), Paul Huljich explains that we tend to use coping mechanisms as distractions, a crutch that we lean on as a way of avoiding stress, which seemed to be what Amanifu and Asali described, especially as it pertains to their smoking habits. Behaviors such as habitual smoking, drinking, and sex often become addictions that prevent us from dealing directly with stress and are, therefore, harmful to our wellbeing.

Though some of Amanifu's coping mechanisms were not healthy, she did find other, more positive ways of managing her stress like engaging in volunteer work:

I like working with challenged youth. Kids that are obnoxious, kids that would get on the average teacher's nerves, kids that are in foster care, maybe have some other issues going on at home that don't nobody know about like homelessness. Gimme them kids. I'll take them all day long. I don't need the perfect ones. Give me the kids failing in their grade; give me the straight $\mathrm{F}$ kids. Give me them kids. Sister Amanifu found pleasure and purpose in mentoring underserved, underprivileged youth who may, otherwise, be cast-off or abandoned by impatient, intolerant adults. Working with this population, however, requires a great deal of time and energy—for example, attending school district board meetings; working with families of youth; maintaining presence on various campuses — which often left Amanifu feeling over worked and worn out. While some believe there is a connection between trauma and overwork, there is little to no research on why survivors of traumatic experiences (like 
losing a father to incarceration and by homicide while incarcerated) might turn to work to cope with their feelings (Paperny 2017).

Suzie Cain assumed her initial coping mechanism immediately after her daughter's arrest and imprisonment was a common one:

I think I did what most people do--I retreated.

According to Covington (2016) retreating, or, behaviors such as isolation, are indeed common responses to trauma and stress, which has potentially harmful effects to one's physical and mental health. Suzie elaborated on the shift in her stress management practices, however, after having endured RiRi's imprisonment for some time:

I have a really strong prayer life. I have started to exercise three to four times per week. I walk; my richest exercise is just walking and meditating but the weather sometimes interferes with that, so I joined a gym for the days that I can't do that. I do get a release from that, just walking and meditating.

Over time, Suzie learned how to not only mitigate her stress through prayer, meditation, and exercise, but she also found such activities offered her a "release" from the pressure of enduring RiRi’s imprisonment.

Tia Cason shared a wide range of coping mechanisms and ways of managing her stress during our interview:

My maid of honor is an opera singer and she tours, and when we get together we act a fool. Just hanging out with her and talking with her...We sing. Music. Kenny introduced me to a lot of music. J. Cole, Kendrick Lamar. I listen to everything. Music soothes me. Alone time too. Processing. I do a lot of writing. I don't know what I'm gon' do with it. I'm gon' let God... I have a lot of stuff 
written, a lot of stuff in my head. I need a secretary. Just helping out whenever I can. And learning as much about his illness as I can. Taking care of myself. I'm not high maintenance but I do like certain things. I'll go to a thrift store or a garage sell in a heartbeat. And that's calming to me, too. Getting out all day. Just trying to take care of myself; trying to make sure I'm good.

Tia's plethora of coping methods is reflective of extant research findings which suggest that "coping methods are not static, but are unpredictable and adjustable and each [person] uses what is perceived as the best method. Their current strategy is simply what works the best at the time" (Jackson 2011:207).

Cheree said one of her coping mechanisms was talking her problems out with, and getting feedback from, other people:

How creative I've learned to be going through the process. Whenever I'm feeling like it's something I can't handle, I'll just kind of bounce it off somebody else. So I would say it alleviates. Maybe that's why I would say I don't stress as much because I feel like if there's something I'm going through, hearing another opinion - even if it doesn't do anything to help - it just gives me another way to move.

Hart-Johnson's (2014) research exploring how African American females experience adverse psychosocial responses to separation from an incarcerated mate argues that many African American women, like Cheree, tend to draw upon the support of their family and friends as a coping strategy. Seeking counsel from respected family/community members is common practice among Black women; however, reluctance to call on family for fear 
of putting too much on their loved-ones, fear of stigma, and even for prideful reasons is as common.

Kali described phases of coping - more specifically, how her coping mechanisms changed with her age and maturity. For example, she describes how she coped as a teenage girl:

...as I got older, and my dad would send me money and stuff, I was just using that money to fulfill needs that didn't even matter. Buying those Jordan's, buying those Guess jeans because that made me feel good on the inside.

Kali describes being pacified by material things like money and shoes in her youth. Having and wearing nice clothes and shoes made Kali "feel good" for the moment. But as she grew older, she realized those things "didn't even matter," and has grown to appreciate the benefits of therapy and mindfulness:

...well now I have a therapist and I also try to put myself in spaces that validate my feelings, that lifts me up; try to surround myself with people that support me, a big village. And then just trying to be mindful of coping methods and practicing those coping methods. And just know that every day is a new day. You can have those dark spaces, you can have those dark moments, but eventually, you gotta get up out of it. You gotta get up out of it.

Kali also explained that talking to her mother - a Black woman with shared experiencewas insightful and healing:

I like to talk about things that I've been through and why I'm here now and so understanding where she came from, the decisions that she made, the decision she 
didn't make helps build our relationship and it helps me not have that much resentment toward her.

Kali mentioned during another part of our interview that during her childhood, she had not felt comfortable enough to talk to her mother about what she was going through mentally and emotionally; that her role was as a child was to be seen but not heard. However, as an adult she is able to talk to her mother and gain clarifications about things that she may not have known or completely understood as a child. As a result of their more vulnerable, open, and transparent communication, and deeper comprehension of her mother's life experience, Kali has been relieved of indignation and bitterness that she long held, and they have been able to heal from past times.

Bailey et al. (2011) found that the major coping mechanisms of families effected by separation from incarcerated Black men were family support and religion. In line with this research, Oprah opened up about her spiritual practices and the support from her husband that helped her cope with her brother's absence:

Number one, I have a fantastic husband. I really do. He—anything that I ask, he is willing, often, to do. My husband is very loving and very charismatic and very affectionate, of which I am the primary beneficiary. Both myself and my daughter. I think that's a level of self-care. I also like to spend time alone. Me time is important for me. I pray a lot. I have a lot of different practices-whether it be the gratitude call with our [mutual acquaintance], whether it be with my prayer partner, we connect once a week for about an hour; whether it be some of the readings that I do; even some of my research work, you know, it looks at spirituality in higher education spaces. So there's ways in which I'm able to 
weave that into the work that I do. That serves as a certain source of empowerment for me, I would say. But also, just being alone with my own thoughts, I think you know, I go home to the east coast for about 2 1/2-3 weeks every year.

Oprah emphasized the intentionality of practicing "preservation and emotional and psychological awareness." Traveling a few weeks out of the year gave Oprah the time and space she needs to "be alone with [her] own thoughts," reflect, and pray—practices she believes are vital for her mental and emotional fitness. In line with assertions from Abrams et al. (2014), Oprah's spirituality compelled her to make appropriate decisions and be actively involved in life. Through her testimony, we recognize that "such inward practices are grounded in empowerment, and can offer a source of replenishment for women who continuously expend their physical, emotional, and financial resources to everyone but themselves" (Abrams et al. 2014:512).

Raychelle explained that her coping mechanisms often involved engaging with her brothers - a privilege many of the other women did not have:

I'll send them pictures. They have JPay now, so I'll send an email cracking jokes; sending them something to say like, "Yo mama!" or "Remember this?" Making sure that I can hear my brother's voices... it has to be enough.

This level of contact and communication was not available or even realistic for all of the women. Furthermore, any random institutional shift could disrupt Raychelle and her brother's level of communication. For example, the institution could be locked down because of a riot or a virus, which in most cases will impact the imprisoned's contact with the outside and vice versa. This matters because Raychelle considers close contact 
with her brothers a coping mechanism, or a thing that helps her deal with their physical absence, but if at any moment, that contact is thwarted for an indefinite amount of time, it could incite additional stressors (e.g. worry, anxiety, etc.).

Besides connecting with her brothers, Raychelle discussed other ways she attempts to manage stress:

The gym. Everybody goes to the gym and everybody wants me to go (laughter). I don't really do counseling, that type of thing, but just talking it out. When my kids go to practice: walking the track. Educating myself and trying to figure out ways to deal with stuff in a positive way.

One of the most underutilized methods of managing stress is exercise. Scientists have found regular exercise to decrease overall levels of tension, elevate and stabilize mood, improve sleep, and improve self-esteem, among other benefits (Jackson 2013; Anxiety and Depression Association of America 2020). Raychelle seemingly recognized the benefits of exercise seeing as though she mentioned walking and going to the gym for stress relief. However, Raychelle rejects counseling (therapy), a common response of Black people. Counseling/therapy has long been rejected or frowned upon by the larger Black community for various reasons, including the characterization of "depression as a 'white disease'...and...a sign of personal weakness" (Walker-Barnes 2014:54); however, culturally-competent counseling/therapy is positively emerging as a useful method for addressing stress, depressive symptoms, and other mental health concerns as of late. National Alliance on Mental Illness (2020) reported only about 30 percent of Black people receive mental health treatment (compared to the U.S. average of 43 percent). Concerningly, Black people only make up four percent of active psychologist in the 
nation (Lin, Stamm, and Christidis 2018). These findings remind us that not only is mental illness/health still a taboo subject in the larger Black community, but there is a huge deficiency of Black mental health professionals to inform the field and address racerelated stress and trauma.

Erin said that one way she coped with her father's absence was by avoidance. People who use avoidance as a coping strategy often try not to take actions that trigger painful thoughts or memories. Describing the process of receiving letters from her dad, Erin said:

I'll take like months to read them because I can't even read the letter without like, just crying, without getting tearstains on the page, the picture... and the most recent time he wrote me a letter, it took me two years to open it. And when I opened it, I was with my now ex-boyfriend — and um, same thing, just couldn't stop 'em (the tears). And I remember telling myself, "I'm never doing this shit again. Forget it. If I get a letter, it's never getting opened. I might send it back.” Erin explained that when she received letters from her father, or merely allowed herself to think about the sad reality of his circumstances, she could easily and quickly become despondent. However, Erin also disclosed that occasionally talking to her mother about her dad was therapeutic:

When I think about my dad, my step-dad, I talk to my mom. And I don't know if she recognizes it, but in these conversations, it's me seeking closure over and over again. And just trying to make sense of the fact that this is real and that this is some that -like my first love, like, my dad, but—but I don't really know what it's like to experience him because he was always in and out of prison. 
Much like Tyra, Erin used bracketing/compartmentalization to maintain her ability to function and navigate the everyday without the worry or anxiety engendered by thinking about her father's imprisonment. However, when she wanted or needed to talk about his imprisonment, Erin sought support from her mother, finding comfort in hearing nostalgic stories about him and making sense of his absence.

\section{Who Supports Black Women Impacted by Incarceration?}

In her latest book, Intersectionality as Critical Social Theory, Collins (2019:168) asserts that "in the face of assaults on Black men," - - like those committed by the criminal justice system - "the burden of community work has fallen more heavily on Black women." It is undebatable that Black women have long been the protectors, defenders, supporters of, and have sacrificed for Black men, assuming a great deal of responsibility in helping our communities not only survive, but thrive in the face of racial oppression. This role as strong Black women (SBW) "is handed down to us, it's not heard, we see it and it just is" (emphasis on original; Scott 2017:25). Black women's motherwork (Collins 1994) is, and always has been, an essential contribution to the vitality of Black families, Black neighborhoods, Black communities, and the Black race in totality.

Studies have shown that because Black families have not been "provided with the structural social or political resources families need to function well in their society, Black families constructed their own support and survival, and as such developed a selfdefinition and dynamic that was external to the U.S. ethnocentric norm" (Dodson 2007:51). Historically, African societies have implemented and used the extended family structure as a survival strategy, with "all the members of the extended family help[ing] to 
provide for the basic needs of food, clothing, and shelter" (Degruy 2005:29). Through extended family and kinship ties, Black women and men tend to assume more extensive roles within family and community compared to European American families who are more alienated from their families (Green et al. 2006). Still, "oppression and the limited socioeconomic mobility of Black men appeared to have strongly influenced women's beliefs about being strong leaders of households and families" expressing feelings of obligation to take on leadership roles in the family and community to simply survive (Abrams et al. 2014: 509). Considering the removal of Black men from Black communities by mass incarceration, and the compensation for their absence by Black women, it comes as no surprise that Black women bear the brunt of the responsibility for maintaining, sustaining, and caring for families, neighborhoods and communities.

Understanding this reality as a Black woman, mother, daughter, sister, aunty, village mother/othermother, activist, supporter of incarcerated and formerly incarcerated loved ones, in addition to my other roles, I was interested to know who supports the Black women who are performing life-saving, life-supporting, life-sustaining, work throughout our communities in general, and in support of incarcerated loved ones, specifically. Thus, I inquired by asking the question: Who do you talk to about what is going on with your incarcerated/transitioning loved one? Most of the women revealed they turned to family/community—-primarily, other Black women—for advice, support, and uplift.

When asked who she talks to about Randi, Oprah said:

My sisters, primarily, I think because we're the ones who are most invested in him right now. 
Kali explained why her mother was her go-to for conversation:

She understands that her relationship with him, or the lack thereof after he came home, had a lot to do with why he didn't really come back into the home, why he was there for a short period of time and then left. And so she's always apologizing for it.

Similarly, Erin briefly explained why she turned to her mother when she needed to talk:

I talk to my mom about my step-dad for the closure.

Asali had a more extensive network of individuals she could turn to for comfort and/or advice:

A lot of times I used to talk to my friends or talk to his friends. I talk to my mom or my brother. I especially talked to my brother because the guy was his friend... And then, to my husband. I did find a couple of classmates who had been through the process themselves and we kind of created our own little thing with each other but nothing real concrete, you know what I'm saying?

Cheree explained having a relatively large support system to help her process and deal with Jamal's absence:

My daughter, my friends, my co-workers, my sisters. They're supportive. I'm gon' say everybody is supportive. Just the support, having somebody support me even if it's just in conversation or listening-that's fine. That's all I need.

Tia Cason named several different Black women who either worked for, or were affiliated with, a local non-profit grassroots faith organization as individuals she turned to for advice and comfort. Tia specified that these women encouraged her to get her and 
Jason's story on TV and in the media to shine light on his case and the ill-manner in which he was being depicted and treated by the criminal justice system. Tia further described her support network:

I gotta friend in N.Y. I call and talk to. I gotta couple friends here-I get validation. I gotta friend here whose son was shot by Sac PD and right after my son's incident. He was shot at [the] park, seven times, but he survived. He's still in jail right now. So me and his mother kinda cliqued cause she saw me on the news. And there was a lady with ACE [Adverse Childhood Experiences] who hooked us up. So it's like, me supporting her-she's so grateful to have me; I'm so grateful to have her! Because I don't know what the "F" I would've done if my son was shot in front of me! I probably missed two court dates. Just being there and seeing how the system did them...

Suzie Cain described the people in her corner with gratitude: I have a tremendous support system. I have friends that have walked this whole way, this whole journey. They are praying sistas, but they are also just sistas. And we talk-one of them I talk to everyday. Before this happened, we were close and we were raising our kids, and they're just as welcomed going on a vacation with me and my husband and my kids as my kids were with them. It was that kind of cohesiveness. So, when it gets stressful, those are my go-to people. Those are my go-to and lift-up and hold up the arms. Because they've walked with me through every phase of our journey, they don't give me little mamsey-pamsey, "The lord will never put more on you than you can bare." Somebody told me that once and I was ready to poke them in the face. They thought they were helping but it was 
like GRRRR! But that support system, they can really understand the pain. And they're in pain too because of her incarceration 'cause they loved her. They're like aunties.

Suzie also made sure to reiterate that her husband was a major part of her support system: ...as I said, my husband has been right there with me every step of the way...

Suzie elaborated further on her support system:

When something is going on, something is detrimental, I get on the phone and call my two friends Ellice and Denise. Those are my go-to people. My husband too, but there's something I get from these two ladies because mothers, they share the pain of mothering, right? My friend Ellice, who I talk to every day, she had one son who was very close to my family, my daughter's age, and he was shot and killed and then they didn't find the body for six years. We walked with her through that horrible tragic time. She kept saying at that time, "Something is wrong, something is wrong. He wouldn't just not call me." So, she knows the crazy that can come on you and we walked through that as sistas, together. That was her only child, and she has no other. So when it gets really crazy, she's the one that can really hit it right on the head. Those are my go-to persons and I appreciate them so much.

When asked who she spoke to and confided in about her father's incarceration and subsequent death, Amanifu explained:

I've got an uncle. He's [her father] got a brother. We're real close. The brother was the first to accept me in the family. He came down from San Francisco and spent the weekend with me. We went to go visit my dad together...I talk to my 
Tio in the movement...[and a] person, may she R.I.P.—-she was a former Black Panther and freedom fighter in her own right...

Amanifu also explained that while he was alive, her father was a primary source of support for her:

I talked to [my dad] about everything. If there was something—family stuff—I'd talk to him about everything. I'd write him about it. And if I didn't talk to him, I'd talk to my husband.

While the participants who were married made sure to credit their spouses, the primary sources of support for these women were other Black women — many of whom were also connected and/or related to the participant's incarcerated loved one(s), e.g. sisters, aunties, etc. Bryant-Davis (2013) confirms in her study of African American women's friendships that "sister friends" can be crucial in assisting African American women to face, address, and overcome, major transitions including stress and traumatic stress, such as that brought about by the incarceration/reintegration of a loved one. And, considering that almost half of all Black women know someone who is incarcerated, the likelihood that sister friends can relate to one another and offer support due to shared experience is great.

Thus, it is important to keep in mind that the women who offer support are often suffering from their own traumas and stress related to incarceration, as well. Compounded stress can be detrimental to the mind, body, and spirit, further affecting the ways these women are able to show up in their families/communities, work settings, etc. Recent research centered on health implications of strong Black womanhood, including the tensions inherent in the maintenance of strength, find that while the "superwoman" 
role had its benefits contributing to self, family, and community preservation, it can also result in additional stress and strain (Scott 2017).

Resources for Black Woman Impacted by Incarceration: What's Available and What's Needed

It is clear that Black families and communities generally turn to one another for assistance, however, too often we lack the appropriate structural social and/or political resources we need to function well. It is important, then, to identify where and what resources are available, accessible, and most importantly, helpful. More specifically, it is useful to know which resources are available and accessible to Black women supporting an incarcerated or formerly incarcerated loved one being that we are the population 1) most likely to be supporting them, 2) most impacted by their incarceration/reentry, and thus, 3) need useful resources to reduce the burden on both our loved one(s) and ourselves.

In attempt to satisfy this inquiry, I asked the women in this study: What types of resources are available to you? Which resources do you use the most (e.g. family support, donations, health services, etc.)? A common response among participants to the first part of the question was that there were no resources specifically dedicated to the women/families supporting an incarcerated/formerly incarcerated loved one.

For example, Oprah's response to the question about available resources was: None that I know of! So if you know some, let me know cause I'll definitely hit 'em up! (laughter) Honestly, I think for me, I think I do what I do, not just in regard to this situation but my life in general, you know, a spiritual community is really important to me. While I don't belong to a particular church, I do go to two 
churches in particular that I think help to sustain me. I mentioned a number of the other practices that I have...I don't know about a lot of things. Like I know Beyond the Stats. I haven't really connected with them, but I know they're there. One of the other things I noticed I have been able to connect with Ralph Angel. And just my connection with Ralph Angel has helped in terms of him [Randi]. [Ralph Angel] has provided just perspective and inspiration, and that's really been a godsend to be able to connect with him. And he's actually reached out to my brother which has been really nice, so I've been really grateful for that. I would say [we need] counseling, a safe space for process, financial resources are great; I think being in a community of people who understand this and are committed to providing a high level of support for those who are directly impacted-'cause it's always nice to never be alone. It's always nice to have that kind of presence. I think reestablishing trust with individuals becomes very important. Reengagement; what does reengagement look like for these individuals? Financial for sure, legal advice is important. I think engagement with those who are still living with the trauma of it, like his kids and his wife. There's a high need there. And then of course looking at him-- all the various things from health to finances, to independence and him being able to be set up for success in transition.

Oprah's response points to not only the lack of resources for incarcerated/formerly incarcerated individuals that assist with reengagement with family and community, but also the lack of resources that include assistance and guidance from individuals, groups, and organizations that have experience with imprisonment, vicarious incarceration, and reintegration. Ralph Angel was formerly incarcerated for more than 30 
years and has a wealth of information and insight about the criminal justice system, prison life, and the obstacles reentry presents. His willingness to share with Oprah and connect with Randi has been helpful and inspirational, and Oprah praises him for his fellowship. Oprah's belief that more people like Ralph Angel are needed to support individuals/families/communities in dealing with the impact of incarceration is a reflection of a common saying among community members I engaged during this research: "the people closest to the pain are the people closest to the solutions." In other words, with regard to people enduring the struggles related to imprisonment and vicarious incarceration, those who have firsthand experience are better equipped to act as a resource for individuals and families navigating the criminal just system, and to inform processes and programs that assist individuals and their families in dealing with the residual effects and collateral consequences of incarceration.

We were sitting in a restaurant eating brunch when I asked Cheree what resources that had been available to her as she navigated Jamal's arrest, trial, and ultimately, his incarceration. Initially, she drew a zero in the air with her fork and laughed, but eventually, took a long pause to really contemplate the question before she responded: This is the hardest question you asked so far. Cause I was thinking about it and I'm like, none. Cause every program they sent me to has done absolutely nothing; every person that they sent me to that was supposed to be able to help, did nothing. Every...(thinking)...there was nothing. I can't think of one positive thing that I can say that actually helped me do something besides researching "modification." Because I had to modify everything that I had learned in order to make it work. So I don't know of any resources. I mean even down to the smallest 
thing — if you read the thing, they tell you they have transportation for you and that they provide all of this...they don't. They don't make it easy for you. They place your loved one somewhere you can't possibly get to. They tell you they have programs if you're disabled or something and then you have to jump through so many hoops just to get them to listen to you, let alone to do it, and so I haven't found anything. And all those programs where we had the inmates, and exinmates - it was designed to help them; it wasn't designed to help us (when you're going through the process). They have things set up for after the fact, and then they have some programs that are supposed to deter them from getting in this process. But once you're in the process, I haven't found anything.

Cheree explains that in addition to resources for the incarcerated and formerly incarcerated being scarce and often unreliable and ineffective, there are virtually no resources for the families impacted by their loved one's incarceration. The resources that are available are not easy to access, which makes it difficult to consider them resources at all.

Suzie Cain echoed the sentiment of the previous two sisters explaining the limited availability of resources that fit her or her family's particular needs:

We really have not used or had very many resources. I'd say this is what I would need, this is what I thought I needed: When we first started on this journey, I found it easy to find women whose child had died, whose child had been killed. But it was very difficult to find — not just women, but parents—parents of kids who had taken someone's life. And I can remember saying, I think I would just like to talk to somebody. I can clearly remember-I don't know, it was probably 
five years in or so- I wish I could talk to a mother of the child who took somebody else's life. Just as a check-in; to say, am I ok? Kinda like the question you asked...Am I mentally ok? Am I emotionally ok? Am I spiritually ok? You know? Or am I just making this stuff up in my own head? Right? But maybe if I could just talk to the mothers of someone who had taken someone else's life, maybe I could understand some of the stuff that was going on inside my own head. These many years later, one, I can clearly see why those resources aren't just readily available cause people are not just going to pull up and say my child took somebody's life. It's much easier to say my child lost their life to so and so, whatever. The second thing is, as I've continued to make this story a part of my public addresses, I have found women who-I mean, in the middle of the presentation because this is the first time they've heard someone else say "My child took somebody else's life...my child is responsible...murder" whatever you call it...but my child's actions are responsible for the loss of somebody else's' life"-which is the way I try to put it, but suddenly, there is just this breakthrough for them because they've never had anyone say it to them either. Right? So then they always seek me out after the presentation to talk. I still don't think there are groups available, but if there are, it would be---I truly think---that would be groundbreaking; to set up some type of support group for those parents or loved ones of someone who was responsible for the death of another person. Cause I don't think we ever give audience to what that is like. Cause you feel like I did everything I could and I raised a...the world tells me I raised a killer. Right? Let's talk about that. Let's talk about what that means. Let's talk about what the 
implications are. Let's heal from that. You know? But I have not seen it. But that is definitely something that I would see as a support system. There has been the Angel Tree program that has helped her son and so those matters work well. Of all of the things, that's the one thing I'd say is missing.

Considering that homicide is not uncommon in our society, it is a wonder why there are programs available for parents who have lost a child to homicide, but there are no programs to support parents of children who have committed homicide. Sister Suzie brings attention to this deficiency and admits that the inability to access such a resource keeps her "inside [her] own head" questioning what she did or did not do as a parent (self-blame, guilt) that led RiRi to commit such a heinous crime. Without proper support (outside of her family/community who is also dealing with RiRi's incarceration), Suzie is left to process and deal with her emotional, psychological, and spiritual turmoil alone, which can be detrimental to her mental health.

Tyra met my question about resources with laughter asking, “...like, is there a resource? Like, seriously?" She went on to say:

Besides confiding in somebody who might have a little more experience than you, there is no resource. There is nothing that our people—not even just Black people — but women of color (Hispanic women, women who come from different isles) they don't have any type of support in this. It's kind of like, hopefully somebody can answer that question differently, but until then, what is there? What types do you need? Is that the last question? That sounds like a drum-roll question (laughter). Maybe community, 'cause you know shared experiences are powerful. Community, that right there...it's like you can say, "oh, you need this this and 
that..." But without community, how can you form that? That's like the essential, main, bottom line that people who deal with incarceration need: those people who've had those experiences, that can help them get through it or can provide that financial, or all that other stuff that we listed before, and can lead you in the direction of gaining that; that's the only thing that can really help—or not even help, 'cause nothing can help, but like, make it easier.

Sister Tyra's thoughts on the matter reinforce the adage that the people closest to the pain are those closest to the solution. Individuals and groups who share experience have a greater understanding of one another's struggles, have more informed opinions to be able to offer advice and guidance, and are more likely and able to be genuinely empathetic. Thus, Tyra believes community—especially people who have been impacted by the criminal justice system — are the best, most reliable resources for women like her.

The general consensus among the women was that there is a scarcity in resources; in particular, there are little to no resources from government (e.g. social services, probation/parole agencies). There are, in fact, supposed resources in the form of lists with phone numbers to call and offices to visit, but often those phone numbers are dead ends, offices have been shut down, or the accessibility and availability of the supposed services offered is not as advertised. In other words, the social services and other governmentsponsored "resources" provided turn out to not be resources at all—at least, not from their perspective and perspective shapes reality.

What the women do find to be useful, however, are the resources that are rooted in community. Similar to Tyra's statement about reaching out to community, Raychelle explained that she gained support from her personal networks in the community: 
I would say networking has been the biggest resource overall...just because I meet so many people where I work and I'm really invested in my kid's sports so you meet people. Networking. So I've learned a lot. The sister circle (EEC)! The sister group. Going there and just talking, that's been a lot for me! Cause I don't just have those kinds of outlets. So finding different outlets for me and getting involved with stuff at work, going to trainings and learning about trauma, and people like myself in the community and what their struggles are, and why our babies are dying left and right and why is there's so much violence in [the southern part of town where she lived previously].

Raychelle is ambitiously curious, taking advantage of almost every opportunity to build and grow herself, her family, and her community. Investing in her children's current pleasures and potential future aspirations; engaging other community parents, teachers and coaches; investing in her own healing by attending sister circles; seeking knowledge and truth via trainings and workshops; overall, building her social capital in the community.

Like Raychelle, Erin also considered Emotional Emancipation Circles ${ }^{\mathrm{SM}}$ (EECs) - a community-based healing circle that met bi-weekly —a resource for her dealing and healing:

The only resource that has been available has been the EEC support group...I facilitate... So the only time I have to talk about it in a healthy setting by exercising what it is in a rhythmic way-not because I'm trying to help someone else with their emotions, i.e. my mother, but because this is the space to talk about 
it and be around like minds, is through the EEC. But prior to that, no resources. Like nothing.

Sister Circles like the one Erin discussed are support groups that build upon existing friendships, fictive kin networks, and the sense of community found among African American women (Neal-Barnett et al. 2011). Studies have shown that sister circles tend to offer many components Black women desire in anxiety interventions (Neal-Barnette et al. 2011); are effective in modifying health-related knowledge, attitudes, and certain high-risk behaviors in African American women (Gaston et al. 2007); provide safe spaces of inclusion and belonging (Allen 2019); promote confidence and self-respect (Boyd 1997); and are recognized as an effective therapeutic tool that encourages women to support each other, seek help, and thrive (Sisterhood Empowerment Academy 2015). Though several of the women mentioned $\mathrm{EECs}^{\mathrm{SM}}$ or other sister circles as helpful and therapeutic, the availability and capacity of such groups are lacking.

Tia's response to the question about available resources revealed more about the assistance she needed in her daily life (which she would have likely been able to get from Jason were he not incarcerated) rather than those which would help her deal and heal emotionally and psychologically:

I do have an in-home support person who comes and helps me-why she won't clean that oven out, I don't know. (laughter) I need certain help around the house and sometimes I don't know how to ask for help. I need all them leaves raked. I wish there was a resource for people like myself who've gone through something where people come in and see "What do you need?" Like in old Baptist church, they have the mission, the women, they check on you. What do you need done 
sista? What do you need? That's it. I might need some blinds hung up or something. Just as simple as that. Can you take my car and wash it? You know? It's not being lazy; it's just, those things that what just take something up off of you.

Tia's testimony highlights a common trait—perhaps, a flaw—of many Black women: our reluctance to ask for help. There is a difference between seeking resources and asking for help. Tia sought resources to help with Jason's case through local social justice organizations and networks. However, when it comes to her own very basic needs, like hanging up blinds in her home, or cleaning out her gutters, - things that she is not physically capable of doing as a physically disabled woman—Tia finds it difficult to ask for help. This may or may not be attributed to the SBW or Superwoman syndrome. Nevertheless, women like Tia who are so used to be supportive to others often need people to reach out and offer help to them, lest they may never receive the assistance they need.

Tia did mention her appreciation for listening sessions as resources. However, she questioned their usefulness and overall benefit:

I love the listening sessions. I haven't been to one in a while. But to be honest, I feel like sometimes, that we're preaching to the choir. 'Cause I've been to a lot, I mean A LOT, A LOT. And it's like, the same people show up. We're talking about the same things to the same people, we got a piece of paper, writing down the same suggestions and in that moment, it's still powerful 'cause it's like you're in class and its being reinforced, you're reabsorbing it. 
What Tia describes about the listening sessions can be considered positive and negative. On the one hand, "talking about the same things to the same people" indicates consistent dialogue (work) towards a particular issue and commitment from the people involved. On the other hand, it can imply a lack of progress, and an absence of interest or support from people outside of the "same people" working toward solutions. So, while she appreciates the fellowship, and acknowledges the power in gathering, the monotony causes listening sessions to sometimes feel ineffectual as a resource.

Kali recounted growing up without the proper resources to address her thoughts and feelings surrounding her father's imprisonment:

Not having resources to help me get through those feelings growing up; not having a good therapist, not really having anyone to talk to about that kind of stuff. Because I grew up in a household where what they say goes and there is no talk back. So then I didn't make good decisions because I didn't have that authority to really trust and talk to about it. 'Cause even though it's wrong, you're looking to your peers to get advice, and they're not the right source. Then you-I don't want to go to my dad who I know is going to be 10 times harder on me and is not going for it, and then don't wanna go to my mom cause she's who I'm actually living with and I don't want to hear from her so...

Kali talks about the different people and places she would look to, or consider looking to, for support to no avail. As a child, it was difficult for Kali to communicate what was bothering her and what she needed in her household. It is common for Black children to grow up practicing being seen and not heard, which was the case for Kali. However, having to hold her thoughts and feelings inside because she lacked a safe space 
to express them caused her to act out and behave poorly - a common consequence of parental incarceration (Foster and Hagan 2009). The only space she perceived as relatively safe was with her equally young peers who may have been "supportive" but were not equipped to offer sound advice on how to deal. Now an adult, Kali said she believes culturally relevant (Black) safe spaces — capable of helping her understand both her racial stress and her vicarious incarceration-would have been helpful.

Sister Oprah also emphasized the need for safe community spaces designated exclusively for and by Black people. She referenced a developing non-profit organization which offers monthly healing circles throughout the city facilitated by and designed specifically for people of African ancestry called Safe Black Space ${ }^{\mathrm{SM}}$ :

For example, with Safe Back Space-Safe Black Space is amazing! I tip my hat off to the women who do it and even the men who do it. The folks that show up to really heal the community is amazing! Doing amazing, amazing work! There's this group called Beyond the Stats which is a group of formerly incarcerated students here at UC Davis creating programs and services for both those who have been incarcerated [and] those who have been impacted by incarceration. I have been wanting to go to one of their meetings, have not gone, but I do plan to go.

Although Safe Black Space ${ }^{\mathrm{SM}}$ is not an organization dedicated to supporting people impacted by incarceration per se, it is specifically geared toward providing a safe space for Black people to learn about, process, talk about, racial oppression and offering tools and strategies to heal from race-related stress and trauma. Mass incarceration has countless intergenerational effects which disproportionately impacts Black 
families/communities, thus, Oprah suggests programs like Safe Black Space ${ }^{\mathrm{SM}}$ are needed to facilitate psychological and emotional healing in Black communities.

Asali also mentioned the lack of availability, but the potential benefit of therapy and support groups, specifically for Black folks:

I did some counseling. I think it would've been helpful if there had been some groups. And there may have been groups that I didn't reach out to. I think there are more groups now than there used to be. But not just groups, but support groups for Black families. You have a tendency to see a lot more white support groups than black support groups. But ironically, there are a lot more Black people touched by incarceration. And it's like, just dealing with—not just the dudes you're dating...like I see a lot of support groups online. I'd see stuff like that but not really stuff in person.

Sister Asali pointed out a few problems: 1) quality of care (counseling), 2) type of care, and 3) lack of availability of culturally relevant/competent care. Not only were the resources scarce, but the quality of her counseling was inadequate, the groups she found were online (impersonal) and lacked components to directly address issues of race. Even though Black people are impacted by incarceration more than any other racial/ethnic group, there is a deficiency in resources that support us in dealing with its effects.

Recent studies have shown that exclusively Black safe spaces are both imperative and necessary to the mental and physical health of Black communities (Blackwell 2018; Jones 2015). Black people need to feel free of the white gaze; escape from everyday racial oppression; space to privately address issues within our own community; an environment conducive to healing, uplift and love. It was clear that while many of the 
women found benefit and value in community resources like the EECs ${ }^{\text {SM }}$ and Safe Black Space $^{\mathrm{SM}}$, community-based programs were not consistently available. Such programs lack the proper funding to maintain, sustain, and build capacity. Mental health providers (e.g. psychologists/psychiatrists, counselors, first responder teams, etc.) of color already constitute a very small number of professionals in the field; thus, the ones that exist lack the capacity to serve the number of individuals in need of their services. That leaves many untrained, unpaid, yet passionate and dedicated community members offering the best of themselves to service and support community members in need, outside of their day jobs and home responsibilities. Put simply, ordinary people are stretched psychologically, emotionally, physically, spiritually and financially, trying to provide safe spaces and adequate services for community members in need, with little to no assistance (i.e. funding) from the powers that be.

The final question I asked participants with regard to resources was: What type of resources do/did you need? When asked what she needed and/or what she would have found helpful as she navigated her father's incarceration and reentry, Kali replied:

Therapy I think would've been a really good resource that just wasn't available. I was offered therapy but that's because I was seen as an angry child in school. And so it was more of a requirement cause I was getting into a lot of fights. But it wasn't the right type of therapy. I really believe in Black therapy. I really do believe we need to have role models, we need to have people of authority that can validate our feelings and understand our feelings and understand it comes from systems of oppression and trauma and to offer the right type of healing. So there wasn't that type available. I didn't know that I needed that to be able to advocate 
for myself at that age...Community. I had church, but even that in a sense can be a bit hindering. More community resources, more after school programs. More Black spaces in the community would've been helpful.

Much like research shows on education, extant research on mental health shows that there is not only a lack of mental health providers or color, but there is an overall lack of cultural competence in the mental health field (National Alliance on Mental Illness, 2020). Thus, the culturally competent mental health services that are available often do not have the bandwidth to meet the high demand of need.

As a co-facilitator of an Emotional Emancipation Circle, Erin shared about what type of resources she wanted to seek out:

I think that eventually I want to look into finding opportunities - support groups or whatever else - where I maybe am not a facilitator or co-facilitator, but just a participant so that I can kind of move through it 'cause I was saying earlier, I don't want to be either extreme. So I think that at some juncture, I think that at some juncture it would be very beneficial for me to be a participant of some type of support group where these conversations are brought up and it's healthy to express it. You're not being judged, you're just— the flow of your ability to articulate is what is welcomed in the setting.

Similarly, Asali declared:

I wish there was something a little more supportive, a little more support for people going through it.

The types of groups Erin and Asali sought/seek are scarce and are typically held and facilitated by volunteers without pay, with "day-jobs," children, and other obligations that 
make it more difficult for them to dedicate time, and commit to holding these spaces consistently.

Cheree mentioned the need for resources such as legal aid, which she believes can benefit supporters of incarcerated/previously incarcerated loved ones:

I think we need mentors, legal information; even if it was just some type of system almost like legal aid that takes care of renters-when you call they'll fight for your landlord issue. But I mean even if there was just something that would help you with the DAs office-I mean when you're dealing with an attorney that does not help, there is no middle person to run interference. You know, to tell you, you don't have to do everything that they tell you to do; that just because you give them your money [doesn't mean] you have no recourse. You know? I think that would be one of the best things you could ever do for a parent.

Cheree's comments suggest that even for families who can afford legal representation (which, many cannot), they are often not knowledgeable enough about their rights as clients and the responsibility of their legal aids. Even with her 20+ years of experience in social work and child services, where she had plenty of contact, communication, and collaboration with law enforcement, lawyers, etc., Cheree still felt ill-informed when it came to advocating and fighting for justice for Jamal. Cheree could have benefitted from a "middle person" to help her navigate the criminal justice system, but instead, she sought information and support from her family/community.

Sister Tia reflected on what she needed around the time Jason was initially arrested and imprisoned, then explained where she found support afterward, and what she is seeking moving forward: 
During those times, I need to be somewhere-church. And then a lot of stuff started happening with police shootings — one that went national, Stephon Clark. And then [I went to] Safe Black Space, just being there, just talking about it, and having people give you tools and let you know that your feelings are valid. First you get to own your feelings, they're validated, and they're not dismissed. It's a work in progress. And just hearing people speak about the culture of it, where it's coming from and why this is happening to our race, and also understanding that our race is powerful.

This is something I would like to be available to me: drums and other manipulatives; aromatherapy, calming music, relaxing massage chairs...just a place to go to relax...24-hour churches or worship club. Sometimes you just need to hear gospel. People that love country music just need to be able to hear country. Something that fills you back up. Just somewhere to go and talk without it going on record and know it's not going to go any further.

Overall, Sister Tia calls for the types of spaces that promote healing with culturally specific, culturally-affirming elements and practices that have been recognized as having therapeutic value by and for Black people themselves.

\section{Conclusion}

Each of the women have/had their own unique methods for dealing with incarceration-related issues and navigating the everyday. However, there were some similarities in their ways of dealing that ultimately revealed a pattern of two categories of inverse responses: 1) subsumption and compartmentalization, and, 2) veiling and disclosing. In other words, the women either found ways to incorporate the support and 
care of their loved one(s) into their daily lives and routines (subsumption), or they bracketed off that part of their lives (compartmentalized) and only dealt with/addressed their vicarious incarceration at very specific times; and, they either kept their vicarious incarceration especially private (veil) or they were intentionally open about it (disclosure).

For example, Suzie set a weekly schedule to take RiRi's phone calls, including RiRi's needs into their monthly budgets, and designated times during the year to visit (subsumption). Erin, on the other hand, refused to open her father's letters to avoid the emotions that would accompany reading them and only spoke to her mother about him when she needed closure, or shared her experiences with clients to build trust and rapport (compartmentalization). Asali was very private about her vicarious incarceration fearing the stigma that may result in others knowing (veil). However, Cheree was extremely forthcoming about her son's incarceration because she wanted to call attention to issues within the criminal justice system and act as a resource to others who have been impacted by it (disclosure).

The broad range of coping mechanisms the women used speak to the diversity in thought processes and behavioral practices across Black women with similar roles in the lives of their incarcerated loved ones. Some practiced avoidant behaviors like smoking and sex, while some others actively worked to reduce stress by engaging in physical recreation. However, the most common coping strategy among the women of this study was seeking care and counsel from family/community, namely other Black people, especially Black women. They described venting to, and confiding in, people that were familiar with the circumstances, had shared experiences, and/or may serve as helpful 
resources. It was clear, though, that support from family/community helped the women persevere through both the stresses of everyday life and hardships of vicarious incarceration. The common practice of reaching out to friends and family for advice, an open ear, and/or resources demonstrates the trust Black women have and place in our kinfolk, and our reliance on them.

Testimonies shared in this chapter provide some understanding of how the women deal with, or cope, with the reality of vicarious incarceration and supporting an imprisoned loved one(s). The next chapter will discuss how the women heal and grow from their experiences. 


\section{CHAPTER SIX: THE HEAL}

Most of the women interviewed were heavily involved in their communities. Whether their roles consisted of supporting their child(ren)'s sport teams or regularly leading and/or attending community healing circles, each of the women were invested in the wellbeing of the Black community and improving Black life in their own way.

Though women invested a great deal of time in their families and serving their communities in some capacity, it became clear that many of them tended to neglect their own wellbeing. The tendency of Black women to provide boundless love, care, support, protection, etc. to our loved ones may not be as well studied as it is well knownespecially within the Black community itself. In this chapter, I argue that Black women use loving on others (i.e. motherwork; caregiving, community service) as a method of healing ourselves (i.e. improving mood, maintaining hope). I also argue that, for the Black women of this study, caregiving essentially coexists with, or is an ingredient of self-care, which sometimes means the women unintentionally overwork and/or overwhelm themselves with feelings of responsibility and obligation to others making it more difficult for them to tend to self (e.g. rest, exercise; heal etc.).

\section{Self-Care}

The third question I asked participants during our interviews was: In what ways does your support of your incarcerated/formerly incarcerated loved one affect your selfcare? I asked the question without defining or characterizing self-care and left the women to decide and define self-care for themselves. Amanifu responded enthusiastically, reflecting on self-care habits she practiced prior to her father's murder: 
It honestly affected my self-care a lot! I stopped smoking. I'd go see him every weekend. All my family and friends said it was the happiest they had ever seen me in my life.

Cultivating her relationship with her father gave Amanifu something to look forward to and reasons to strive for better-for her that meant quitting smoking. However, the trauma and stress that manifested after his murder led Amanifu back to smoking and overworking to cope. Acknowledging that she had fallen back into poor habits, Amanifu tried to find ways to get back on track:

Self-care is something that I've really been working on. The only thing I started doing for self-care is attending Safe Black Space. That's my self-care day, once a month. If I don't do nothing else, I'm going to Safe Black Space. That's my place to-waiting to exhale type thing you know. 'Cause there's so many injustices. Amanifu's self-care went from, at one point, being cigarette free, to attending a healing circle just once per month while maintaining her smoking habit. The injustices she fights against daily trigger her urges to smoke which she knows is not healthy. Since she is not mentally and emotionally ready to quit smoking, Sister Amanifu has made it practice to attend the monthly healing space to address the issues that feed her cigarette habit.

Suzie said that self-care had just began to be an idea she adopted and was taking more seriously. She explained that aging worried her, specifically because she is afraid of dying before her daughter is released from prison:

I really have just started to - and that's one of my commitments for 2019-to just really take care of myself. And not have days like today [back to back meetings]. I'll have two or three of these [days] where I've got four or five things I gotta do, 
and then I'll have three that I'm not gon' do nothing! I'm not going to do anything. I'm not gon' answer calls, I'm not going to commit to giving it over to somebody. And what makes me stay with that-'cause I've committed myself to that many, many years - but what makes me stay to that last year and this one, is that image of her. I have an image of her that says, "no you really need to take care of yourself.' Her incarceration is my inspiration and my incentive to do better because I'm scared to death. It's a negative incentive but it is an incentive.

Sister Suzie cannot stop aging, nor can she control when or how she dies. Still, Suzie is taking accountability for her wellbeing by doing the things that are within her control to keep herself as healthy as possible. For her, that looks like setting time aside to rest, rejuvenate, revitalize, and take care of herself-as she knows RiRi would encourage her to do. It is important for Suzie to honor RiRi in that way as she anticipates their reunification.

When presented with the question about how her son's incarceration impacted her self-care, Tia responded:

Me taking care of myself is taking care of my son too. Cause if I'm no good, he ain't getting no money, I'm not putting money on the phone. I do a lot of selfcare. Look at funny movies, or I'll have my grandkids, I'll get to Monterey to the ocean. I fly, I love the train. My health doesn't allow me to drive so much. Just being around people that are like minded and that can pour into me, not pull from me. And then whenever I can take off and get up out of here. Me and my arthritis and this cane, we get up out of here! Whatever I got to do cause it's gon' be a day where I'm not able to do that. But even sitting here talking about it is self-care. 
That someone is going to be reading this; you don't know where it's going to go. It's important. Just trying to relax as much as I can; helping other people. When I'm helping someone, and giving someone else advice, or standing in solidarity with someone, that helps me. And even when I'm in front of law enforcement, that helps me because I think I have poured into them, or into someone there, that somebody's life 'don got saved.

Tia incorporated a variety of activities into her self-care practices, including riding the train, visiting the ocean, and helping others. It is important to Tia to "pour into"-i.e. give time, effort, and support—others, as it provides her a sense of purpose. Booker T. Washington once said, "If you want to lift yourself up, lift up someone else." Tia's (and many of the other women) tendency to be supportive of others in spite of her own troubles is as suggestive of self-serving (self-care) behavior as it is the love and compassion she (they) has for others (community care).

Sister Cheree seemed to bracket, or compartmentalize, her life as a practice of self-care. She made sure to prioritize herself on the days not dedicated to her son: "On the days I don't talk to him, I make it my days.” By designating certain days for Jamal and certain days for herself, she avoided feeling overwhelmed by the circumstances.

Oprah was very intentional about preserving her well-being, thus drawing clear boundaries in the ways she supports her brother during his imprisonment:

The other thing is that I actually had to start to do is that when he calls me, sometimes I don't take his call. And at one point, there was some guilt associated with that. But as time has gone on and as I've been a lot more reflective about what support looks like and also all the other places in which I need to show up, 
there needs to be a level of preservation, if you will, that I maintain for myself and all the other role and places and people and things.

So there's times when I don't take his call. But there's also times when I make sure I take his call because I have to hear his voice, I have to hear that he's ok, I have to be connected with him as part of my family allegiance to him. So, selfcare is hard.

Sister Oprah is in tune with her self enough to recognize if and when she is in a healthy mental and emotional state to provide support (e.g. answer Randi's phone calls). Oprah is aware that she needs to preserve her spirit and energy for other areas of her life and she is adamant about making sure she "shows up" to give the people and things she values proper attention and investment of time and effort. From their testimonies, it appeared that Oprah and Cheree had rather healthy understandings of their boundaries, what was within their control and what was not, and how to navigate their everyday with those things in mind, so as not to overburden or overwhelm themselves.

Raychelle was transparent in her confession that she felt caring for everyone else was wearing her down:

I think physically investing in everybody else all the way around is taking a toll on me -in all areas: mentally, physically, and emotionally. I just touched on this conversation on my way home, but it's because I've always learned to invest in other people, all the way around. When you become a mom, 'Oh, I'm going to give them everything!' And you do! And the same thing with those around you who you love. So I think I've put myself on the back burner to make sure that I'm giving enough love because there wasn't a lot of love given at one point. So, I 
think that is another component of it: Not having enough self-care and self-love because - not even that it was ever really a thought, like, no, you gotta love you and take care of you first. Cause if you can't, duh, you can't do nobody else! So, I think now, at 33, with having the kind of experiences I'm having now in life in general, it's like, you gon' be 53! So what you gon' do about it?! I know now, through awareness, you gotta take care of yourself, mentally, physically, spiritually and emotionally or you not gon be available to nobody else. I think that the fact that I've invested in my brothers and my mother during her addiction and incarceration and my brothers in theirs and this and that, it's definitely been that I'm a giver, I'm a giver, I'm a whole-hearted giver. Giver, giver, giver. But the giver has got to be the receiver at some time.

Raychelle's sentiments reverberate those of Abrams et al. (2014) and Walker-Barnes (2014) in which each discuss characteristics of the strong Black woman (SBW). Abrams et al. (2014:511) warns that while a SBW's abilities to embrace numerous roles is considered an asset, all too often our dedication to caring for others is so strong that it takes priority over self-care, potentially causing harm to physical and mental well-being. Reiterating Abrams et al. (2014) argument, Walker-Barnes (2014) — who asserts that early in our development, Black girls are taught that to be considered a "good black woman" one must embody independence, be a giver and not a receiver of help — it is all but ingrained in us that to be considered a "good Black woman" we must put everyone else (and their needs) first. Furthermore, Scott (2017) argues that "the myth of strength and the mandate to be strong requires that Black women care for everyone elsenurturing and supporting their needs before her own, foregoing self-care, drawing instead 
on "strength" as a mythical quality that keeps her going despite such neglect. But as increasing disparities in chronic illness reveal, that legacy has taken a toll on Black women" (also see Beauboeuf-Lafontant 2009). Raychelle recognizes the toll her dedication for others is taking on her mind, body and spirit, yet—in line with the quintessential SBW—-Raychelle she continues to give the best of herself to others, even if it is to her own detriment.

\section{Self-Care, Caregiving and Caretaking}

Collins (1994) introduced the concept of motherwork-a type of reproductive labor that "goes beyond ensuring the survival of members of one's family, and recognizes that individual survival, empowerment, and identity require group survival, empowerment and identity." Thus, it is conceivable that when discussing self-care, the women of this study found it difficult to separate self-care from family- and communitycare.

While not all of the women of this study were biological mothers, each of them performed motherwork within their families and communities. Each of them accepted the social and cultural expectation for Black women to be caretakers of families and communities "for survival in a hostile and violent political economy" (Scott 2017:9). Thus, each of them was invested in creating better, more promising futures for Black children and the parents of Black children. With such ambitions and commitments, however, comes a loss of autonomy for the sake of the "greater good."

Discussing the support she offers her brothers (one older, two younger, Raychelle) stated plainly: 
My brothers are like my children — they were like my children before I had children.

Raychelle's motherwork extended into the community as well:

Being that person in the community is teaching them to be aware too, to watch their surroundings, to be mindful. I see me as that person in the community, as that aunty, that one who they can call. My kids, they have their group of friends, but I am that one. Caressa—she's got this friend, they talk about they wanna take off and run away, I will go get them; you tell them to come here, because they're safe here. I know what kind of environment is here. Anybody's children [are] going to be ok here. Now, I ain't gon' hide you, I'm gonna call your parents and let them know that you're safe. That's who I am in the community. No, I'm not going to PTA, no I'm not doing that. Girl I can't deal with them. But I am a helper, a giver, I'm the helping one. If I don't know, we gon' ask around, we gon' figure it out. I'm going to connect you to who does know. I'm the plug. I try to be that, because a lot of people don't have a support system, so I try to offer that to as many as I can; support—everybody needs some support, no matter big or small. Everybody needs some TLC. Everybody needs somebody at some time no matter how high you are. And I try to be that person to everybody that I can be that person to. That's who I am in my community, that's who I am in my family. That's who I am as a person. That's who Raychelle is. And sometimes it can be like, whoa, slow your role, but I'm aware of that, and I'm aware when self needs to just take a chill pill, 'cause you can't fix it. So I've learned through my work actually how to be ok with not having an answer, right? Cause that's takes 
practice - when you've always been the one that people come to cause you've always got the answers, and you've always got it figured out. Sometimes, it's beyond me bro. I love you and all of that. I'm here if you wanna talk about it, if you wanna cry about it, if you wanna drink about it. But there's nothing really I can do beyond this point; you gotta ride this wave. Right? So I've learned to be ok with that. In that same role. But just being able to just love on somebody during their struggle and their hurt without really bringing my own into it. That's hard to do too. I'm a big girl, I can manage, but it took a long time to get to that place. You know, that victimized mentality. Oh no, I can't be of that! Because you stay suppressed, you stay hindered; all that stuff on top of you. You have to learn how to heal, 'cause you can't try to heal nobody when you're broken. That's the message of my life, girl! So being able to just try to help, support, when I can. bell hooks (1994) introduces us to the notion of the "home place" in which she describes the "pivotal role of self-sacrifice as integral to the survival of the African American family and communal life." King and Ferguson (2006:113) explain the notion of "home place" as one that "makes focal the role of the African American woman in the preservation of the home place as synonymous with the creation of a warm, loving, and protective environment supporting the physical and emotional development of kith and kin as a form of resistance." Raychelle's assumption of the "aunty" (i.e. othermother) role to young people and her fervent efforts to be supportive and offer a safe space to almost everyone she comes across within the community is characteristic of Black womanhood and our role in preserving home place. 
Raychelle later discussed how and why she found it important to keep her children informed and involved in the support of their incarcerated uncles:

I want [my children] to know what goes on with their uncles, not sugarcoating anything; teaching them, exposing them to that side of the wall because on this side of the wall, they don't have the same experiences as me and my brothers. But they are aware of making a good or a bad choice. So these are the consequences when you make a bad choice.

Like Raychelle, Oprah also discussed the importance of keeping her daughter informed and not shielding her from "real life":

And I do educate my daughter about my brother's circumstance because I think it's important for her to know where he is and when I do have to engage with him, this is what I'm doing and why. But I also don't want her to be thinking that the world is some other place. You know? The world is the world and I think we do a disservice to our children if we try to paint it in any other way than it really is. So that's why I think it's very important I do that for her.

For both of these women, caring for their children included educating them about incarceration, and emphasizing the importance of understanding incarceration as a reality for many people who look like them, and what that means for their family/community members, and for each of them. They each believed it was necessary to introduce their children to the truth (i.e. "not sugarcoating") early on so they are well-informed and wellequipped to navigate the world on their own. 
Oprah provided further insight into the motherwork she performs and why it has always been important to her to be supportive of Randi prior to and during his imprisonment:

Partially because he's my brother; at one point I took care of him, when I was in graduate school, so there's a certain kind of bond that he and I have. Also, he's my younger brother, someone that I want to try to provide a level of high care for. Right?

Oprah also shared about her sisters' roles in supporting Randi, and how the three of them supported him in a way that they believed their mother would have, and/or would have wanted them to in her absence:

I think my sisters also feel that way; the level of care we offer is a way that we kind of honor our mother as well, who was the pinnacle of all of our existences, right?...We make sure that at least one of us has written him or if he's asking for money, which one of us can give money this month, or whatever. We make sure that someone has actually heard his voice on the phone to make sure that he's actually doing ok.

Continuing their mother's legacy as caregiver is important to Oprah and her sisters. Whether directly or indirectly, Oprah and her sisters learned how they are to navigate life and situations based on their mother's behaviors and actions (Abrams et al. 2014:505). Walker-Barnes (2014:35) reminds us that being a SBW - and in Oprah and her sisters' case, continuing the legacy of a SBW - is considered an effective method of coping with the stresses of our existence, enabling us to survive and "function by repressing grief, 
sadness, and anger by covering emotional distress with an outer façade of imperturbability, independence, and caregiving."

During our discussion about how she became a member of her son's support system, Cheree emphasized her "duty" as a mother. For Cheree, there was no question as to when or whether she would support Jamal:

I brought him into this world so it's my job to take care of him until he leaves this world, or until I do.

At one point, Cheree talked about the stress of dealing with the criminal justice system, and how she eventually found balance when it came to matters of Jamal. Although she felt relief in finally achieving a sense of balance, she ensured that the work (motherwork; community-care) was never done:

I don't have as much stress now. My only stress is trying to figure out-if anything — what I can do to keep the next kid out. It's not about him [her son], it's about someone else now, and their children. Educating the community. I felt like it was my job to be that resource for someone else. So, I think that stepped up my game instead of backed off.

After learning how complex and confusing navigating the criminal justice system can be, it became Cheree's goal to assist others in the process by offering information and resources when and where she can. Being a resource to other families in need gives Cheree a sense of purpose and peace.

Amanifu expressed her desire to be a resource and a helpful hand to her family and community. During our interview, she talked about wanting to leave a home-where she and her husband currently house homeless veterans - for her children/grandchildren, 
but was concerned that her consistent support for them makes them too dependent on her. Amanifu noticed that her children/grandchildren's dependence on her sometimes causes them to become resentful when she dedicates her time to other people and causes in the community:

I hold on to [the] house considering phasing the vets out so my granddaughter and son could stay in that house. If I knew they were going to pay their bills, I'd do it. They ain't gon' pay no bills and I ain't carrying 'em. It's time for me. It's time for my husband. And I just want to do what I want to do. My kids is grown, my grandbabies, I support them — the ones that are here. And I don't want to babysit all day long. And don't be getting jealous cause I want to go help some disadvantaged kids cause I'm gon' do that. Especially if it's kids headed down the wrong lane.

Amanifu's testimony reveals her conviction to be more than just a mother and grandmother to her own children/grandchildren; Amanifu also wants to be a positive influence and supporter for young people throughout her community (motherwork; othermother). One way she wants to do this is by sharing her father's story as inspiration and encouragement for young people to fight for justice and liberation.

Amanifu explained that while her father was alive, he did not want her to spend a lot of time advocating for his freedom and justice. Amanifu felt like her father thought it would take away from their time together, particularly, because now she recognizes how much time advocacy work requires:

Man, now I gotta write his story. How am I gonna write his story? And then I thought about it: In his letters, he did write a story in the letters that he wrote to 
me. He did write his story — told me everything, told me about his original crime, told me about how he went to jail, told me about the San Quentin Six and the uproar in SQ, all of it. So, he did write his story. It's a lot of letters. I wanted to fight for him while he was alive, but he said no. Advocacy work is how I keep him ever present...if I don't speak for him, who will?

Not being able to advocate for her father in the way that she wanted (as a way of honoring her father's wishes), Amanifu is steadfast in her commitment to advocating for, and serving underserved, disadvantaged communities. Working with youth at-risk of becoming victims of the school-to-prison pipeline and entangled in the juvenile/criminal justice system like her dad has become Sister Amanifu's passion and life work. Amanifu's love for her father and the importance of his story is what fuels her work. Tyra described the struggle between trying to be present in her own life experiences while also being present and supportive of incarcerated loved one's and their children/families:

Maybe that's like an energy thing. Like you're putting too much energy here and you're not enough over there. Because I can't think of...that's one of the trickiest questions you've asked. I can't say well, “Oh I'm doing for him so I can't...” like that's [support] still benefiting the kids. That's a father or that's an uncle, and you're taking care of that person, that's a person they are looking forward to seeing. So that's still a good thing for that child even though you're giving your attention to so and so at that moment. More so, just draining you and making you less engaged with what you're going through with the next person. 
Tyra struggled with not wanting to be "selfish," but wanting to do the things she wanted without having to consider her incapacitated loved ones and their impacted offspring. Her dissonance is reflected by sisters in Harris' (2015:105) text, The Sisters Are Alright, where one explains "We are taught to take care of everybody else. We are always giving our strength away...We're strong for our children. We're strong on the job. We're strong if we're in church. It's always outpouring. We're never allowed to say, 'Hey, I'm really tired. Hey, I'm hurting. Hey, I'm exhausted. You're exhausting me. I need a break. I don't want to do anything for anybody.' We're just geared to give."

Asali describe the process of essentially losing herself as she tried to be a strong support system for her former lover:

...in my pursuit of what I thought was trying to be what I thought was loyal, I ended up becoming insecure and I ended up finding myself in a situation where I allowed my insecurity to override my personal judgement. And since I was so worried about what he was doing, I allowed myself to be placed in a situation where I let someone take advantage of my kindness.

There's a lot of things I did wrong. And I did them wrong with this person that asked me for a favor. But the way she did what she did was not something I would have ever done. It was just down right shady. And I felt like I was being set up. And I later felt like he was being set up too. And even at that end, I still protected him because I felt like, why would I let him be accused for something that I know for sure he didn't do.

Sister Asali admits to making poor decisions when it came to supporting her former lover. In hindsight, Asali feels as though she was taken advantage of, that her kindness 
was abused, and that her desire to be supportive and helpful overshadowed her judgement of certain situations. Sister Asali's clouded judgement also made her question and feel insecure about herself, which influenced her poor decision-making, and negatively impacted her self-care and overall wellbeing.

The testimonies of these women inform what we already know about the typical, and as some may believe, inherent caregiving nature of Black women. Their accounts also speak to the mental, emotional, spiritual, physical, and financial costs of being a caregiver and/or caretaker to an incarcerated loved one and the family/community, and how these women justified their behavior/actions (e.g. avoidance; social sacrifices).

\section{Lessons Learned}

Reflecting on both positive and negative experiences resulting from the unfortunate circumstance of their loved one's imprisonment, each of the women shared with me what they felt like the overall experience has taught them thus far.

When asked if she felt like her experience of losing multiple family members and loved ones to incarceration was a life lesson, Raychelle replied:

Absolutely. And I'm raising a son. I'm raising a young Black man right now. I refuse for my son to be a statistic. I will do whatever it takes, whatever is within my power to do to make sure that my son is not in a cage. I will give my last breath to make sure that my son is not in a cage. My daughters too. But more so my son because that has been the generational curse, not only in my family but in his dad's family also. So far, so good. He is the one out of the next generation to have different exposure. The ONLY one. Well, him and my nephew, but he's got a different mama - a different kinda momma, and that is the life lesson. To break 
this, how do we break this, how do we change this? What do I gotta do to make sure that my children are not sitting in the back of a police car at 12 [years old]? What am I gonna do differently to make sure that my son don't have to worry about selling no dope to feed somebody — to feed his brothers, his sisters? What am I gonna do differently to make sure that my children are not stealing because they don't have clean clothes? Life lesson, for sure! What am I gonna do differently with the little people whose lives I'm raising? That's the life lesson, for sure, for sure. It has taught me a lot and it's emotional. It has taught me that no matter how hard it gets, and no matter what your loved one's situations are, they still need somebody. So I would say that it's taught me to learn to be available; you can't always be available, but you have to learn how to do that. I had to learn how to be available to other people; make time, 'cause time is precious. You don't know how much time you're going to get with somebody. People go to jail for this and that, wrongful convictions; life and double life and all that kind of stuff. So it's definitely taught me to stay close to my children, and to raise me children to stay close to one another and to be each other's support system. 'Cause me and their dad ain't always gonna be there. But you fall on each other., you lean on each other, and always, always educate yourself! Don't take nobody's word for shit! Know the law - if you don't know anything else, study the law. Don't let nobody tell you about you. That is what I've learned the most because like, "[slaps on imaginary cuffs] you have the right to remain silent"...says who? Know that! Know if what somebody is saying to you is true! 
Sister Raychelle reveals that incarceration is common in both her and her partner's families, especially among the men. Hence, it is important for her to break the cycle of intergenerational incarceration and vicarious imprisonment for her children. Raychelle's experiences have taught her that to be able to break that cycle, she must do more than teach them right from wrong; Raychelle believes she must expose her children to much different things than what she and her brothers (and other family members) were exposed to (e.g. sport teams instead of, or in addition to neighborhood gangs; healthy food and lifestyle instead of, or in addition to drinking alcohol and smoking weed). Sister Raychelle has also learned the importance of showing up, or, being present for people. She understands how life can change in a moment, so it is important to invest time and effort into the ones we love when and while we have the opportunity to do so. She ingrains that message into her children, encouraging them to take care of, and stay close to, one another. Raychelle also emphasized the importance of education — not just formal education, but also education and understanding of self — believing that knowledge is key in making good life decisions.

Raychelle elaborated on her lessons learned highlighting that one wrong choice in an instant can mean a lifetime of pain and regret:

It has definitely taught me to stay close and think before you do cause sometimes when you are in survival mode, you don't think, all you know is “I'm on my next mission; however I gotta get there, I gotta get there regardless of who or what is in my way." And that can be life changing for the worst. For so many. Think before you do. We don't always think before we speak, but think before you do. 
Cause something, in a split second, lives can change drastically and there's no undoing that.

In general, Raychelle emphasized the importance of communication within her household - between her and her partner, between the two of them and their children, and specifically between her and her children. Raychelle demonstrates her commitment to instilling healthy values, compassion, and ambition by the conversations she has with her family, and the motherwork and role she plays in the community.

I asked Kali if she felt like her experience as a child of an incarcerated father was a life lesson. She responded,

Yes, I do. It's a life lesson because it's opened me up to be able to experience things; experiences make you the person you are today—good and bad experiences. Um, hell, it's taught me to realize that, you break the law, that's exactly where you gon' go. And that's not a place I want to be. So it's a life lesson in that sense. And even when I do break the law, being aware of the consequence and being able to see that firsthand. It's a life lesson in understanding the way the drug community was in Los Angeles back in the 80s, and how, you know, it was just poured into that environment and men growing up without proper resources, without proper education, without strong family systems, and getting caught up in that lifestyle. And you know, some of them are still in prison 'til this day!... from things in the 80s, from those hard, hard, hard drug laws that came about. So it's taught me to look at things differently and to understand that---to not be...to not look down on someone just because they've been incarcerated, you know? 
Kali highlights the importance of both reserving judgement about individuals' circumstances (e.g. incarceration) and acknowledging the structural and institutional inequities marginalized communities are challenged with (e.g. the Drug War). By doing so, she has learned how to be more open-minded allowing for more opportunities for learning and growth.

Erin discussed the ways the experience of having incarcerated loved ones permeated and influenced so many other areas of her life:

...So learning from that, going into—-just literally stepping into this season—still doing human service training through the Looking Glass, the business that I started, but also moving into being an instructor/professor, I'm very, very careful not to share those intimate things about myself. I care to listen a lot more than I speak. I don't know how I'm perceived at all, and I think I like that because I know that just learning in my professional life, that a powerful as these things can be, some people are just not equipped enough to take what I'm sharing and still look at me as equal to them or having the same potential or ability as them as they have not experienced that. So, in professional life, to sum it up, I've definitely learn probably not to share that.

Erin also shared about how one decision could change the entire trajectory of one's life, thus leading her to a "poindexter" lifestyle:

But still, that influence, almost that criminal lifestyle or that inability to potentially think about the options that you have in the moment to make a better decision. So yes, I've definitely learned, I see patterns and trends that have led to certain things and I think that's why I'm such a poindexter; I don't smoke, I don't 
drink, I don't do nothing, so yes, I have certainly learned some things by watching.

Erin's lessons involve practicing caution. As a result of her experiences with vicarious incarceration, Erin has become cautious of the way she navigates spaces, making careful decisions about how to engage certain people and situations. She also intentionally abstains from certain behaviors to avoid falling into patterns similar to those which culminated in the imprisonment of her loved ones (e.g. drug use).

Asali's lesson was similar to Erin's in that they each felt the need to be more cautious of other people and their true intentions. When asked if she considered her experiences supporting loved ones a life lesson, Asali replied:

Oh definitely...I mean, it was an unfortunate lesson that I learned with the relationship because in my pursuit of what I thought was trying to be what I thought was loyal, I ended up becoming insecure and I ended up finding myself in a situation where I allowed my insecurity to override my personal judgement. And since I was so worried about what he was doing, I allowed myself to be placed in a situation where I let someone take advantage of my kindness. But it was something that I learned because I learned I was too trusting toward a lot of people and it reassured me that everybody don't have your best interest at hand. Asali had one too many painful experiences and unfortunate consequences that led her to an overall sense of insecurity. She was insecure about herself, certain relationships, and situations - all of which could cause her to feel fearful, anxious, paranoid, among other unhealthy emotions and compromise her overall wellbeing. Therefore, Sister Asali had to modify the ways in which she engaged people and let them into her life. 
Cheree was very transparent in her response regarding what she learned from her experience. Interestingly, what Cheree learned seemed to have been things she had already been taught, yet, met with resistance until she had lived experience that validated certain truths:

Everything that you learned growing up, it was true. When they said, "you can't trust the police" it was true. Even though I believe-because I worked for the system - there was always a few good police officers that, you know, fight for you and be there for you. But in the end, you learn that every man is for himself when it comes to that. And every social worker-every entity that was designed to protect and serve was not - they were designed to protect and serve themselves....and the state of California. And that's what I've learned. Sister Cheree's ultimate lesson is that each individual puts his or her own interest foremost. As a former social worker — who took her job to be of help to families and communities in need - Cheree did not want to accept this claim. However, as she became more immersed in the work, navigating social services, the criminal justice system, etc., she began to understand the rhyme and reason behind the messages she grew up hearing. Sister Cheree came to accept the belief shared with her earlier in life that the institutions and systems in place (e.g. law enforcement, social services) are self-serving and not truly interested or invested in improving the lives of "The People." It is because of this that Cheree is compelled, and feels a level of responsibility, to be a resource for her family and the broader community.

Tia explained the mental and spiritual lessons she has learned, and practices she has adopted as a consequence of her experiences: 
Yes, I believe it's a life lesson and in some of my presentations I let people know that I didn't choose it. I didn't choose this lesson. Cause in life, we get to choose our classes in school; we get to choose... But I didn't choose this, it chose me. It's definitely a lesson. I've learned how to do a self-inventory of myself and check myself. Talking about stuff, talking about the situation...And I just had to remain humble. It taught me how to listen and not be so quick to just start talking. We need to know that we don't learn from talking. We learn from listening. So it's taught me to listen and pay attention and not be so quick to just start speaking. I mean speak up! But don't...it's almost like when you're in front of $d$ or pulled over by the police—just stop running your mouth. Gather your thoughts. Think about what you're getting ready to say. It's taught me that I don't know as much as I thought I knew. It's like, you have to learn how to just be quite and listen. What is my next move? Listen to your inner voice. Listen to yourself. And just take your steps strategically. You don't have to be everywhere. I was doing that for a long time. I was trying to be everywhere "cause somebody told me that I needed to be everywhere.

Tia accentuates the importance of getting in tune with one's self. Learning to slow down, gather her thoughts, look inward (self-inventory) and "listen to [her] inner voice," has been one of her most valuable lessons. In doing so, Sister Tia has also learned how to be more intentional about to what and where she dedicates her time and efforts.

Tia describes how the experience of supporting her son has made her want to reach out to, and connect with her family and distant loved ones for the fellowship and to understand more about herself and Jason: 
It helps me to realize what's important in my life. It also made me-after my son's suicide attempt, which is now going on three years-I said it's time for me to see the family...I wanted to lay my eyes on them. I wanted to talk to them. I wanted to talk to them about my son. I wanted to get documentation about how many in my family have been incarcerated. What are their age groups? Who's suffering from mental illness in this family? Where did this come from?... I needed to find out who I was, where I came from, who look like me, who's other sons are suffering from mental illness and what are they doing about it, and how can I be of help? How can I help my cousins (all of our kids are around the same age) — how can I help my cousins kids who are going to the pen or in jail and what have you?

The experience of dealing with Jason's incarceration and mental illness reminds Tia about the importance of knowing and understanding family histories and heritage if we are to understand ourselves, and make informed decisions for ourselves, our children, and generations to follow.

When asked if she believed her experience with RiRi's incarceration is a life lesson, Suzie answered:

Absolutely. I really do. I think that had this not, had this journey not started for us, I'd be among those same people [she was just talking about]. I think I'd be closed-minded, I think I'd be resentful, I'd be accusatory, I think I'd be dogmatic. I do! I think the only way I could have pushed all of that out of me was for it to impact me in this kind of intimate, up close and personal way. I really do. Cause I think I only would've seen half of the picture. I tell people all the time that I 
wasn't even big on prison ministries. You could give me any ministry in the church, and I'm going, I'm going...prison ministry was the furthest thing from my mind, cause if they did something to go to prison, they probably needed to be there. So I absolutely think - because it stretched me, but it also gave me a deeper understanding of who God is and who is it that God loves. Right? Cause I had a very narrow view of who he loves; they've got a very narrow view of who God loves. Right? So, that's my yes.

Suzie describes the various ways RiRi's incarceration transformed her spiritually. Suzie admits becoming more open-minded and less judgmental. Importantly, Sister Suzie's understanding of God has become greater and more clear, so much so that her ministry has expanded into prisons - a route she never had an interest in taking. Overall, Suzie learned that discomfort is often an antecedent to growth, and the pain of dealing with RiRi's imprisonment grew Suzie to the point that she feels there is no obstacle she cannot overcome.

Amanifu shared that the most powerful lesson for her came from her father before his passing:

In that time that I spent with my dad, I thought it was pretty interesting that the one thing he told me before he died was: "Honey, I need you to work on your anger. Down the road, you're going to come across a few things and you're going to need to have your anger in check. Honey, I want you to work on your anger." I remember saying, "nope, not today!" I think the hardest thing with dealing with my anger is I don't have no problems with people seeing me raw. You can see me good, bad or indifferent. If you gone be in a relationship with me, that's gon' be 
up to you. I just am who I am and you either accept me or you don't. And I really don't care; it doesn't faze me one bit. It depends on who it is, sometimes it does phase me. But with that, I just decided that I wasn't going to run from the anger. I want to be mindful about it and how I'm processing it. But there's been a couple times this summer...I think the hardest part about the anger is when the anger is stirred up from the work that we're doing, and when it's stirred up from other people doing the same work. I hate mess, and I hate messy people. Don't come to me with no mess. Before, I would allow people to come talk that mess to me, and I just realized, I need to stop allowing that, I need to shut that down. That's a boundary. Here I am almost 60 and now I want to draw some boundary lines! Just trying to figure out when it's appropriate to operate in my anger and when it's appropriate to heed in what my father told me. I do know that because I am a confrontational person, it's best for me to just say what I need to say in the moment, or if I'm too emotional, say "hey, I really want to talk to you about this right now, but I need to deal with my own stuff and can we meet in a couple days?" "cause it's something that I as a person need to be able to communicate when things are not good. When I think about that, I think about that with people in the movement, more so I'm thinking about that now days with my family. And how do you address what's affecting you and say what you don't like without it being blown up? So, it's a delicate dance, I'm still learning and I'm still practicing. My biggest thing is, we all know we're living in a broken village. There's broken villages everywhere. So when we escape our village and go outside and try to help the larger village, am I fronting? What's wrong with my 
village? Am I addressing the issues in my first village? Any and everything I do outside my first village is phony, it's just full of shit, cause what you doing at home?

Amanifu identified anger she needs to deal with; however, she admitted to struggling to do so at the time of our interview. It was the overwhelm of dealing with family, community, and social justice issues that impeded her ability to do address her own anger, especially because much of her anger was incited by people in her own village (family/community). Like Suzie questioned her qualifications to serve as a mentor in the community when her own daughter was imprisoned for a heinous crime, Amanifu questioned her authenticity as a mentor and activist calling for others to heal our broken villages, when some of her family/community relationships were broken too.

Nevertheless, Amanifu learned that she has work to do when it comes to getting a hold of her anger.

Tyra also believed her experiences supporting incarcerated loved ones has been a life lesson, explaining that,

...it kinda, almost molds you into who you are. But it is a part of you. You know? If you never had them people or that person be in your life, and be incarcerated, and alter...you know, like a butterfly affect almost, like every little thing matters, so why wouldn't something that big matter?

\section{Conclusion}

The sentiments of the respondents reflect the idea that healing (e.g. protecting self from ill-intended individuals, addressing anger issues) is necessary not only for themselves, but for the larger Black community. The women acknowledged their own 
accountability and responsibility in addressing intergenerational trauma and divisions among Black people. Each of the women either directly spoke, or alluded, to the need to reach out and make a positive impact on family/community members-especially younger populations, who will ultimately be passed the baton in the journey to achieving racial healing and equity.

Just as the women practiced a multitude of coping strategies, they also had a diverse set of self-care practices and resilience strategies. For example, some of the women attended healing circles (self-care practice) in hopes of finding support and potentially building connections within the community (resilience strategy). Some others dedicated their time and efforts to service in the community (self-care practice) with the intent to find and/or pursue purpose (resilience strategy). Still, some others began setting new boundaries (self-care practice) to avoid negative thoughts and people, and embrace more positive, healthy thoughts, behaviors, and people (resilience strategy). Most of the women used a combination of self-care practices-like Amanifu, who attended Safe Black Space ${ }^{\mathrm{SM}}$ community healing circles and served as a youth mentor; and Oprah, who was firm in maintaining boundaries and traveled often — which helped them manage resilience in everyday life. 


\section{CHAPTER SEVEN: THE IDEAL}

Healing from the CJ System: Black Women Impacted by Incarceration Envision the Future

Considering that each of the women in this study performed various levels of motherwork, I was curious to understand why. That is, I wanted to know what they were working toward and what they envisioned for the future of their families and communities. Thus, at the conclusion of the interviews, each of the women were asked, "What is your role in your vision for your family and community?"; and, "What do you need, and what do you think the community needs to achieve the vision you have?"

Tyra described wanting to see unification instead of competition among community members and Black people in general:

First of all, just understanding, getting along - I don't even wanna say getting along, it's a word that I can grasp right now but like...it's like always a competition or a one-up with our people. And it's like, if I'm growing, you're growing; and if you're growing, I'm growing. So why we gotta have that competition, that shift of energy, when it's not necessary. It's more of a mindset. And a lot of people don't want to do the work. It's like, I'm willing to do the work, but it's a two-way street, so it's like if that other party ain't willing to do the work, then the work ain't being done. And that is definitely what we need because it's a little thing that's made into a bigger thing and that avalanche or snowball effect has caused people to like blur their reality.

Tyra's sentiments reflect those of Na'im Akbar (1996:16), who strongly asserts that "one of the most serious disturbances of community advancement coming from the slavery 
experience is disunity or 'community division'. The competition (e.g. 'Keeping up with the Jones'; colorism; gang wars, etc.) Tyra calls out is a clear representation of the consequences of the divide and conquer method used by our captors to maintain division between us and prevent us from understanding the value in our common identity (Akbar 1996:42).

Tyra also emphasized the importance of education and positive messaging:

So education, that's like my foundation. I'm getting into my platform, but when I do develop my platform, I do want it to be more so like me being able to display messages on a constant basis. And not just messages in general, but positive messages that put us in a better position in life. You know? I don't wanna be sitting there like, "rake it up rake it up, back it up back it up, twerk, twerk"; it's duality involved in that. People just push that all the way to the right when you supposed to be a little bit more to the left. And then everything will be alright. Cause nobody is perfect. We all got our lil' vices or whatever we want. But, my position in making things better would be more so to just let people know they're not alone. To let people know there is a way out if you're seeking that. If you're not, to each his own, you know what I'm sayin'? But if you is, there's possibility. You know?

Positive messages through music, media, culture, etc. is imperative to psychological and emotional wellbeing (Jackson and Boutte 2009). Akbar (1996:15) affirms this notion asserting that, "if we begin to direct our children's attention to strong images like themselves, they will grow in self-respect.” Thus, positive images of Black people in music, art, movies, etc. are important to the wellbeing of our race and the way we see 
ourselves, and the way we see and connect with one another. Considering the lack of unity, education/knowledge, and positive messaging within the Black communities she navigates, Tyra expressed concern for the mobility of Black communities due to mental bondage:

I don't even want to say knowledge because I wanna say more knowledge on certain situations because a lot of times sometimes people be stuck in they own heads and their own opinion of stuff, they need like an avenue of more openmindedness. Something like that. You know what I'm sayin'? Cause Black folks are stuck! I don't wanna not-I'm trying not to say that, but it is what it is. We're stuck in like, being mad. Ok, that's one thing but what are we going to do about it? And it's easier said than done. So we need whatever push that is to get us out of that, what we're mad about and more so than what are we going to do moving forward.

Tyra's sentiments shined light on the psychological rut many Black people find ourselves in. Akbar (1996:31) explains that "the process of human slavery is ultimately a psychological process by which the mind of a people is gradually brought under the control of their captor and they become imprisoned by the loss of the consciousness (awareness) of themselves." Unfortunately, the lingering effects of enslavement, and the racially oppressive systems, institutions, laws, policies, and practices that followed continue to have a tight grasp on our people, and "awakening" the masses is a monumental, time and energy-consuming task. 
As she explained earlier in our interview, Amanifu discussed a desire to heal the Black community with compassion. When I asked about her role in that healing vision, she said her role was to be

... an elder to impart knowledge, wisdom, advice and experience on younger generations. That's what all of our [elders] role is. Are y'all gone listen to everything? Of course not. But it is our role as elders to wrap our arms around you and say, "that's alright baby, but next time..."

Like Amanifu, Tia believed her role in the community was that of an elder who could provide guidance for the younger generations:

I think at this point, my role is an elder role and pouring the wisdom in. Cause I see this happening by y'all. Y'all got the voice, y'all got the energy, y'all got the knowledge, y'all are spit fires, y'all ain't breaking down with arthritis, y'all ain't got all these kids and grandkids, you know? Folks perishing away all over the world; seven funerals in a month, y'all don't be dealing with that right now. It's like, I'm burying uncle after uncle after aunt, and it's like, whooooo, goodness gracious. But I think what is gon' save the community is the younger folks that are woke and not afraid or can pull from the elders and drive it home. Y'all can do what we can't do. Y'all can say what we can't say. Y'all can speak truth to power when they think that you don't know what you should be knowing; but you don talked to an elder who don' told you about stuff... I want to reinvent myself. I want to pour into you, the young folks, the other folks...Let's stop all this talkin' and present a plan. We do so much damn talking it gets on my nerves! 
Amanifu and Tia each expressed their desire to be conduits of information for younger people to understand where we have been, where we are now, and where we have the potential to go. As elders, they find value in the knowledge and wisdom they have accumulated during their time on Earth, and they wish to pass it on. Akbar (1996) advised that information is the roadmap to awareness, thus, Amanifu and Tia's assumption of roles as conduits of information is vital to building and maintaining healthy and thriving communities.

Tia also made it very clear that she wanted more transparency between elders and young folks:

We need to start being a little more real with our young folks. When we talk about the future, like insurance, and burial, car insurance, sewing classes, little things. When presented with the questions about her role in, and her vision for the community, Suzie Cain described her ordained role as a change agent:

I think my role in my family and community is to help lift up, help lift us to a place of greatness that we really deserve, that we really are capable of. And my vision for my family and my community is that we would be able to live free, to be able to excel, use all of our creativity, be able to live in peace, not constantly looking over our shoulders, that we will prosper. That we will prosper and flourish. We pray every morning at 4:30 and one of the ways that I state my prayer for my daughter is that our family will be made whole again. And her coming back will make our family whole. I pray, I mean I believe that that is one vision for my family, but I also believe that wholeness is the vision I have for our community. Wholeness. 
When I asked Tia what her vision was for the community, she told me:

For everybody to be on one accord as much as they can. It would be boring if we were all the same. It's time for some healing.

In ancient African teachings, there is a concept called Ma'at. Originating from the ancient Egyptian Goddess of truth, justice, harmony, and balance, the principle of ma'at is considered the "operational function of life and that of heka (magic) the power source which allowed for it" (Mark 2016). The spirit of Ma'at is translated into a concept-a model for human behavior, with order, justice, and harmony at the center. Living in accordance with this principle aligns with what Suzie describes as her vision for her family/community, and Tia's ultimate desire, as well.

Suzie describes methods she believes are necessary to manifest this vision of wholeness, highlighting a need for education and collective independence, which can and will only be achieved by unification:

We need education, we need jobs, we need security. Security looks like independence. We are a very resilient people, we are a very capable people, we are a very creative people. The problem that hits us most is that we're not allowed to be independent and find our own way and use our own way. So much has been shoved on us until we have forgotten what our way is. Security means I am not bombarded, my community is not bombarded by outside forces constantly, constantly coming in. Security look like us being able to buy within our own community, sell within our own community, hire within our own community, educate within our own community. Honestly. I mean, go out certainly if we wanted to, but not because we are dependent upon it. That's why I'm saying 
independent in our own ways. That's what security looks like for me and my family. If you've noticed, most of my family works for themselves. You know? I mean, by hook or by crook, we survive not working for somebody else. And it's a fulfilling — not fulfilling because our purses are full—but because it's our own work. It's our own work and our own effort. And that gives us a sense of balance. And as soon as RiRi gets out, she's gonna be involved in that same thing. Right now, she's doing a college program, Business Management, and she's already written a business plan about the business she'd like to start up. You know? Not coming out and getting a job for somebody else. We just don't flourish in that environment.

Suzie is passionate about Black people making our own way, becoming less dependent on (white) people with power by using and enforcing the power of The People (i.e. the masses). Her sentiments are reflective of Akbar's (1996:15) argument that our present position as "consumers and laborers, rather than manufacturers, planners and managers, has a lot to do with [our] sense of inferiority." He further maintains that "the ultimate human power is our mental power, our consciousness, our awareness" (Akbar 1996:30). Therefore, if we are to achieve the type of collective independence (as manufacturers, planners, and managers, etc.) and harmony (through justice and balance) Suzie envisions, she insists it will require education (knowledge), unification, and interdependence. For, "the most potent weapon that we have in developing any kind of independent freedom is through unity" (Akbar 1996:42). 
Elaborating on her vision for the community, Tia expressed a desire to see young people creating new, and innovative opportunities for other young people that are transferable to future generations:

I don't need a whole team, I just need a few people to pull together a plan without it being about them. Pull together a plan for the city; and hopefully one that can be passed on to others. Nothing too intricate but not difficult. Like a life planwhen kids are in special education, IEP — an individualized life plan that all the kids should have. Everyone should be allowed to have the same opportunities. The same kids living up in [well-to-do suburbs] should have the same opportunities as the kids living in [disadvantaged communities]. They should get to experience what's going on in each other's worlds. I don't want my granddaughter growing up with so much division; we need to learn how to get this together before we all perish... I just need a few people that are ready to sit down and devise a treatment plan for the city that's going to promote healing, that's going to promote jobs; kids need to be able to look and see where they can be. There needs to be training in the schools too.

Tia emphasizes the grave importance of investing in our youth, highlighting equal opportunity as a key component in doing so. Tia proposes forward planning for education, training, and jobs to even the socioeconomic playing field for our younger generations, which will in turn, allow for healing to begin to take place in our communities.

Finally, Tia describes what she wants to see in the community and how she wants to see the community show up for one another: 
I want something put together that when there is a crisis, we have a crisis intervention team that responds on site, or we have the resources for an immediate response. 'Cause [local] Pastor shouldn't have to show up for everything. That can wear on him and we don't know when he gon' break. You know? But there's so many other pastors and people that can show up.

I asked Cheree what she believed her role was in her vision for the community and she said:

To be that middle man. I would like to be able to be a person who is able to hook the knowledge up with the person seeking the knowledge and to be a voice for those who don't have a voice; for my family and for others; to figure out how I would be able to hold people accountable who are taking advantage of those who don't know no better.

Like several of the other sisters, Cheree emphasized the importance of education, and the need for people who look like us, and have our best interests in mind, to occupy positions of power:

More educated us [Black people]. More people in positions, in office to make the changes that we need in order to make programs work for us. I think we need the finance. Maybe even set up programs where-I know in some states, they have programs where if you don't have any money, they have money for legal fees and different things they can do. (I don't know, they may have it here, but I didn't...) Maybe more pro- bono attorneys. You know, really good attorneys, not just people who are sitting in the position just to say that they took a case. More officials to hold people accountable when they take advantage of others. That's 
not gonna happen but that's a nice thought though (laughter). It was a beautiful thought.

Cheree wants people to have access to resources_-regardless of their socioeconomic or financial status. Because she has identified a lack of access and availability, she has assumed the role of a "hook up," or resource, to fill a long-standing gap. Abrams et al. (2014:511) reminds us this is typical behavior of SBW: "She will assume multiple roles without receiving acknowledgment. If she recognizes a need, she puts on the appropriate 'hat' and works to address it."

When I asked Asali what she believed her community needs to thrive, she highlighted a need for positivity and acknowledgement of the trauma engendered by incarceration:

What I would really like for our community is for us to be so much less negative. In more ways than one, decrease the negativity. I do want to bring more focus to the mental health of the incarcerated and what impact trauma has had on our lives and-I know that trauma is like the coin-word right now-but knowing that incarceration is also increasing the trauma and that we're coming out of these situations worse than we started. We need to create healthier environments and stop perpetuating this environment of cheap labor. I understand everybody is about a dollar, but its slavery all over again. And then also we have laws that are supposed to make it easier for people to get out of prison and out of jail situations to be able to become employed, but we still constantly find ways to make it harder for them. So if you if you gon' forgive and forget, forgive and let it go. And don't 
say people can expunge their records and every time they turn around, they have to divulge it. It's more of a systemic change and a trickle down to help our community overall.

Asali calls out the systems that are supposed to facilitate the successful transition from imprisonment to freedom after one has served their time. Instead of prioritizing public safety and healthy environments, the criminal justice system,_-including, but not limited to probation and parole departments, substance abuse programs, housing servicesmakes transitioning from incarceration back into society extremely difficult for the formerly incarcerated and their families, often creating more drama and trauma.

Asali described the ways she is actively working to become what and who she wants to be to move her vision for the community forward, including becoming more educated:

What I'm doing is becoming more educated on the topic not just from a personal level, but also from a policy level and also from a more engaged mental health level, trying to enhance my mental health skills and become more involved in that. Trying to seek out more education on the topic and just trying to help heal our community as a whole. And help others heal our community as far as addressing mental health in our community which is something I was steered away from years ago because I did have a record. And finding my voice, or regaining voice and seeing that I can't allow other people to tell me what I can't do. And offering that sense of hope back to the community and allowing other people to see that we are told what we can't do so often, we really have to be 
more positive and be our own self promoters and encourage each other and ourselves and hopefully we can do better for each other.

Asali mentions being steered away from pursuing a career in mental health because she had a record. However, individuals like Sister Asali-who has lived experience with the criminal justice system and educational training in social work-who have great potential to contribute valuably to conversations about the impact of the criminal justice system on individuals and influence education and policy related to incarceration and reentry. Asali intends to find her voice and identify where she can be the most helpful to the community.

Educating self and community was a common response among participants and a primary goal for Erin:

My role...I feel like this might sound so grandiose; I hope I don't sound ignorant but it's something I think about literally every day. I think I am going to bethrough climbing this ladder of an educational career, in education and academia-I believe there is going to be a day where I can speak about this because my influence is so solid and my ability is so clear until I can share what the hell I want to and there's nothing you can do. It's not like you can determine if I'm demoted or not give me a teaching job. But it's like, I'm so in an influential place, it's until I can share what I need to and do what I need to so that people can be elevated. And it's going to come. Every single day I write a letter to God and I can literally feel it's going to happen. I don't know if I'm going to be on TV or doing motivational talks to millions of people, but it's going to happen because all of this - this learning how to compartmentalize it, and not being able to speak to 
certain people about it because it might make me look unprofessional, these are only things that are making me more skilled to be able to talk about it once the time comes.

Erin believes her experiences and her educational training have given her the ability and skills to assume a position of influence. She is intentional about using her position as a teacher to educate people about social problems and motivate them to tackle the issues that move them. In closing, Erin said her hope for her community [Black people] is to "keep that desire and just keep trying their best, there's going to be some resources coming through."

Kali's vision was to liberate and heal. She revealed her role in her vision:

To awaken - I think that's what my role is. Since I've been awakened, there's this passion flowing through me to try to awaken others in my family and my community so that we can all be on the path to liberation and self-healing and not wanting to leave anybody behind. Wanting to take on those challenges; wanting to help somebody else. You can see the ignorance and then maybe you stop, you stand back, you at least want to give those words, those experiences, the statistics, so that people can understand and maybe overcome their ignorance and maybe become awakened later in life like I was.

Kali, too, believes that formal education is instrumental in her vision for herself, and education by way of experience is vital for the community. She is also passionate about sharing her knowledge and understanding with her family and community in hopes that we all will want to liberate and heal ourselves from oppressive systems and institutions. 
When I asked what she needs and what the community needs to be liberated and healed, Kali replied:

I struggle with that because I feel like I need—me personally, I need education. I'm not going to say that for the community because look at Ms. Pat [woman in EEC group]. Wisdom, all over. Wear it like a crown. And still has not finished her BA. So I know for the community it's not only about education-it's about experience, this is about power, it's about spirituality. Me though—always comparing myself to that white space that I grew up in for so long-- education is of high value for me. So I feel like I can't be the best for my community until I attain that level of education. So that's something I'm working on. A goal that I'm still tryin' to attain. Learning from others is also a part of education so putting myself in spaces where I can learn from someone is also important. Oprah also explained a need for collective unity and commitment to supporting one another:

...there is a need for I don't want to say being my brother's keeper, because that almost insinuates almost a kind of responsibility for others, and I don't think anybody is really responsible for anybody else. I really don't. But I do think that there is a need for honest and authentic demonstration of commitment to one another. What that looks like, it could look like a lot of different things. It could look like respect, it could look like helping to ensure some of your basic needs are met, it could look like a lot of different things, but I think that's a place where it starts. When I think about the amount of people that are incarcerated, and the amount of people that are broken and black — and not to dismiss my white 
brothers and sisters - but when I look at those numbers, one of the things I immediately think about is they fell between the cracks. And maybe that's not the case for everybody, but somehow, they fell off somebody's radar. And maybe if they were on somebody's radar, they still made the choices they made and landed them in situations, perhaps, but what I do think is there needs to be a high level of care and commitment for us individually in terms of the community wrapping their arms around us - especially those who are most vulnerable. I think that is a need. The other things is that we need systems that allow people to be independent and be self-sufficient in a way that is integral and a way that is ethical and a way that is healing. Not just these quick, bandaid do this for now, type of things. I think people's spirits are under real assault as a result of what is transpiring. I think there's a need of awareness around what the prison industrial complex does directly and indirectly to our communities. I think that that's a heightened need. I think my role first and foremost is to always show up with love. I think that's that important. I think as cliché and as basic as that sounds, I know that that goes a long way because I've seen it.

Oprah shows concern for the people who "fell between the cracks"-likely, the same young people Sister Amanifu invests her time with to avoid their falling off anyone's radar and into the school-to-prison pipeline. Oprah calls for more pointed efforts to care for and address the needs of vulnerable populations (e.g. individuals reentering society after imprisonment and their families), and insists that our methods for addressing these issues must be respectfully and ethically carried out. 
In accordance with the other women, Raychelle emphasized the importance of knowledge and education in her role as a mother, and in her vision for the community. She discussed how she was beginning to impart strong values and positive teachings to her children:

My vision for my family is that I am leading by example, and that me and their father are taking the necessary and appropriate step to bring our children up in a manner where they know how to utilize their tools in the world to not let things and people hinder them. For them to be knowledgeable. It's that important. It's that important for you to be educated. It's that important for you to know yourself. It's that important to know what you come from, know your roots, so that... One of my biggest fears used to be that they would fall victim because they're taught...there is white privilege, we know that exists, but that don't mean you're less than. Teaching them how to think outside of their box, how to maneuver outside of their box. How to not stand in a box. Don't just stay right here 'cause this is where you think you fit. Get on out there. We gotta teach them better; when they know better, they do better. You be who you are, you will have those who love you; there will be a handful who really genuinely love you, and you will be hated but the rest of them and that's ok. Because they don't define you, that's not what you're made up of. Let it be, it is what it is.

Raychelle is clear about being the change she wants to see and modeling positive behaviors for her children. Although her testimony reveals on many occasions that the SBW or superwoman complex compels her to want to save the world, Raychelle understands and finds it critical to impart strong, ethical values in the home first. Her 
sentiments echo that of Akbar (1996:15) in which he declares that as a collective, "the ability to influence our environment in some small way is the first step towards building or restoring our self-respect."

When I asked her what she needs and what she thinks the community needs to achieve her vision, Raychelle stressed the need for unity and open-mindedness: I think two things: I think being open minded and really, really being able to unify. People are in a box. You know your way, your way works, it's been working for you for 20 years, and with the hiccups it works. But it doesn't always work for everybody connected to you. It doesn't always work for those surrounding you. But if we can be open -minded and step outside of that box, not even be in a box, but hanging out in this hoola-hoop (laughter); what can I do for you and what can you do for me? How do we do that genuinely? How do I genuinely and respectfully, and be available to you in a way that I know how, but in a way that you receive it? Right? That is unifying. That is saying, you know what? You're not in this alone, and I will do my best to be there for you, to support you, to walk side by side with you. Shit if we don't know, we don't know but at least we could say we tried together. Feedback. Nobody's open to constructive feedback. Oh, she's hating on me. Bitch, ain't nobody hating on you. We're just trying to tell you about your wig, dang (laughter). But again, that comes from being open-minded. Tell me how I can improve. Tell me what you see, how this could be better; how I could do this better. Or maybe an idea you could share that I can implement for it to be better, for it to boom, then it's a bang! If we had more of that. And I try that in my personal life, I try that at work, 
I try that open-mindedness and I try to unify. Let's get together outside of this... how do we keep our children connected? How do we support us? In my football family and my cheer family—I don't do everybody—but my handfuls, we have that unity. The moms, the dads, we sit around and talk about life, our ups and downs, our highs and our lows... and girl, I never...15 years ago? I'm not 'bout to be sitting around talking 'bout...but being open-minded, I don't know how these people can pour into my life. We're one of the youngest couples and it's so amazing that we pour into a lot of people. You could be old as my mama, but you never know though! You never know! So being open-minded and wanting to unify. You gotta want that. You gotta want somebody to be on your side, you gotta wanna be on somebody's side. People need to act right!

As for her own role in achieving her vision for the community, Raychelle said she made it a priority to "root for other people's children...encourage[e] them and provid[e] hope."

Collectively, this group communicated that information gathering and sharing is a core requirement for community restoration, healing, and growth. Whether by formal education or self-education, knowledge of self and society (through historical teachings and awareness) is a major component to the collective healing and advancement of our people. With knowledge and information, one will inevitably gain a greater understanding of self. Self, however, cannot be fully realized without understanding of family/community, society—-the people and things which influence and help to shape individual identity.

The African concept of ubuntu, translating to, "I am because we are," emphasizes the idea that our sense of self is shaped by our relationships with other people. 
Theoretically, ubuntu means believing the common bonds we share within our communities are more important than the divisions within them. Practically, ubuntu means acknowledging and appreciating differences, and sharing responsibility in the sustainability of our families, communities, and cultural identities. Akbar (1996) powerfully asserts that unity does not demand or require uniformity. Thus, we can acknowledge and appreciate our differences and use them to the advantage of the collective as opposed to allowing our differences to divide us. Interdependence within our communities is imperative to achieving our independence from our oppressors. Institutions of healing from racial trauma and racial oppression are imperative if we are to be restored from the damage and wounds cause by the racist institutions, like the criminal justice system, built to keep us in a subjugated position, and prohibit us from achieving ma'at (harmony and balance). 


\section{CHAPTER EIGHT: DISCUSSION AND CONCLUSIONS}

When I began this project, I set out to gain a clearer, more complete understanding of the resilience strategies Black women used to navigate daily life while also supporting an incarcerated and/or formerly incarcerated loved one. The testimonies of the women in this study told stories not only of resilience, but also, willful survival and powerful resistance to racist power structures with righteous, feminine action. In the face of painful loss, constant uncertainty, and extreme distrust for, and disappoint in, humans and institutions, the women clearly demonstrated a fierce battle for preservation of self, family, and community.

A central component of this research was the ways in which Black women manage resilience and thrive under oppressive circumstances, with a specific contextual focus on Black women impacted by incarceration. By gathering accounts and testimonies to hone in on the day-to-day thoughts and practices these women use in the struggle to survive, sustain, persist and thrive as individuals and for their families/communities, I explored strategies of resilience. I used my lived experience as a Black woman impacted by incarceration most of my life to ask the appropriate questions to make visible and shed light on common experiences of women facing this reality, and I used my privileged position as a community-engaged scholar to gather evidence and validate these experiences. Thus, this research theoretically contributes to the field by calling attention to the particular ways Black women shoulder the responsibility of sustaining Black families and Black communities as the phenomenon of mass incarceration continues to plague our communities, inhibit our upward mobility, and sustain racial inequality. 
The narratives of the women from this study provide insight into the ways Black women impacted by incarceration strive for social transformation and commonweal in their daily activities and practices. Though many feminist and womanist scholars have explored various ways in which Black women have and continue to actively work toward achieving social change, these studies have not examined both the effects of, and responses to, our experiences with the criminal justice system and the havoc it wreaks on our lives as we fight for individual and collective survival. Thus, this research fills important gaps in the literature by focusing on the intersections of race, sex/gender, and social position, and the specific ways in which 1) the collateral damage of the criminal justice system is burdened upon and fought against by Black women; 2) Black women resolve to resist, survive, persist, and thrive with the criminal justice system playing an antagonistic role in their lives; and ultimately, the ways resilience is built, exercised and exemplified.

\section{The Feel}

In summary, the "feel" or, the experience of supporting an incarcerated and/or formerly incarcerated loved one was difficult for each of the women. Whether they experienced feelings of sadness, neglect, or stress every day or periodically, each of them described feeling pain and sorrow surrounding the circumstances. Importantly, many of them expressed grave concern for their loved one's wellbeing and the wellbeing of the children and other family members the incarcerated/formerly incarcerated individual(s) left behind/was returning home to.

Extant research highlights how and why families support their loved ones and the emotional experience of providing support. Women of these studies have expressed 
feeling some level of familial/communal and personal obligation to be supportive of their loved one(s) (Hairston 1991; Comfort 2008; Harris and Miller 2002; Turney, Schnittker, and Wildeman 2012; Hiller 2013; Holligan 2016; Hart-Johnson 2017). That is, they felt a need to be supportive of the incarcerated/formerly incarcerated individual as well as their children (and/or other family members) out of relational obligation, with the intent to assist in the survival of all impacted by the individuals' removal from home and community (Hairston 1991; Comfort 2008; Hiller 2013; Hart-Johnson 2017). This study builds upon previous research by not only affirming the various reasons and ways Black women support our incarcerated/formerly incarcerated loved ones, and the impact giving support has on their lives, but by adding how we cope with juggling supporting our incarcerated loved ones, our families/communities, and ourselves, and what we need to ensure the sustainability of ourselves as individuals and our beloved communities in the absence, and upon return, of our incarcerated loved ones. With this research, we have elevated both the socioemotional navigation strategies of this population of Black women (and undoubtedly others like them/us), and what they (we) need to maintain, sustain, resist and persist in the face of adversities connected to vicarious incarceration, specifically, and systemic racism in general.

There were a range of emotions and reasons that went into the women acquiescing to becoming a part of their loved one's support system. Although there were mixed emotions surrounding their ultimate decisions to be supportive, all of them took their respective roles seriously. They wrote letters, managed finances to be able to pay for phones calls and commissary (among other things), made regular visits, and cared for children, to name a few of the ways they offered support. These approaches to support 
are consistent with other studies that have examined how families are impacted by, and respond to, a loved one's imprisonment and reentry (Hairston 1991; Comfort 2008; Ella Baker Center 2015; Hart-Johnson 2017).

With the acceptance of their supportive and caregiving roles came additional responsibility. Additional responsibilities for many of the women meant loss of time, money, access (e.g. to employment), among other important things. For example, many of the women discussed how expensive it is to keep money on the phone for their loved ones to be able to call—money that could have been used for other needs and personal desires. Loss, however, was also much more than material. For example, several of the women discussed the loss of relationships; that is, the ability to maintain closeness and a certain level of emotional security with the incarcerated loved one(s), and friends and family on the outside. In her study about the ways prisons shape and infiltrate the lives of women with husbands, fiancés, and boyfriends on the inside, Comfort (2008) found similar responses among the women, further substantiating the narratives of the women of this study.

In some ways, the incarceration of their loved ones changed the women's entire lives; in other ways, it did not change much at all. Suzie Cain summed it up nicely when she explained, "There are some days when I carry [the daily stress] better. Cause there are days when I wake up in the morning and I am just so sad. I just wish we didn't have to do this. But our story is a rich part of my life." Considering the time her family reserves to be available for RiRi to call, and to travel several hours away to visit; the effort and sacrifice to manage money to provide her basic necessities and pleasantries; dealing with the harsh reality regarding her whereabouts and the conditions under which 
she lives; bearing grave concern for RiRi's health and wellbeing; all of these were things Suzie wished she "didn't have to do." However, as RiRi's mother, Suzie was prepared and willing to do whatever she needed to support her daughter-incarcerated or not. When she told me, "I was going to face it...The fact is, you are still mine," she was implying that it was her responsibility as a mother ("you are...mine") to stand by her daughter ("I was going to face it"). Similarly, most of the women expressed they were gripped by familial bonds that essentially required, and sometimes compelled, them to adapt to any and all circumstances. In other words, although things may have to shift or be modified to accommodate the circumstances of the time, life must go on, and with our identity as Black women comes the expectation to hold it all together (Hairston 1991; Bailey 2011).

The experience of supporting an incarcerated loved one also tended to exacerbate other daily concerns of the participants. For example, Asali discussed her reluctance to apply for certain jobs because of the extensiveness of background checks that could reveal her proximity to her incarcerated cousins and lover and potentially damage her chances at securing a position; Amanifu referred to conflicts within her family stemming directly from the politics of her father's imprisonment; Kali described the difficulty of living in a low-income neighborhood with a single mother and incarcerated father. Extant research on incarcerated individuals, their families, and the communities from which they come, is consistent with the testimonies of these women, showing that supporting a loved one in prison often had the effect of turning them into "quasi-inmates" wherein, although they were not imprisoned themselves, their loved one's imprisonment exerted a certain level of control over their lives (Comfort 2008). Because Black women are 2.5 to 3 times 
more likely to have an incarcerated loved one, we are disproportionately and undeservingly impacted by the controlling mechanisms of penal/correctional institutions.

Nonetheless, most of the participants felt a sense of familial/communal obligation to remain supportive to their loved one in some way, shape, or form, regardless of the price they had to pay to do so. Incarceration was such a common occurrence in some of their families and all of their communities, each of the women had a healthy understanding about the importance of support for imprisoned/reintegrating folks.

\section{The Deal}

Extant research focused on the experiences of the families of incarcerated humans underscore the severe stress and strain incarceration places on relationships (Hairston, 1991; Comfort 2008; Bailey 2011; Wildeman, Schnittker, and Turney 2012; Murphey and Cooper 2015), finances (Grinstead et al. 2001; Bailey 2011; Ella Baker Center 2015), health (Wildeman and Muller 2012; Lee et al. 2014), and more. I was particularly interested in learning about how the women dealt, or coped, with emotions, feelings, and real-life situations as they endeavored to navigate everyday life with their loved one's incarceration looming in the forefront or back of their minds. The narratives in this study primarily centered around the women's strivings to maintain mental and emotional stability to be able to function in the home, at work, in their roles in the community, and elsewhere. Participants were vocal about having to implement particular strategies to maintain mental and emotional balance in their home/work/community spaces just by virtue of being Black women and the expectations that come with such an identity. Such efforts were exacerbated when caring for an incarcerated/formerly incarcerated loved one was added to their duties. 
While each of them had their own unique ways of dealing with their issues and navigating the everyday — from finding solace through music to trying to escape through sex and cigarettes - the most common coping strategy was seeking care and counsel from family/community. The broad range of coping mechanisms the women used speak to the diversity in thought processes and behavioral practices across Black women with similar roles in their incarcerated loved ones' lives. However, the common practice of reaching out to friends and family for advice, an open ear, or resources is indicative of the trust Black women have and place in our kinfolk, and our reliance on them for love, guidance, and support.

As the women worked to maintain their households, roles at work and in the community, etc., they often sought support specifically from other Black women. Among the reasons why Black women were the main source of support were shared experience with loss to incarceration and/or shared understanding of the collateral consequences of incarceration. Extant research shows that Black women are most effected by incarceration (Lee et al. 2015), thus we are more likely to be useful resources for other system-impacted humans due to our personal experience with the matter. Furthermore, men (e.g. husbands, sons, brothers) are typically the individuals imprisoned, so, not only are they unavailable to be supportive in certain ways, at certain times, but women are the socially and culturally established caregivers/caretakers, are usually the most emotionally invested, and it is, therefore, more likely for Black women to reach out to other Black women for advice, care, and support.

In terms of formal resources - entities or individuals that provide specific resources - the women assured me they were scarce. In fact, when the question about 
available resources was posed, it was often met with laughter. While many of the ten women were well-positioned professionally and well-connected in the community with knowledge and access to a wide range of resources, not one of them was able to find a resource that met their specific and/or common needs of support for dealing with their loved one's incarceration/reintegration. Their responses are in line with responses from participants in Grieb et al.'s (2014:1194) study in which "not a single participant was able to name a program or support system available to the family members of individuals in reentry."

It could be argued that "the reform and successful reentry of prisoners is a matter of governmental responsibility, which should attract appropriate funding, resources and professional staff' (Codd 2007:259). However, by releasing formerly incarcerated humans to their families with the expectation that the families will facilitate and/or assist in the reintegration process, "the State is, in effect, handing over some responsibility for successful reentry to under-resourced and undersupported family members" (Codd 2007:259). This deficiency of state and federal resources for incarcerated/formerly incarcerated people and their families suggests that the government relinquishes all responsibility for the rehabilitation, reentry, and reintegration of incarcerated/formerly incarcerated and leaves the responsibility for their successful transition up to the families of those individuals. In other words, "family support is our national reentry program" (Ella Baker Center 2015:18).

Hasley and Deegan (2015:132) powerfully argue:

...given the impressive body of evidence linking pro-social family members with post-release success - we know the state 'assigns'... women a good measure of 
'responsibility for increasing the effectiveness of the criminal justice system' (especially in terms of post-release life and protection against further offending) (Light and Campbell, 2006: 298). This responsibility—one that (ex)prisoners' female significant others rarely if ever actually 'ask for' — exposes such persons to an array of potential problems (stigma, financial ruin, chronic fatigue, mental collapse, violence, neglect of other family members and the like.

By relegating the responsibility of successful release and reintegration to families of the incarcerated, Codd (2007:259-260) argues that, "to some extent...the government could 'shift the blame' deflecting issues of recidivism away from discussions of the failures of negative, disintegrative punitive practices, towards making it not only a failure of the individual offender, but also a failure of his or her family." Furthermore, Codd (2007:260) argues that "it is women who will be partially responsible for the successful community re-entry of both male and female family members." Without effective support, loved one's of incarcerated humans are often "penalized and punished in ways that additionally threaten family members' health, stability, and financial wellbeing, increasing challenges to help their loved one[s]" access necessary services and support (Ella Baker Center 2015:11). While resources were undoubtedly scarce, and families of incarcerated humans get essentially no support from the justice system to help their family members, most of the women from this study agreed that the best resources came in the form of family and community, including support groups and healing circles hosted by local community groups and organizations. 


\section{The Heal}

Women of this study shared the sentiment that support groups and healing circles were beneficial to their mental and emotional wellbeing. They emphasized groups and organizations that were Black- or African-centered in nature and practice. For example, several of the women mentioned Safe Black Space ${ }^{\mathrm{SM}}$ — a monthly community healing circle established for and by Black people which provides culturally specific strategies and resources to help Black people heal from historical and current wounds of racism and racial oppression - as a frequented space to receive support, hope, and healing. Some of the women discussed the benefit of participating in Emotional Emancipation Circles ${ }^{\mathrm{SM}}$ which also focuses on providing African-centered strategies for self-, family- and community-care. Research on mental and emotional health of Black women (and Black people in general) suggests that racially and culturally affirming spaces that are free from judgment, marginalization, and mainstream stereotype - where we can be our authentic selves - are conducive to our overall wellbeing (Blackwell 2018), thus supporting the idea that resources like those aforementioned are not only useful but imperative to the collective health of Black communities. In line with this research, the women insisted that these types of "safe" spaces for Black people are needed, but lacking.

Interestingly, many of the women connected their concern and need for self-care with their concern and need to be available for their incarcerated loved ones and their families/communities on the outside. Put more simply, the women expressed a desire to take care of themselves so they could be mentally, emotionally, and physically available for their children (loved ones) at home as well as those who would eventually return from imprisonment. Several of the women found it healing and therapeutic to be of assistance 
to other Black people dealing with stressful circumstances or suffering from painful experiences. Several others found pleasure in working with underprivileged, underserved youth and adolescents. It was clear that the women sometimes found it difficult to separate caregiving from self-care, as caregiving was a form of self-care, in that loving and supporting others in need lifts their spirits and affirms their sense of purpose. The women essentially practiced the sentiment of Booker T. Washington: "If you want to lift yourself up, lift up someone else."

\section{The Real}

As the women reflected on their experiences supporting an incarcerated loved one(s), most agreed that there were life lessons imbedded within the experience. The women shared that the experience of supporting an incarcerated loved one while also navigating life as a Black woman in America taught them lessons of accountability, selfsufficiency, the importance of healthy and supportive relationships, self-love, among others. The women learned that the people closest to the pain-i.e. people with shared experiences of vicarious incarceration, community members with shared understanding

of cultural and racial adversity, and the women themselves — were also the people closest to the solutions. In other words, those with lived experience possess greater insight to contribute to, and inform conversations about the impacts of incarceration. Although the road has been and continues to be rough, the experience itself has strengthened, grown, and cultivated these women and their families.

\section{Implications: The Ideal}

At the close of our interviews, the women told me what they envisioned for their families, loved ones, and communities. Collectively, the group expressed a desire for 
Black unity, freedom (psychological, emotional, economic, physical), and healing. In some way or another, each of the women expressed disappointment in the seeming disjointedness of our communities, further exacerbated by the removal of Black men and women by incarceration.

When asked what they thought they needed and what they thought the community needed to achieve the vision they imagined, the collective response was education/knowledge. Each of the women emphasized the importance of not simply formal (academic) education, but self-education (autodidacticism), and education of self (ancestral history, heritage, culture, etc.). The women are proponents of our (Black) communities teaching and training our youth on matters of race, history, culture, economics, and collective autonomy, for example, in addition to, or even independent of, what our children are taught in traditional U.S. classroom settings.

Also at the forefront of their needs and vision was unity. The women's responses about unity ranged from the need for elders to connect with youth, to building Black economics. In general, the women called for competition and division within our community to cease, and unification to begin and/or be strengthened. With knowledge of self and knowledge of our collective history as Africans in America, the women believed we could unify and improve the current conditions of our families/communities.

One of the most common sentiments the women shared was the hope that other women and families did not have to experience the trials and tribulations they did as a result of their loved one's imprisonment. Some of the women had more strict boundaries than others with regard to expenditure of energy, but each of the women considered themselves a resource to their families/communities. It was their intent to provide love, 
care, knowledge, encouragement and inspiration in whatever way they could to whomever they could (with or without overextending themselves) to prevent other people from having to deal with the stress and strain that accompanies supporting an incarcerated/formerly incarcerated loved one.

Each of the women assigned themselves vital roles in their visions of the future. Their roles ranged from guiding elders, to educators and conduits of information, to cultural brokers. Nonetheless, each of their roles involved information sharing and the transference of knowledge. Several of the women already worked in education in some capacity and recognized the shortage of teachers, administrators, counselors, etc. of color. With a shortage of Black educators (Department of Education Statistics 2016), and the traditional U.S. education system failing too many Black students, some of the women were advocates for self- and community-education.

All of the women were keenly aware that race played a significant role in their experiences as women, in general, and their experiences with incarceration, in particular. Most of them expressed that as Black women, or, being Black in general, they almost expected to have some type of experience with incarceration. However, despite the fact that incarceration is such a common occurrence in Black families/communities, each of the women was still extremely passionate about trying to prevent other Black families from having to endure such tragedy; they were adamant about breaking the cycle. Nonetheless, because we are all aware that it is going to take an unknown amount of time and effort for the cycle to be broken, we are committed to softening the blow, if at all possible, by sharing our experiences, sharing information, spreading knowledge, building bridges, and whatever else is in our power to do to ease the burden on others. 
Ultimately, the testimonies of these women demonstrate the need to consider how the holistic health and wellbeing of Black women is being affected by mass incarceration. Black women, our households, families, and communities we care for, manage, maintain and sustain, are also directly and indirectly affected by the collateral consequences of our loved one's incarceration. Because nearly half of all Black women are impacted by incarceration, it is imperative that we begin to devote faithful and focused attention to the ways supporting incarcerated/formerly incarcerated loved ones impacts the psychological, emotional, physical, and spiritual health of this large, vulnerable, vital population. For example, Lee et al. (2014) examined the association of family member incarceration with cardiovascular risk factors and disease by gender and found that family member incarceration has profound implications for women's cardiovascular health and should be considered a unique risk factor that contributes to racial disparities in health. Black women, in particular, are both disproportionately diagnosed with cardiovascular diseases and more likely to have an incarcerated loved one, hence, our susceptibility to cardiovascular-related issues are substantially increased and should be immediately addressed—our lives depend on it.

Regardless of class background or socioeconomic status, Black women are disproportionately impacted by conditions like heart disease, stroke, diabetes, breast cancer, cervical cancer, fibroids, and mental health issues. Perhaps this is why sisterscholars like Karla Scott (2017), Audre Lorde (2007) and others have written about revolutionary self-care and self-care as an act of political warfare. The concept of selfcare has become a popular topic and concept among Black women of various backgrounds; however, popular culture's adaptation of "self-care" has led many to 
associate self-care more with consumption (e.g. shopping, massages, baths, or pedicures), not revolution and sustainability. Notwithstanding the different ways Black women conceptualize self-care, it is quite possible that the recent adoption of the idea and/or practice itself has become so popular and important because Black women often lack support in many areas of their lives, thus we must prioritize our own health and wellbeing.

Black women's right to health and wellbeing seems to always be up for debate, requiring explanation, qualification and/or justification. For example, the impetus behind the topic of this study was my personal experience as a Black girl with an incarcerated brother who grew into adolescence watching many of my peers taken away to serve time in prison, and currently living the life of a relatively successful Black woman still supporting incarcerated loved ones and community members. In my experiences, I have witnessed countless Black women-mothers, sisters, daughters, grandmothers, aunties, etc.- - fighting for their loved ones' fair and humane treatment, and enduring the stress and strain brought about by the collateral consequences of incarceration that all too often fall hard and heavy on their shoulders. And I have witnessed them handle these experiences with insurmountable courage and grace, all the while breaking down internally. Their spirits are often broken, and their mental and physical health suffers from the overwhelm that they refuse, or are reluctant, to acknowledge or accept because fighting for our helplessly caged loved one's wellbeing seems more pressing. Witnessing this, and realizing that Black women, including myself, are hurting ourselves trying to save others inspired me to write this. However, only via Black women's connection to the hot political and economic topic of mass incarceration (primarily of Black men) is this 
academic inquiry qualified and justified. That this is a common way of life for Black women, in general—giving and not receiving support—means little and warrants very little interest in academic studies. All things considered, our ability to persevere in spite of lack of support and advocacy for our lives is a demonstration of active resistance and resiliency and warrants delicate, thoughtful inquiry.

Nonetheless, knowing more about the health and wellbeing of Black women who support incarcerated/formerly incarcerated loved ones can inform what we already know about the broader impacts of incarceration and reentry. For example, understanding what Black women go through as they navigate daily life experiencing vicarious incarceration while simultaneously fulfilling our roles in our families and communities may provide insight for how to support our loved ones on the inside and outside more efficiently. Because Black women bear the brunt of the burden caused by incarceration, providing useful support and accessible resources to benefit us and, by extension, our families, is especially important if we want to find ways to reduce recidivism and break generational cycles of incarceration.

\section{Conclusion}

The African concept that permeates throughout this work is that of ubuntu. Ubuntu essentially calls for us to recognize and act with humanity towards each other. This research is a clear and valuable demonstration of this, highlighting the ways that Black people rely on other Black people, and importantly —in the absence of our brothers due to alarming rates of incarceration and death-Black women heavily relying on other Black women. Thus, our strongest, most reliable strategy for survival and resilience is leaning into and on our community, namely our sisters (i.e. other Black women). 
An affirmation we often use throughout our village is, "We are our own medicine. Help and be helped" indicating that we, as a unified family, are the remedy to our problems. Black families and communities "share a feeling of interdependency - that is, a feeling that the destiny of each person is tied to that of every other person" (Green et al. 2006:53-54). This provides at least some explanation as to why the women of this study were so committed to supporting their imprisoned loved ones in addition to those they always and already support.

This study buttresses extant research that asserts, "across jurisdictional boundaries, regardless of the gender of the inmate, it is women who bear the burden of caring for prisoners from the outside" (Codd 2007:260)—primarily wives, mothers/grandmothers, sisters, and other family members (Naser and Visher 2006:27). Wives, mothers, sisters and other family of the imprisoned rely on their sisters and mothers, and other family members - biological or fictive kin — for support as they navigate vicarious incarceration. Often times, the people we turn to for support are also being, or have also been, impacted by the incarceration or reintegration of a loved one. We consider them resources for information, advice, and refuge. That Black women (Black people) rely on family and community is both beautiful and binding. One may find comfort in knowing that support is offered by people within the community that look like us and have similar experiences, and still structural constraints make it difficult for families and community members to offer the level of support required for their loved ones to be lifted up and out of strenuous circumstances.

The initial goal of this research was to identity resilience strategies Black women use as they navigate daily life while experiencing vicarious incarceration and/or 
reintegration. Masten (2001:9) reminds that "resilience does not come from rare and special qualities, but from the everyday magic of ordinary, normative human resources in the minds, brains, and bodies of children, in their families and relationships, and in their communities." It is important to acknowledge resilience as a characteristic that is developed and strengthened through interaction and connection with other people. In other words, building strength and resilience is a shared effort; and freedom is a collective endeavor.

Bernard (2004) points to specific individual personal strengths of social competence, problem solving, autonomy, and sense of purpose as manifestations of resilience (see Appendix). Positive identity, self-awareness, altruism, insight, optimism, and sense of meaning are among the developmental possibilities of building strength and resilience. Importantly, as many of the participants of this study declared, safe spaces created by and designated exclusively for Black people emphasizing core Africancentered values (e.g. Seven Principles of Ma'at) are needed and important to our wellbeing and the development of competencies (e.g. self-awareness, etc.). Participants mentioned community healing efforts such as those made by Safe Black Space ${ }^{\mathrm{SM}}$ and Emotional Emancipation Circles ${ }^{\mathrm{SM}}$, created by the Association of Black Psychologists and the Community Healing Network, which promote and nurture racial healing, and awareness of self through historical understanding of race and racism. These programs, and others like them (see Sisters Mentally Mobilized of California Black Women's Health Project), offer place, space, and resources for healing from the wounds of racism (e.g. mass incarceration), and equip Black people with tools and strategies to resist and persist in the face of adversity. However, funding to create, establish, and maintain 
sustainable programs with these goals and the capability to provide such opportunities is not merely limited and/or difficult to access, but virtually non-existent in many American cities where Black people reside.

Unfortunately, most entities who control federal and state funding are predominantly run by white (or, at best, non-black) people who, in general, have very little understanding of, or incentive to provide funding to support safe spaces exclusively for Black people. Generally speaking, white people are less likely to have an understanding or concern about how awareness of self (through education of ancestral history, culture, etc.) is beneficial and empowering to Black people, even though it is by these very means that white people empower themselves and gain a sense of entitlement. Because our institutions operate out of western, colonized thought and ideology, white people learn about themselves (i.e. their contributions to history, science, culture, etc.) from the moment they are born, and thus gain a greater awareness of self and are empowered early on. From the beginning of our lives, almost all of us are taught that whiteness is the standard in the U.S. Because this standard is imbedded within institutional fabric, there is very little interest from non-marginalized people (i.e. those in power) in changing the status quo by empowering marginalized populations. This translates into a lack of effort to provide education and resources for the empowerment and uplift of marginalized populations. Because funding and other opportunities are unavailable, or at best, severely limited, we (Black people and under marginalized groups) must rely on ourselves to do what is needed. Ultimately, this means we volunteer a great deal of time, effort, energy, emotional labor - in addition to working traditional 
jobs, raising children, etc.- - to serving our communities, including our loved ones behind bars.

This research underscores the pressures placed on Black women-whether by cultural or societal expectations, or feelings of relational or moral obligation - to be supportive of incarcerated and/or reintegrating loved ones while also remaining the backbone of our households and communities. Mullings (2000:8) describes the plight of strong black women as "the assumption of economic, household, and community responsibilities, which are expressed in family headships, working outside the home (like a man), and the constant need to address community empowerment—often carried out in conditions made difficult by discrimination and scarce resources." The stories in this study demonstrate the ultimate reliance of grieved Black women on other struggling Black women and afflicted communities; the reliance of marginalized Black people on other marginalized Black people; and the overall resilience of a people, largely led and held up by Black women.

\section{Limitations}

There were several limitations to this study. First, the sample size was smaller than initially desired. A larger, more diverse sample can provide broader insight to the experiences of this population and present alternative perspectives about the ways Black women and their families/communities are impacted by incarceration. Furthermore, this sample was made up of relatively middle-class, educated women, leaving a gap in contribution from women of lower socioeconomic status (who are most likely to experience vicarious incarceration) and upper-class women. 
Additionally, most of the women interviewed were involved in some sort of social justice advocacy or activism. Their level of exposure to information, people, and places influences their stocks of knowledge, their social and cultural tool kits, their social capital, and even their access to certain opportunities. Interviewing women outside of this population may reveal more about the differences in outcomes for the vicariously incarcerated and their loved ones on the inside or reentering society.

\section{Recommendations}

As someone who has been impacted by incarceration, I recommend that we look closer at the benefits of EECs ${ }^{\mathrm{SM}}$ and programs like Safe Black Space ${ }^{\mathrm{SM}}$ on the mental health of Black women experiencing the incarceration/reentry of a loved one. EECs ${ }^{\mathrm{SM}}$ are support groups - designed by the Association of Black Psychologists and the Community Healing Network - that provide positive strategies for Black people, by Black people, to heal from racial trauma. Since incarceration and its collateral consequences are direct results of America's racist foundation, participation in EECs ${ }^{\mathrm{SM}}$ may provide healthpositive strategies for resilience in an oppressive, often hostile environment. Since Black women are essentially, yet undeservedly, tasked with supporting their loved one during imprisonment and facilitating successful reentry upon their release, it is imperative we are mentally, emotionally and spiritually equipped with health-positive strategies to endure the trials and tribulations which are likely to arise.

Participation in EECs ${ }^{\mathrm{SM}}$ and programs like Safe Black Space ${ }^{\mathrm{SM}}$ foster trustbuilding, mutual aid, accountability, self-help, love and communal support, as it simultaneously provides the opportunity for introspection and self-reflection. Four of the ten interviewees and I participated in $\mathrm{EECs}^{\mathrm{SM}}$, and all but one had attended at least one 
Safe Black Space ${ }^{\mathrm{SM}}$; they offered us a safe space to process our pain, share experiences, and have our feelings validated. Cultivating connections and community, learning about and understanding one's history, are key to healing from racial trauma and stress such as that which results from the mass incarceration of Black bodies.

When we improve the overall health and wellness of Black Women, it will have a bottom up effect: Black women who take good care of themselves are better able to take good care of others, if they so choose- this applies to our incarcerated/formerly incarcerated loved ones. Being able to effectively support our imprisoned loved ones while they are away and when they return can have a powerful impact on recidivism. But giving communities strategies to heal from racial trauma and stress, in general, can transform the overall wellbeing of Black families, and potentially reduce the prevalence of imprisonment in our communities. 


\section{APPENDIX}

Table 1. Participant Background Information

\begin{tabular}{|c|c|c|c|c|c|c|}
\hline Participant & Age & Occupation & $\begin{array}{l}\text { Marital } \\
\text { Status }\end{array}$ & $\begin{array}{c}\text { Children/ } \\
\text { Dependents }\end{array}$ & $\begin{array}{l}\text { Relation to } \\
\text { Incarcerated } \\
\text { Loved One }\end{array}$ & $\begin{array}{l}\text { Physical or } \\
\text { Mental } \\
\text { Health Issue }\end{array}$ \\
\hline Asali & 40 & Social Worker & Married & $\beta$ children & $\begin{array}{l}\text { Cousin; } \\
\text { former } \\
\text { lover }\end{array}$ & $\begin{array}{l}\text { Multiple } \\
\text { Sclerosis }\end{array}$ \\
\hline Amanifu & 57 & $\begin{array}{l}\text { Community } \\
\text { Action } \\
\text { Advocate }\end{array}$ & Married & 6 & Daughter & Fibromyalgia \\
\hline Suzie Cain & 68 & $\begin{array}{l}\text { Licensed } \\
\text { ordained } \\
\text { minister and } \\
\text { pastor; } \\
\text { Seminarian } \\
\end{array}$ & Married & $\begin{array}{l}\beta \text { children }+ \\
1 \text { dependent }\end{array}$ & Mother & None \\
\hline Erin & 30 & Professor & Divorced/Single & None & $\begin{array}{l}\text { Daughter; } \\
\text { sister }\end{array}$ & None \\
\hline Oprah & 40 & Administrator & Married & 1 & $\begin{array}{l}\text { Sister; } \\
\text { friend }\end{array}$ & None \\
\hline Tyra & 24 & $\begin{array}{l}\text { Special needs } \\
\text { educator }\end{array}$ & Single & None & $\begin{array}{l}\text { Daughter; } \\
\text { family } \\
\text { member; } \\
\text { former } \\
\text { lover } \\
\end{array}$ & None \\
\hline Kali & $\beta 1$ & $\begin{array}{l}\text { Eligibility } \\
\text { worker; } \\
\text { activist }\end{array}$ & Single & None & Daughter & $\begin{array}{l}\text { Depression } \\
\text { and Anxiety }\end{array}$ \\
\hline Raychelle & 33 & Social Worker & $\begin{array}{l}\text { Domestic } \\
\text { Partnership }\end{array}$ & $\begin{array}{l}4 \text { children }+ \\
1 \text { dependent }\end{array}$ & Sister & None \\
\hline Cheree & 56 & $\begin{array}{l}\text { Retired Social } \\
\text { Worker }\end{array}$ & Single & $\beta$ children & Mother & Work injury \\
\hline Tia & 58 & $\begin{array}{l}\text { Retired; } \\
\text { Mental Health } \\
\text { Advocate }\end{array}$ & Single & 4 & Mother & $\begin{array}{l}\text { Aggressive } \\
\text { Rheumatoid } \\
\text { and Osteo } \\
\text { Arthritis }\end{array}$ \\
\hline
\end{tabular}


Table 2. Personal Strengths: What Resilience Looks Like

\begin{tabular}{|c|c|c|c|}
\hline Social Competence & Problem Solving & Autonomy & Sense of Purpose \\
\hline Responsiveness & Planning & Positive Identity & $\begin{array}{l}\text { Goal Direction } \\
\text { Achievement }\end{array}$ \\
\hline Communication & Flexibility & $\begin{array}{l}\text { Internal Locus of } \\
\text { Control }\end{array}$ & $\begin{array}{l}\text { Motivation } \\
\text { Educational }\end{array}$ \\
\hline $\begin{array}{l}\text { Empathy } \\
\text { Caring }\end{array}$ & Resourcefulness & Initiative & Aspirations \\
\hline & Critical Thinking & Self-Efficacy & Special Interest \\
\hline Compassion & Insight & Mastery & Creativity \\
\hline Altruism & & & Imagination \\
\hline Forgiveness & & Adaptive Distancing & \\
\hline & & Resistance & $\begin{array}{l}\text { Optimism } \\
\text { Hope }\end{array}$ \\
\hline & & $\begin{array}{l}\text { Self-Awareness } \\
\text { Mindfulness } \\
\text { Humor }\end{array}$ & $\begin{array}{l}\text { Faith } \\
\text { Spirituality } \\
\text { Sense of Meaning }\end{array}$ \\
\hline
\end{tabular}

Source: Resiliency: What We Have Learned, Bernard 2004, p. 14 


\section{REFERENCES}

Abrams, J. a., M. Maxwell, M. Pope, and F. z. Belgrave. 2014. "Carrying the World with the Grace of a Lady and the Grit of a Warrior: Deepening Our Understanding of the 'Strong Black Woman' Schema.” Psychology of Women Quarterly 38(4):50318.

Akbar, Na'im. 1996. Breaking the Chains of Psychological Slavery. Tallahassee, FL: Mind Productions and Associates, Inc.

Aker, J., P. Braveman, E. Arkin, L. Leviton, J. Parsons, and G. Hobor. 2018. “Mass Incarceration Threatens Health Equity in America." RWJF. Retrieved August 23, 2020 (https://www.rwjf.org/en/library/research/2019/01/mass-incarcerationthreatens-health-equity-in-america.html).

Alexander, Michelle. 2010. The New Jim Crow: Mass Incarceration in the Age of Colorblindness. New York, NY: The New Press.

Allen, Courtney. 2019. "Calling All the Sisters: The Impact of Sister Circles on the Retention and Experiences of Black Womyn Collegians at Predominately White Institutions.” PhD dissertation, Educational Leadership-Higher Education, Clemson University.

Anxiety and Depression Association of America. 2020. "Exercise for Stress and Anxiety." Silver Spring, MD: U.S. Retrieved August 28, 2020 (https://adaa.org/living-with-anxiety/managing-anxiety/exercise-stress-andanxiety).

Apel, Robert, Arjan A. J. Blokland, Paul Nieuwbeerta, and Marieke van Schellen. 2010. “The Impact of Imprisonment on Marriage and Divorce: A Risk Set Matching Approach.” Journal of Quantitative Criminology 26(2):269-300. 
Arditti, Joyce. 2005. "Families and Incarceration: An Ecological Approach." Families in Society: The Journal of Contemporary Social Services 86:251-60.

Bailey, Hassan. 2011. "Secondary Prisonization: The Effects of Involuntary Separation on Families of Incarcerated African American Men.” PhD dissertation, African/African American Studies, University of Kansas.

Beauboeuf-Lafontant, Tamara. 2003. "Strong and Large Black Women? Exploring Relationships between Deviant Womanhood and Weight." Gender and Society 17(1):111-21.

Benard, Bonnie. 2004. Resiliency: What We Have Learned. New title edition. San Francisco, CA: WestEd.

Berger, Peter L., and Thomas Luckmann. 1966. The Social Construction of Reality: A Treatise in the Sociology of Knowledge. New York, NY: Anchor.

Billingsley, Andrew. 1988. Black Families in White America. New York: Touchstone Books.

Black, Angela Rose, and Cheryl Woods-Giscombé. 2012. “Applying the Stress and ‘Strength’ Hypothesis to Black Women's Breast Cancer Screening Delays.” Journal of the International Society for the Investigation of Stress 28(5):389-96.

Black, Carol Frances Agnew. 2008. "Working for Justice: Families and Prison Reform." PhD dissertation, Criminology, Purdue University.

BlackPast. 2012. “(1977) The Combahee River Collective Statement.” Retrieved August 24, 2020 (https://www.blackpast.org/african-american-history/combahee-rivercollective-statement-1977/). 
Blackwell, Kelsey. 2018. "Why People of Color Need Spaces Without White People." The Arrow. Retrieved August 28, 2020 (https://arrow-journal.org/why-people-ofcolor-need-spaces-without-white-people/).

Boyd, Julia A. 1997. In the Company of My Sisters: Black Women and Self Esteem. New York, NY: Plume.

Braman, Donald. 2007. Doing Time on the Outside: Incarceration and Family Life in Urban America. Ann Arbor, MI: University of Michigan Press.

Brodsky, Stanley L. 1975. Families and Friends of Men in Prison: The Uncertain Relationship. Ann Arbor, MI: Lexington Books.

Bronson, Jennifer. 2017. Indicators of Mental Health Problems Reported by Prisoners and Jail Inmates, 2011-12. NCJ 250612. Bureau of Justice Statistics.

Bronson, Jennifer, and E. Ann Carson. 2019. Prisoners in 2018. NCJ 252156. Bureau of Justice Statistics.

Bryant-Davis, Thema. 2013. "Sister Friends: A Reflection and Analysis of the Therapeutic Role of Sisterhood in African American Women's Lives." Women \& Therapy 36(1-2):110-20.

Bureau, US Census. 2019. “America's Families and Living Arrangements: 2019.” The United States Census Bureau. Retrieved August 28, 2020 (https://www.census.gov/data/tables/2019/demo/families/cps-2019.html).

Carlson, Bonnie, and Neil Cervera. 1992. Inmates and Their Wives: Incarceration and Family Life. Westport, Conn: Praeger. 
Centers for Disease Control and Prevention. 2019. Fact Sheets on Smoking and Tobacco Use. Retrieved August 28, 2020 (https://www.cdc.gov/tobacco/data_statistics/fact_sheets/index.htm).

Chaney, Cassandra. 2011. “'So My Family Can Survive:' Prisoner Re-Entry and the Risk and Resilience of Black Families.” Journal of African American Studies 15:95114.

Chaney, Cassandra, Frances C. Lawrence, and Linda Skogrand. 2012. "An Exploration of Financial Coping Strategies for College-Educated African American Working Women: A Research Note.” Black Women, Gender \& Families 6(2).

Chapman, Benjamin P., Kevin Fiscella, Ichiro Kawachi, Paul Duberstein, and Peter Muennig. 2013. "Emotion Suppression and Mortality Risk over a 12-Year Follow-Up.” Journal of Psychosomatic Research 75(4):381-85.

Charmaz, Kathy. 2014. Constructing Grounded Theory. Thousand Oaks, CA: Sage Publications, Inc.

Christian, Johnna. 2005. "Riding the Bus: Barriers to Prison Visitation and Family Management Strategies." Journal of Contemporary Criminal Justice 21(1):31-48.

Christian, Johnna, and Leslie W. Kennedy. 2011. "Secondary Narratives in the Aftermath of Crime: Defining Family Members Relationships with Prisoners." Punishment and Society 13(4):379-402.

Christian, Johnna, Damian J. Martinez, and Denisse Martinez. 2015. "Beyond the Shadows of the Prison: Agency and Resilience Among Prisoners' Family Members" edited by J. A. Arditti and T. le Roux. Groves Monographs on Marriage and Family. 
Christian, Johnna, Jeff Mellow, and Shenique Thomas. 2006. "Social and Economic Implications of Family Connections to Prisoners." Journal of Criminal Justice 34(4):443-52.

Chui, Wing Hong. 2010. “'Pains of Imprisonment': Narratives of the Women Partners and Children of the Incarcerated." Child \& Family Social Work 15(2):196-205.

Coates, Story by Ta-Nehisi. 2015. "The Black Family in the Age of Mass Incarceration." The Atlantic. Retrieved August 23, 2020 (https://www.theatlantic.com/magazine/archive/2015/10/the-black-family-in-theage-of-mass-incarceration/403246/).

Codd, Helen. 2007. "Prisoners' Families and Resettlement: A Critical Analysis." The Howard Journal of Criminal Justice 46(3):255-63.

Codd, Helen. 2008. In the Shadow of Prison: Families, Imprisonment and Criminal Justice. Portland, OR: Willan.

Cokley, Kevin, Shannon McClain, Alicia Enciso, and Mercedes Martinez. 2013. “An Examination of the Impact of Minority Status Stress and Impostor Feelings on the Mental Health of Diverse Ethnic Minority College Students." Journal of Multicultural Counseling and Development 41(2):82-95.

Collins, Patricia Hill. 1986. "Learning from the Outsider Within: The Sociological Significance of Black Feminist Thought.” Social Problems 33(6):14-32.

Collins, Patricia Hill. 2009. Black Feminist Thought: Knowledge, Consciousness, and the Politics of Empowerment. New York, NY: Routledge.

Collins, Patricia Hill. 2019. Intersectionality as Critical Social Theory. Durham, NC: Duke University Press Books. 
Collins, Patricia Hill. 1994. "Shifting the Center: Race, Class, and Feminist Theorizing about Motherhood." Pp. 45-65 in Mothering: Ideology, Experience, and Agency, edited by E. N. Glenn, G. Chang, and L. Forcey. New York, NY: Routledge. Comfort, Megan. 2007. "Punishment Beyond the Legal Offender." Annual Review of Law and Social Science 3(1):271-96.

Comfort, Megan. 2008. Doing Time Together: Love and Family in the Shadow of the Prison. Illustrated edition. Chicago, IL: University of Chicago Press.

Comfort, Megan L. 2003. 'In the Tube at San Quentin: The 'Secondary Prisonization' of Women Visiting Inmates." Journal of Contemporary Ethnography 32(1):77-107.

Covington, Stephanie. 2016. Beyond Trauma: A Healing Journey for Women. 2nd ed. Center City, MN: Hazelden Publishing.

Cox, Robynn. 2012. "The Impact of Mass Incarceration on the Lives of African American Women." Review of Black Political Economy 39(2):203-12.

Crenshaw, Kimberle. 1989. "Demarginalizing the Intersection of Race and Sex: A Black Feminist Critique of Antidiscrimination Doctrine, Feminist Theory and Antiracist Politics." University of Chicago Legal Forum 1989(1):31.

Crutchfield, Robert D., and Susan R. Pitchford. 1997. "Work and Crime: The Effects of Labor Stratification." Social Forces 76(1):93-118.

Dallao, Mary. 1997. "Coping with Incarceration." Corrections Today 59(6):96.

Degruy, Joy Angela. 2005. Post Traumatic Slave Syndrome: America's Legacy of Enduring Injury and Healing. Milwaukie, OR: Uptone Press. 
Dodson, J. E. 2006. “Conceptualizations and Research of African American Family Life in the United States.” Pp. 51-68 in Black Families, edited by H. P. McAdoo. Thousand Oaks, CA: Sage Publications, Inc.

DuMonthier, Asha, Chandra Childers, and Jessica Milli. 2020. "The Status of Black Women in the United States.” IWPR 2020. Retrieved August 23, 2020 (https://iwpr.org/iwpr-issues/race-ethnicity-gender-and-economy/the-status-ofblack-women-in-the-united-states/).

Dyer, Lauren, Rachel Hardeman, Dovile Vilda, Katherine Theall, and Maeve Wallace. 2019. "Mass Incarceration and Public Health: The Association between Black Jail Incarceration and Adverse Birth Outcomes among Black Women in Louisiana.” BMC Pregnancy and Childbirth 19.

Ella Baker Center. 2015. "Who Pays? The True Cost of Incarceration on Families." Retrieved August 23, 2020 (http://whopaysreport.org/who-pays-full-report/). Equal Justice Initiative. 2018. “Mass Incarceration: How Racial Inequality Shapes Criminal Justice." Peace and Justice Summit in Montgomery, AL. Retrieved August 23, 2020 (https://eji.org/news/mass-incarceration-michelle-alexandersherrilyn-ifill-jelani-cobb/).

Fahmy, Christin, and Anne H. Berman. 2012. "Children of Male Prisoners: The Free Mother's Perspective." Scientific Annals of the "Alexandru Ioan Cuza" University, Iaşi. New Series SOCIOLOGY AND SOCIAL WORK Section 5(2).

Fishman, Laura T. 1986. 'Repeating the Cycle of Hard Living and Crime: Wives' Accommodations to Husbands' Parole Performance.” Federal Probation 50:44. 
Fishman, Laura T. 1990. Women at the Wall: A Study of Prisoners' Wives Doing Time on the Outside. $1^{\text {st }}$ ed. Albany, NY: State University of New York Press.

Foster, Holly, and John Hagan. 2009. "The Mass Incarceration of Parents in America: Issues of Race/ Ethnicity, Collateral Damage to Children, and Prisoner Reentry:” The Annals of the American Academy of Political and Social Science.

Fritsch, Travis A., and John D. Burkhead. 1981. "Behavioral Reactions of Children to Parental Absence Due to Imprisonment.” Family Relations 30(1):83-88.

Gaston, Marilyn Hughes, Gayle K. Porter, and Veronica G. Thomas. 2007. "Prime Time Sister Circles: Evaluating a Gender-Specific, Culturally Relevant Health Intervention to Decrease Major Risk Factors in Mid-Life African-American Women." Journal of the National Medical Association 99(4):428-38.

Geller, Amanda, and Allyson Walker Franklin. 2014. "Paternal Incarceration and the Housing Security of Urban Mothers." Journal of Marriage and Family 76(2):411-27.

Ghavami, Negin, Adam Fingerhut, Letitia A. Peplau, Sheila K. Grant, and Michele A. Wittig. 2011. "Testing a Model of Minority Identity Achievement, Identity Affirmation, and Psychological Well-Being among Ethnic Minority and Sexual Minority Individuals." Cultural Diversity and Ethnic Minority Psychology 17(1):79-88.

Glenn, Evelyn Nakano, Grace Chang, and Linda Rennie Forcey. 2016. Mothering: Ideology, Experience, and Agency. Routledge.

Goffman, Alice. 2014. On the Run: Fugitive Life in an American City. Chicago, IL: University of Chicago Press. 
Green, Alice P. 1982. "Case Studies of the Impact of Separation Due to Incarceration." PhD dissertation, School of Criminal Justice, The University at Albany.

Green, Kerry M., Margaret E. Ensminger, Judith A. Robertson, and Hee-Soon Juon. 2006. 'Impact of Adult Sons' Incarceration on African American Mothers' Psychological Distress." Journal of Marriage and Family 68(2):430-41.

Grieb, Suzanne M. Dolwick, Amelia Crawford, Julie Fields, Horace Smith, Richard Harris, and Pamela Matson. 2014. “'The Stress Will Kill You’: Prisoner Reentry as Experienced by Family Members and the Urgent Need for Support Services." Journal of Health Care for the Poor and Underserved 25(3):1183-1200.

Grinstead, Olga, Bonnie Faigeles, Carrie Bancroft, and Barry Zack. 2001. "The Financial Cost of Maintaining Relationships with Incarcerated African American Men: A Survey of Women Prison Visitors.” Journal of African American Men 6(1):59-69.

Hagan, John, and Ronit Dinovitzer. 1999. "Collateral Consequences of Imprisonment for Children, Communities, and Prisoners." Crime and Justice 26:121-62.

Hairston, Creasie Finney. 1991. "Family Ties During Imprisonment: Important to Whom and For What?” Journal of Sociology \& Social Welfare 18(1):86-104.

Halsey, Mark, and Simone Deegan. 2015. "Picking up the Pieces: Female Significant Others in the Lives of Young (Ex)Incarcerated Males." Criminology \& Criminal Justice 15(2):131-51.

Harris, Othello, and R. Robin Miller, eds. 2003. Impacts of Incarceration on the African American Family. 1 edition. New Brunswick, NJ: Transaction Publishers.

Harris, Tamara Winfrey. 2015. The Sisters Are Alright: Changing the Broken Narrative of Black Women in America. Oakland, CA: Berrett-Koehler Publishers, Inc. 
Hart-Johnson, Avon. 2014. "Symbolic Imprisonment, Grief, and Coping Theory: African American Women with Incarcerated Mates.” PhD dissertation, Human Services, Walden University.

Hill, Lincoln. 2019. "Why Imposter Syndrome Is Worse for Women of Color.” Medium. Retrieved August 24, 2020 (https://zora.medium.com/why-imposter-syndrome-isworse-for-women-of-color-3bcf37335405).

Hiller, Patricia Hayes. 2013. “A Look at How African-American Mothers Adapt to the Imprisonment of an Adult Son and the Impact on their Identities and Relationships.” PhD dissertation, Texas State University.

Holligan, Chris. 2016. “An Absent Presence: Visitor Narratives of Journeys and Support for Prisoners During Imprisonment." The Howard Journal of Crime and Justice 55(1-2):94-110.

Holstein, James A., and Jaber F. Gubrium. 1995. The Active Interview. Thousand Oaks, CA: Sage Publications, Inc.

Holt, Norman, and Donald Miller. 1972. Explorations in Inmate-Family Relationships. Sacramento, CA: Department of Corrections.

Houston, M. 1989. "Feminist Theory and Black Women's Talk.” The Howard Journal of Communications 1:187-94.

Huljich, Paul. 2012. “Identifying Coping Mechanisms.” Psychology Today. Retrieved August 28, 2020 (http://www.psychologytoday.com/blog/mind-wellnessawareness/201209/identifying-coping-mechanisms).

Jackson, Erica M. 2013. "Stress Relief: The Role of Exercise in Stress Management." ACSM's Health \& Fitness Journal 17(3):14-19. 
Jackson, Ozie White. 2011. "From Strong Black Woman to Womanist: An Afrocentric Approach to Understanding Perspective of Strengths, Life Experiences, and Coping Mechanisms of Single, African American Custodial Grandmothers.” PhD dissertation, College of Social Work, University of Utah.

Jackson, Tambra O., and Gloria S. Boutte. 2009. "Liberation Literature: Positive Cultural Messages in Children's and Young Adult Literature at Freedom Schools.” Language Arts 87(2):108-16.

Jones, Michal. 2015. "5 Reasons We Need Black-Only Spaces (And No, Reverse Racism Isn’t One of Them)." Everyday Feminism. Retrieved August 28, 2020 (https://everydayfeminism.com/2015/09/why-need-black-only-spaces/).

Kane, Emily W. 2000. "Racial and Ethnic Variations in Gender-Related Attitudes." Annual Review of Sociology 26:419-39.

Kerry M. Green, Margaret E. Ensminger, Judith A. Robertson, and Hee-Soon Juon. 2006. “Impact of Adult Sons' Incarceration on African American Mothers' Psychological Distress.” Journal of Marriage and Family 68(2):430.

King, Toni C., and S. Alease Ferguson. 2006. "'Carrying Our Burden in the Heat of the Day’: Mid-Life Self-Sacrifice Within the Family Circle Among Black Professional Women." Women \& Therapy 29(1-2):107-32.

Kristin Turney, Jason Schnittker, and Christopher Wildeman. 2012. "Those They Leave Behind: Paternal Incarceration and Maternal Instrumental Support.” Journal of Marriage and Family 74(5):1149. 
Lee, Hedwig, Tyler McCormick, Margaret T. Hicken, and Christopher Wildeman. 2015. "Racial Inequalities in Connectedness to Imprisoned Individuals in the United States." Du Bois Review: Social Science Research on Race 12(2):269.

Lee, Hedwig, Lauren C. Porter, and Megan Comfort. 2014. "Consequences of Family Member Incarceration: Impacts on Civic Participation and Perceptions of the Legitimacy and Fairness of Government." The Annals of the American Academy of Political and Social Science 651:44-73.

Lee, Hedwig, Christopher Wildeman, Emily A. Wang, Niki Matusko, and James S. Jackson. 2014. "A Heavy Burden: The Cardiovascular Health Consequences of Having a Family Member Incarcerated.” American Journal of Public Health 104(3):421-27.

Liao, Kelly Yu-Hsin, Meifen Wei, and Mengxi Yin. 2019. "The Misunderstood Schema of the Strong Black Woman: Exploring Its Mental Health Consequences and Coping Responses Among African American Women" Psychology of Women Quarterly.

Lin, Luona, Karen Stamm, and Peggy Christidis. 2018. "Demographics of the U.S. Psychology Workforce: Findings from the 2007-16 American Community Survey." American Psychological Association, Center for Workforce Studies.

Lorde, Audre, and Cheryl Clarke. 2007. Sister Outsider: Essays and Speeches. Reprint edition. Berkeley, CA: Crossing Press.

Luthar, Suniya S., Dante Cicchetti, and Bronwyn Becker. 2000. "The Construct of Resilience: A Critical Evaluation and Guidelines for Future Work.” Child Development 71(3):543-62. 
Maciag, Mike. 2019. "Where Have All the Black Men Gone?” Governing. Retrieved August 28, 2020 (https://www.governing.com/topics/public-justice-safety/govblack-men-gender-imbalance-population.html).

Manen, Max van. 1990. Researching Lived Experience. $2^{\text {nd }}$ Ed. New York, NY: Routledge.

Mark, Joshua J. 2016. “Ma’at.” Ancient History Encyclopedia. Retrieved August 28, 2020 (https://www.ancient.eu/Ma'at/).

Martinez, Damian J., and Johnna Christian. 2008. "The Familial Relationships of Former Prisoners: Examining the Link between Residence and Informal Support Mechanisms." Journal of Contemporary Ethnography 38(2):201-24.

Massoglia, Michael, Brianna Remster, and Ryan D. King. 2011. "Stigma or Separation? Understanding the Incarceration-Divorce Relationship.” Social Forces 90(1):13355.

Masten, A. 2001. "Ordinary Magic. Resilience Processes in Development." The American Psychologist.

McCarthy, Daniel, and Maria Adams. 2019. “Can Family-Prisoner Relationships Ever Improve During Incarceration? Examining the Primary Caregivers of Incarcerated Young Men.” The British Journal of Criminology 59(2):378-95.

Modecki, Kathryn L., and Melvin N. Wilson. 2009. “Associations between Individual and Family Level Characteristics and Parenting Practices in Incarcerated African American Fathers.” Journal of Child and Family Studies 18(5):530-40. 
Moradi, Bonnie, and Patrick R. Grzanka. 2017. "Using Intersectionality Responsibly: Toward Critical Epistemology, Structural Analysis, and Social Justice Activism.” Journal of Counseling Psychology 64(5):500-513.

Morse, D. R., and M. L. Furst. 1979. Stress for Success: A Holistic Approach to Stress and Its Management. New York, NY: Van Nostrand Reinhold.

Mullings, Leith. 2000. “African-American Women Making Themselves: Notes on the Role of Black Feminist Research.” Souls: A Critical Journal of Black Politics, Culture, and Society 2(4):18-29.

Murphey, David, and P. Mae Cooper. 2015. Parents Behind Bars: What Happens to Their Children? ChildTrends.org.

Myers, Samuel L. Jr. 2016. "What Have We Learned about Incarceration and Race? Lessons from 30 Years of Research.” Panel presentation at Mass Incarceration of African Americans and Its Economic Consequences, January 1, San Francisco, CA.

Naser, Rebecca L., and Christy A. Visher. 2006. “Family Members’ Experiences with Incarceration and Reentry.” Western Criminological Review 7(2):20-31.

National Alliance on Mental Illness. 2020. Black/African American. Arlington, VA: U.S. Retrieved (https://www.nami.org/Your-Journey/Identity-and-CulturalDimensions/Black-African-American).

National Center for Education Statistics. 2019. Degrees Conferred by Race and Sex. Washington, DC: U.S. Retrieved August 28, 2020 (https://nces.ed.gov/fastfacts/display.asp?id=72). 
National Partnership for Women and Families. 2020. Black Women and the Wage Gap. Fact Sheet. Washington, DC: U.S.

Nayak, Suryia. 2014. Race, Gender and the Activism of Black Feminist Theory. $1^{\text {st }} \mathrm{ed}$. New York, NY: Routledge.

Neal-Barnett, Angela, Robert Stadulis, Marsheena Murray, Margaret Ralston Payne, Anisha Thomas, and Bernadette B. Salley. 2011. "Sister Circles as a Culturally Relevant Intervention for Anxious African American Women.” Clinical Psychology: A Publication of the Division of Clinical Psychology of the American Psychological Association 18(3):266-73.

Nuru-Jeter, Amani. 2018. “'It's the Skin You're In': A dialogue on racial health inequities AND a call to action!” Lecture presented at James E. Clyburn Health Disparities Lecture. April 6, Columbia, SC.

Paperny, Tanya. 2017. "Do Some Trauma Survivors Cope by Overworking?” The Atlantic. Retrieved August 24, 2020 (https://www.theatlantic.com/health/archive/2017/02/do-some-trauma-survivorscope-by-overworking/516540/).

Passel, Jeffrey S., Wendy Wang, and Paul Taylor. 2010. “One-in-Seven New U.S. Marriages Is Interracial or Interethnic." Pew Research Center's Social \& Demographic Trends Project. Retrieved August 23, 2020 (https://www.pewsocialtrends.org/2010/06/04/marrying-out/).

Phillips, Layli. 2006. The Womanist Reader: The First Quarter Century of Womanist Thought. New York, NY: Routledge. 
Pollock, Joycelyn M. 1998. Counseling Women in Prison. ${ }^{\text {st }}$ Ed. Thousand Oaks, CA: Sage Publications, Inc.

Presser, Lois, and Sveinung Sandberg, eds. 2015. Narrative Criminology: Understanding Stories of Crime. New York, NY: NY Press.

Reckdahl, Katy. 2014. “Mass Incarceration’s Collateral Damage: The Children Left Behind.” The Nation. Retrieved August 28, 2020 (https://www.thenation.com/article/archive/mass-incarcerations-collateraldamage-children-left-behind/).

Richman, Laura Smart, and Charles Jonassaint. 2008. "The Effects of Race-Related Stress on Cortisol Reactivity in the Laboratory." Annals of Behavioral Medicine: A Publication of the Society of Behavioral Medicine 35(1):105-10.

Riessman, Catherine Kohler. 1993. Narrative Analysis. Thousand Oaks, CA: Sage Publications, Inc.

Rowles, Joanna, and Changming Duan. 2012. "Perceived Racism and Encouragement Among African American Adults." Journal of Multicultural Counseling and Development 40(1):11-23.

Scott, Karla D. 2017. The Language of Strong Black Womanhood: Myths, Models, Messages, and a New Mandate for Self-Care. New York, NY: Lexington Books. Scott, Marvin B., and Stanford M. Lyman. 1968. “Accounts.” American Sociological Review 33(1):46-62.

Sirois, Catherine. 2020. “The Strain of Sons' Incarceration on Mothers' Health.” Social Science \& Medicine. 
Sisterhood Empowerment Academy. Retrieved August 28, 2020

(https://sisterhoodagenda.com/sea-sisterhood-empowerment-academy/).

Stringer, Ebonie Cunningham. 2009. “'Keeping the Faith’: How Incarcerated African American Mothers Use Religion and Spirituality to Cope with Imprisonment." Journal of African American Studies 13(3):325-47.

Sugie, Naomi. 2012. "Punishment and Welfare: Paternal Incarceration and Families' Receipt of Public Assistance." Social Forces; a Scientific Medium of Social Study and Interpretation 90.

Swidler, Ann. 1986. "Culture in Action: Symbols and Strategies." American Sociological Review 51(2):273-86.

Tafari, Dawn Nicole Hicks. 2015. “Tales from a Hip-Hop DIVA: One Girl’s Journey from the Bronx to the PhD." in D.I.V.A. Diaries: The Road to the Ph.D. and Stories of Black Women Who Have Endured, edited by C. M. Dyce and T. M. Williams. New York, NY: Peter Lang Publishing.

Taylor, Caitlin J. 2016. “The Family's Role in the Reintegration of Formerly Incarcerated Individuals: The Direct Effects of Emotional Support.” Prison Journal 96(3):33154.

Travis, Jeremy. 2004. "Prisoners Once Removed: The Impact of Incarceration and Reentry on Children, Families, and Communities." Retrieved August 20, 2020 (http://webarchive.urban.org/publications/210900.html).

Travis, Jeremy. 2005. But They All Come Back: Facing the Challenges of Prisoner Reentry. $1^{\text {st }}$ Ed. Washington, DC: Rowman \& Littlefield Publishers. 
Travis, Jeremy, Elizabeth Cincotta McBride, and Amy L. Solomon. 2005. "Families Left Behind: The Hidden Costs of Incarceration and Reentry." Urban Institute.

Turney, Kristin, Jason Schnittker, and Christopher Wildeman. 2012. “Those They Leave Behind: Paternal Incarceration and Maternal Instrumental Support.” Journal of Marriage and Family 74(5):1149-65.

U.S. Department of Education. 2016. The State of Racial Diversity in the Educator Workforce. Washington, DC: U.S.

Wakefield, Sara, and Christopher Wildeman. 2013. Children of the Prison Boom: Mass Incarceration and the Future of American Inequality. New York, NY: Oxford University Press.

Walker-Barnes, Chanequa. 2014. Too Heavy a Yoke: Black Women and the Burden of Strength. Eugene, OR: Cascade Books.

Watson-Singleton, Natalie N. 2017. "Strong Black Woman Schema and Psychological Distress: The Mediating Role of Perceived Emotional Support.” Journal of Black Psychology 43(8):778-788.

Weiss, Robert Stuart. 1994. Learning from Strangers: The Art and Method of Qualitative Interview Studies. New York, NY: Free Press.

Wildeman, Christopher, and Christopher Muller. 2012. "Mass Imprisonment and Inequality in Health and Family Life.” Annual Review of Law and Social Science 8(1):11-30.

Wildeman, Christopher, Jason Schnittker, and Kristin Turney. 2012. "Despair by Association? The Mental Health of Mothers with Children by Recently Incarcerated Fathers.” American Sociological Review 77:216-43. 
Wildeman, Christopher, and Emily A. Wang. 2017. "Mass Incarceration, Public Health, and Widening Inequality in the USA.” Lancet 389(10077):1464-74.

Wilson, Jillian. 2020. "This Is What Racial Trauma Does to The Body and Brain." Huffpost. Retrieved August 24, 2020 (https://www.huffpost.com/entry/whatracial-trauma-does-body-brain_1_5efa43b1c5b6acab28459220).

Woods-Giscombe, C. L. 2010. “Superwoman Schema: African American Women’s Views on Stress, Strength, and Health.” Qualitative Health Research 20(5): 668683. 
Teah Monique Hairston was born in Winston-Salem, North Carolina. Her family moved to Sacramento, California in the summer of 1987. Before attending the University of Missouri, she earned a Master's degree in Southern Studies from the University of Mississippi in 2013, and two Bachelor's in Psychology and African American Studies from San Jose State University in 2009.

While completing her studies at the University of Missouri, Teah also volunteered with various non-profit organizations, becoming Vice President of Safe Black Space Community Healing Circles and Sacramento Area Congregations Together (Sac ACT). She also won prestigious awards supporting her academic and community work including the James S. Rollins Slavery Atonement Endowment Award (2015) and the Mary Elizabeth Gutermuth Award for Community Engagement (2018).

Teah maintains both her positions as Vice President and persists in her role as a community servant in the greater Sacramento area. She is also a Research Data Specialist for the state of California. She lives in Sacramento with her two beautiful sons, loving partner, and beloved mother. 